\title{
Loss of Cdk5rap2 triggers cellular senescence via $\beta$-catenin-mediated downregulation of WIP1
}

Xidi Wang ${ }^{1,2}$, Patrick Sipila ${ }^{1}$, Zizhen $\mathrm{Si}^{2}$, Jesusa L. Rosales ${ }^{1}, \mathrm{Xu} \mathrm{Gao}^{2}$ and Ki-Young Lee ${ }^{1}$

${ }^{1}$ Department of Cell Biology \& Anatomy, Arnie Charbonneau Cancer and Alberta Children's Hospital Research Institutes, Cumming School of Medicine, University of Calgary, Calgary, AB, Canada; ${ }^{2}$ Department of Biochemistry \& Molecular Biology, Harbin Medical University, Harbin, China

Running Title: Cdk5rap2 in cellular senescence

Correspondence: Dr. Ki-Young Lee, Department of Cell Biology and Anatomy, Cumming School of Medicine, University of Calgary, Calgary, AB, T2N 4N1, Canada; Tel: (403) 220-8723. Fax: (403) 283-8727. E-mail: kylee@ucalgary.ca; and Dr. Xu Gao, Department of Biochemistry \& Molecular Biology, Harbin Medical University, Harbin, China. Tel: 8645186661684 . Fax: 8645187086131. E-mail: gaoxu6712@163.com 


\begin{abstract}
Loss-of-function mutations in Cdk5rap2 is associated with the developmental disorders, primary microcephaly and primordial dwarfism, but the underlying molecular link remains obscure. Here, we show that Cdk5rap2 loss in BJ-5ta human fibroblasts triggers senescence that is associated with proliferation defect, which is manifested as small body size in Cdk5rap2 ${ }^{\text {an/an }}$ mice. In fibroblasts, Cdk5rap2 loss induces p53 Ser15 phosphorylation that correlates with decreased level of the p53 phosphatase, WIP1. Ectopic WIP1 expression reverses senescence in Cdk5rap2depleted cells, linking senescence to WIP1 downregulation. Cdk5rap2 interacts with GSK3 $\beta$, increasing inhibitory Ser9 phosphorylation in GSK3 $\beta$, which phosphorylates and tags $\beta$-catenin for degradation. Thus, Cdk5rap2 loss decreases GSK3 $\beta$ Ser9 phosphorylation and increases GSK3 $\beta$ activity, reducing $\beta$-catenin that affects expression of NF-KB target genes, including WIP1. Consequently, Cdk5rap2 or $\beta$-catenin depletion downregulates WIP1. GSK3 $\beta$ Inhibition in Cdk5rap2-depleted cells restores $\beta$-catenin and WIP1 levels, reducing p53 Ser15 phosphorylation and preventing senescence. Conversely, WIP1 inhibition increases p53 Ser15 phosphorylation and senescence in Cdk5rap2-depleted cells lacking GSK3 $\beta$ activity. Senescence through GSK3 $\beta / \beta$ catenin downregulation of WIP1 may contribute to the developmental disorders associated with Cdk5rap2 loss-of-function.
\end{abstract}




\section{Introduction}

Cyclin-dependent kinase 5 (Cdk5) regulatory subunit associated protein 2 (Cdk5rap2) was originally identified based on its ability to interact with the Cdk5 regulatory subunit, p35 ${ }^{1}$. Cdk5rap2 localizes to the centrosome in a dynein-dependent manner ${ }^{2}$ and regulates centriole engagement and centrosome cohesion during the cell cycle $\mathrm{e}^{3-5}$. Cdk5rap2 moved into the spotlight as loss-of-function mutations in Cdk5rap2 cause primary microcephaly (MCPH), an autosomal recessive neurodevelopmental disorder characterized by small brain and cognitive deficit ${ }^{6,7}$. In fact, Cdk5rap2 is most abundant at the luminal surface of the brain's ventricular zone, particularly in cells lining the ventricular wall where neural stem and progenitor cells reside. However, since Cdk5rap2 is also expressed in other tissues, it is not surprising that loss-of-function mutations in Cdk5rap2 are further associated with other developmental disorders such as cochlear and retinal developmental defects ${ }^{8}$, primordial dwarfism ${ }^{9}, 10$, as well as Seckel syndrome, a heterogeneous, autosomal recessive disorder characterized by prenatal proportionate short stature, severe microcephaly, intellectual disability, and characteristic 'bird-headed' facial features ${ }^{11}$. However, the molecular mechanisms by which Cdk5rap2 loss-of-function mutations cause these developmental disorders remain elusive.

Cellular senescence is a state of stable cell cycle arrest in which cells remain viable and metabolically active ${ }^{12}$. In addition to cell cycle arrest, cell senescence is characterized by increased senescence-associated $\beta$-galactosidase (SA- $\beta$-gal) activity ${ }^{13}$, formation of senescenceassociated heterochromatin foci (SAHF) ${ }^{14}$ and morphological transformation ${ }^{15}$. Senescence is triggered by a number of cellular stresses ${ }^{16-19}$. For example, activated oncogenes such as $\mathrm{H}$ RAS $^{G 12 V}$ and B-RAF ${ }^{V 600 E}$ induce senescence by evoking sustained anti-proliferative response ${ }^{20}$, a mechanism that acts as an initial barrier in preventing normal cell transformation into malignant cells. H-RAS ${ }^{G 12 V}$-induced senescence is associated with accumulation of DNA damage foci and activation of the p53 kinases, ataxia telangiectasia mutated (ATM), checkpoint kinase 1 (Chk1) and/or checkpoint kinase 2 (Chk2), suggesting that aberrant oncogene activation induces a DNA damage response $(D D R)^{20,21}$. Cell senescence can also be induced by telomere attrition and oxidative stress among others. The molecular mechanisms of senescence have been studied extensively using a variety of cell types. Phosphorylation of the tumor suppressor protein, p53, at Ser15 by 553 kinases such as ATM, Chk1 and/or Chk2 is one of the key events in p53-associated cell senescence ${ }^{22,23}$. Apparently, p53 Ser15 phosphorylation stabilizes p53 by inhibiting its interaction with Mdm2, an E3 ubiquitin ligase that catalyzes polyubiquitination and subsequently

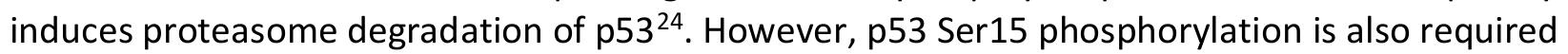
for $\mathrm{p} 53$ activation ${ }^{25,26}$, which blocks cell cycle progression by inducing $\mathrm{p} 21^{C I P 1}$ expression ${ }^{27}$. Aside from phosphorylation by kinases, p53 Ser15 phosphorylation is also regulated by p53 phosphatases such as wild-type p53-induced phosphatase 1 (WIP1). In fact, WIP1 has been associated with p53-mediated cell senescence ${ }^{28,29}$. For example, hematopoietic stem cells (HSC) from WIP1 ${ }^{-/}$mice exhibit senescent phenotypes, impairing repopulating activity ${ }^{29}$. Mouse embryonic fibroblasts (MEFs) ${ }^{29}$ and mesenchymal stem cells ${ }^{30}$ from WIP1 $1^{-1}$ mice also undergo premature senescence. In primary chondrocytes, reduced WIP1 is associated with senescent phenotype, which is reversed by ectopic WIP1 expression ${ }^{31}$. WIP1, which contains an NF-KB binding site in its promoter region, is a downstream gene target of NF-KB ${ }^{32}$. Interestingly, $\beta$ catenin associates with NF-KB and induces the expression of NF-KB target genes ${ }^{33}$ such as WIP1. 
Thus, our investigations examine the possibility that WIP1 expression is regulated by $\beta$-catenin and whether WIP1-associated p53-mediated senescence is linked to phenotypes related to Cdk5rap2 loss-of-function. Since $\beta$-catenin is phosphorylated by GSK3 $\beta$ that earmarks $\beta$-catenin for ubiquitination-mediated degradation by the proteasome pathway ${ }^{34}$, we further examined whether GSK3 $\beta$ controls our presumed $\beta$-catenin-mediated WIP1 expression. To explore these possibilities, we used two model systems: (i) the Cdk5rap2 ${ }^{\text {an }} /$ an mouse $_{\text {model }}{ }^{35}$, which carries exon 4 inversion in Cdk5rap2, and exhibits primary microcephaly that is comparable to that of the human disease, displaying proliferation and survival defects in neuronal progenitor cells ${ }^{35}$. Cdk5rap2 ${ }^{a n / a n}$ homozygotes are spontaneously aborted, appearing to exhibit late embryonic lethality. (ii) BJ-5ta normal human diploid foreskin fibroblast cells, which were immortalized through forced expression of the hTERT component of telomerase. BJ-5ta cells maintain many characteristics of normal primary cells such as karyotype, growth rate, morphology, tissuespecific markers and contact inhibition. Using the Cdk5rap2 ${ }^{\text {an/an }}$ mouse model and BJ-5ta cells, we demonstrate that loss of Cdk5rap2 triggers premature cell senescence. Proliferation defect and senescent phenotypes in Cdk5rap2-depleted BJ-5ta cells are recapitulated in Cdk5rap2 ${ }^{\text {an/an }}$ as reduced embryonic body weights and reduced MEF growth rate, and increased SA- $\beta$-gal staining and reduced PCNA but increased $p 21^{C I P 1}$ levels in MEFs, respectively. We propose that premature cell senescence due to Cdk5rap2 loss-of-function occurs via elevation of GSK3 $\beta$ activity that causes $\beta$-catenin-mediated downregulation of WIP1 and subsequent upregulation of $p 53$ Ser15 phosphorylation. 


\section{Results}

Loss of Cdk5rap2 induces cellular senescence. To investigate how Cdk5rap2 loss-of-function may cause proliferation defects associated with developmental disorders, we examined the effect of Cdk5rap2 depletion in BJ-5ta human fibroblasts by siRNA. As shown in Figure 1, knocking down Cdk5rap2 using two different siRNAs (\#1 and \#2) triggers the formation of senescence-associated heterochromatin foci (SAHF) as demonstrated by staining with DAPI (Figure 1B) and SAHF colocalization with heterochromatin protein $1 \gamma$ (HP1 $\gamma$, Figure 1C), a SAHF marker ${ }^{36}$. Senescence induced by activated $\mathrm{H}-\mathrm{RAS}^{\mathrm{G} 12 \mathrm{~V}}$ oncogene ${ }^{37}$ was used as positive control to detect SAHF and HP1 $\gamma$ staining. To support the suggestion that Cdk5rap2 depletion causes premature cellular senescence, cells transfected with Cdk5rap2 siRNA \#2 (Figure 2) were monitored for the appearance of SAHF-positive cells and the expression of the senescence-associated biomarkers ${ }^{36}$, $\mathrm{p} 21^{C I P 1}$ and $\mathrm{p} 16^{I N K 4 a}$, over 5 days post transfection. As shown in Figure $2 \mathrm{~A}$, the number of SAHF positive cells increases markedly in the first 3 days after transfection with Cdk5rap2 siRNA \#2, reaching peak levels on days 3-5, a period when no or only a modest number of SAHF positive cells was observed in those transfected with control siRNA. The increase in number of SAHF positive cells upon Cdk5rap2 depletion coincides with increased expression of p21 ${ }^{\text {CIP1 }}$ and p16 INK4a (Figure 2B). Together with the noticeable staining for SA- $\beta$-gal, another marker of cellular senescence $^{38}, 3$ days post- transfection with Cdk5rap2 siRNA \#2 (Figure 2C), our findings indicate that loss of Cdk5rap2 induces premature cellular senescence.

Increased levels of SAHF as well as $\mathrm{p} 21^{C I P 1}$ and $\mathrm{p} 16^{I N K 4 a}$, which are also molecular inhibitors of cell cycle Cdks, upon loss of Cdk5rap2 led us to test whether loss of Cdk5rap2 affects cell proliferation. Indeed, we found that cells transfected with Cdk5rap2 siRNA \#2 proliferate at a slower rate compared to cells transfected with control siRNA (Figure 3A). Flow cytometry analysis show greater population of cells at $\mathrm{G}_{0} / \mathrm{G}_{1}$ but reduced population of cells at $\mathrm{S}$ in those transfected with Cdk5rap2 siRNA \#2 compared to those transfected with control siRNA (Figure 3B). In addition, reduced number of Ki-67 positive cells were observed in those transfected with Cdk5rap2 siRNA \#2 compared to those transfected with control siRNA (Figure 3C). Altogether, these findings indicate that Cdk5rap2 loss triggers senescence-associated proliferation arrest.

Mouse embryonic fibroblast cells (MEFs) isolated from Cdk5rap2 ${ }^{a n / a n}$ mice, which have reduced body weights, exhibit senescence-associated phenotypes. The availability of Hertwig's anemia (an) mutant mice (Cdk5rap2 ${ }^{a n / a n}$ ) that carry exon 4 inversion in the $C d k 5 r a p 2$ gene, allowed us to test whether such Cdk5rap2 $2^{\text {an/an }}$ mutation affects body weight and whether the senescentassociated phenotypes observed in cells lacking Cdk5rap2 are also exhibited by Cdk5rap2 $2^{\text {an/an }}$ MEFs. Since Cdk5rap2 ${ }^{\text {an/an }}$ mice have high incidence of death in late embryonic stages, we initially isolated embryonic day 12.5 (E12.5) Cdk5rap2 ${ }^{+/+}, \mathrm{Cdk}_{\mathrm{rap}} 2^{+/ a n}$ and Cdk5rap2 ${ }^{\text {an/an }}$ embryos from pregnant Cdk5rap2 $2^{+/ a n}$ mice and body weights were compared. As shown in Figure $4 \mathrm{~A}$, within the same litter, the Cdk5rap2 ${ }^{a n / a n}$ embryo weighs less than the $\mathrm{Cdk}_{5} \mathrm{rap2}^{+/+}$and $\mathrm{Cdk} 5 \mathrm{rap2} 2^{+/ a n}$ embryos. E17.5 embryos from different litters also show lower average weights of Cdk5rap2 ${ }^{\text {an/an }}$ compared to $\mathrm{Cdk} 5 \mathrm{rap2}^{+/+}$and Cdk5rap2 ${ }^{+/ a n}$ embryos (Figure 4B, left panel). Similar observations were further noted for average weights of E12.5 to E17.5 Cdk5rap2 ${ }^{+/+}$, Cdk5rap2 ${ }^{+/ a n}$ and Cdk5rap2 ${ }^{a n / a n}$ embryos (Figure 4B, right panel). Next, MEFs isolated from E12.5 $\mathrm{Cdk}^{\mathrm{rapa} 2} 2^{+/}$, 
Cdk5rap2 ${ }^{+/ a n}$ and Cdk5rap2 ${ }^{\text {an/an }}$ embryos were examined for the appearance of SA- $\beta$-gal positive cells (Figure $4 C$, left panel). Analysis of SA- $\beta$-gal staining show that the number of SA- $\beta$-gal positive cells in Cdk5rap2 ${ }^{a n / a n}$ MEFs is remarkably greater than those in Cdk5rap2 ${ }^{+/+}$and Cdk5rap2 ${ }^{+/ a n}$ MEFs (Figure 4C, right panel). In addition, Cdk5rap2 ${ }^{\text {an/an }}$ MEFs exhibit decreased proliferation (Figure 4D), which coincides with reduced PCNA but increased p21 ${ }^{C I P 1}$ levels (Figure 4E) compared to Cdk5rap2 ${ }^{+/+}$and Cdk5rap2 ${ }^{+/ a n}$ MEFs. Thus, the senescence-associated phenotypes that we observed in Cdk5rap2-depleted BJ-5ta cells is recapitulated in ex vivo Cdk5rap2 ${ }^{\text {an/an }}$ MEFs.

Cell senescence due to loss of Cdk5rap2 is linked to elevated p53 Ser15 phosphorylation via WIP1 downregulation. p53 plays a key role in triggering the expression of SA- $\beta$-gal. In addition, upon DNA damage and other types of stress that induce cellular senescence ${ }^{25,39}$, p53 is phosphorylated at Ser15 by protein kinases such as ATM, Chk1, and Chk2 ${ }^{22-24}$. Thus, we examined the status of p53 Ser15 phosphorylation in BJ-5ta cells depleted of Cdk5rap2. By immunoblotting using a phosphoSer15 p53 antibody, we observed that loss of Cdk5rap2 causes noticeable increase in $\mathrm{p} 53$ Ser15 phosphorylation, which coincides with elevation of p21 ${ }^{C I P 1}$ level (Figure 5A). Next, we tested whether senescence due to Cdk5rap2 loss involves ATM, Chk1 and/or Chk2 activation. Phosphorylation of ATM Ser1981, Chk1 Ser345 and Chk2 Thr68 was examined in Cdk5rap2-depleted cells by immunoblotting. Cells infected with H-RAS ${ }^{G 12 V}$ oncogene ${ }^{37}$ was used as positive control to detect senescence-associated activation of ATM, Chk1 and Chk2. Interestingly, we did not detect activation of ATM, Chk1 and Chk2 in Cdk5rap2-depleted cells (Figure 5B). Unexpectedly, we observed reduced level of Cdk5rap2 in cells infected with activated $\mathrm{H}-\mathrm{RAS}^{G 12 \mathrm{~V}}$. The mechanism by which this happens requires further investigation but is beyond the scope of the current study. Since phosphorylation of $\mathrm{p} 53 \mathrm{Ser} 15$ is also regulated by protein phosphatases such as WIP1, a critical senescence regulator 28,29 that has been associated with p53 Ser15 dephosphorylation, we examined the possibility that loss of Cdk5rap2 affects WIP1 expression. By qRT-PCR and immunoblotting, we found that WIP1 phosphatase is downregulated at both the mRNA (Figure 5C, left panel) and protein (Figure 5C, right upper and lower panels) levels in cells depleted of Cdk5rap2. Taken together, our findings indicate that premature cellular senescence due to loss of Cdk5rap2 may be induced by p53 phosphorylation at Ser15 via downregulation of WIP1, and that p53-mediated senescence due to Cdk5rap2 loss is independent of ATM, Chk1 and Chk2 activation.

While we note that p53-associated cell senescence induced by loss of Cdk5rap2 is distinct from the p53-mediated senescence induced by activated H-RAS ${ }^{612 V}$, which is often associated with activation of the DNA damage response $(D D R)^{19,21-23}$, we sought to examine the possibility that senescence induced by Cdk5rap2 loss involves DDR. To do so, we performed immunofluorescence microscopy to test whether loss of Cdk5rap2 in BJ-5ta cells triggers the formation of $\mathrm{\gamma H} 2 \mathrm{AX}$ foci, which was assessed by staining with histone H2AX phosphoSer139 antibody (supplementary Figure 1). Cells infected with activated H-RAS ${ }^{G 12 V}$ and cells treated with 4Gy ionizing radiation (IR), which show $96.7 \%$ and $100 \%$, respectively, of cells positive for $\mathrm{VH} 2 \mathrm{AX}$ foci served as positive controls. Cells infected with an empty vector and cells transfected with control siRNA served as negative controls. Examination of Cdk5rap2-depleted cells revealed no 
$\mathrm{YH} 2 \mathrm{AX}$ foci, indicating that $\mathrm{p} 53$-associated senescence that is linked to WIP1 downregulation in Cdk5rap2-depleted cells does not involve DDR activation.

To examine the idea that WIP1 loss in Cdk5rap2-depleted cells accounts for p53 Ser15 phosphorylation that leads to cellular senescence, BJ-5ta cells depleted of WIP1 by siRNA were analyzed by SDS-PAGE and immunoblotting for WIP1, p53 phophoSer 15 , total p53 and p $21^{\text {CIP1 }}$ as well as SA- $\beta$-gal staining. Consistent with our observations in Cdk5rap2-depleted cells, WIP1depleted cells show p53 Ser15 phosphorylation and elevation of p21 CIP1 level (Figure 6A), and increased number of SA- $\beta$-gal positive cells (Figure 6B). To establish a link between senescence induced by Cdk5rap2 loss and downregulated WIP1 expression, BJ-5ta cells were co-transfected with Cdk5rap2 siRNA \#2 and pReceiver-M02 vector carrying WIP1. As shown in Figure 7, ectopic WIP1 overexpression in Cdk5rap2-depleted cells (Figure 7A) reverses the appearance of SA- $\beta$-gal positive cells induced by Cdk5rap2 loss (Figure 7B), supporting our view that senescence due to loss of Cdk5rap2 is linked to downregulated WIP1 expression.

Cdk5rap2 regulates WIP1 expression through $\boldsymbol{\beta}$-catenin. As indicated above, we found that loss of Cdk5rap2 causes downregulation of WIP1 expression at both the mRNA and protein levels. The WIP1 promoter contains a nuclear factor-KB (NF-KB) binding site ${ }^{32}$ (Figure 8A) through which NF-KB positively regulates WIP1 expression ${ }^{32}$, and $\beta$-catenin associates with NF-KB, affecting the expression of NF-KB target genes ${ }^{33}$. These apparent interactions led us to test whether loss of Cdk5rap2, which causes reduced WIP1 level, influences $\beta$-catenin expression. As shown in Figure $8 \mathrm{~B}$, loss of Cdk5rap2 reduces $\beta$-catenin level in the nucleus where $\beta$-catenin associates with NFKB. Depletion of $\beta$-catenin by siRNA downregulates WIP1 level (Figure $8 C$ ), suggesting that Cdk5rap2 loss may reduce WIP1 level through downregulation of $\beta$-catenin.

Cdk5rap2 interacts with glycogen synthase kinase-3 $\beta$ (GSK3 $\beta$ ) and such interaction inhibits GSK3 $\beta$ activity. Because GSK3 $\beta$ phosphorylates $\beta$-catenin, targeting $\beta$-catenin for ubiquitinationmediated degradation by the proteasome pathway ${ }^{34}$, we examined whether Cdk5rap2 interacts with GSK3 $\beta$ and affects GSK3 $\beta$ activity. To do so, lysates of BJ-5ta cells co-transfected with Myctagged Cdk5rap2 and FLAG-tagged GSK3 $\beta$ were subjected to immunoprecipitation using FLAG or Myc antibody then analyzed for Cdk5rap2 and GSK3 $\beta$ co-immunoprecipitation by immunoblotting both immunoprecipitates with Myc and FLAG antibodies. Fig. 9A shows reciprocal co-immunoprecipitation of Cdk5rap2 and GSK3 3 . To determine whether Cdk5rap2 interacts directly with GSK3 $\beta$, GST-Cdk5rap2 purified from baculovirus-infected Sf9 insect cells (supplementary Figure 2) was bound to GSH-agarose beads then mixed with purified GSK3 $\beta$. Analysis of the GST pulled-down complex by SDS-PAGE and immunoblotting using GST or GSK3 $\beta$ antibody show the presence of both GST-Cdk5rap2 and GSK3 $\beta$ (Figure 9B), indicating direct interaction between these proteins. GSH-agarose-bound GST mixed with GSK3 $\beta$ was used as negative control. We then sought to determine whether Cdk5rap2 interaction with GSK3 $\beta$ affects GSK3 $\beta$ activity. Since GSK3 $\beta$ phosphorylation at Ser9 inhibits its activity ${ }^{34,40}$, we first examined whether Cdk5rap2 loss influences the state of GSK3 $\beta$ Ser9 phosphorylation. As shown in Figure 9C, cells transfected with Cdk5rap2 siRNA \#2 have reduced GSK3 $\beta$ Ser9 phosphorylation compared to cells transfected with control siRNA, suggesting that Cdk5rap2 interaction with GSK3 $\beta$ could affect GSK3 $\beta$ activity. Indeed, by in vitro GSK3 $\beta$ kinase assay, we found that the GSK3 $\beta$ immunoprecipitate from cells transfected with Cdk5rap2 siRNA \#2 show greater GSK3 $\beta$ 
activity compared to cells transfected with control siRNA (Figure 9D). To examine a link between increased GSK3 $\beta$ activity and reduced $\beta$-catenin and WIP1 levels in Cdk5rap2-depleted cells, we tested whether inhibition of GSK3 $\beta$ with TWS119 restores $\beta$-catenin and WIP1 levels in these cells. Western blot analysis shows that TWS119 restores $\beta$-catenin and WIP1 levels in cells transfected with Cdk5rap2 siRNA \#2 (Figure 9E), supporting a link between increased GSK3 $\beta$ activity and reduced $\beta$-catenin and WIP1 levels upon loss of Cdk5rap2.

Cdk5rap2 loss induces senescence through upregulation of GSK3 $\beta$ activity and subsequent downregulation of $\beta$-catenin-mediated WIP1 expression. Our next step was to examine whether inhibition of GSK3 $\beta$ with TWS119, which restores $\beta$-catenin and WIP1 levels in BJ-5ta cells depleted of Cdk5rap2, inhibits senescence in these cells. We found that treatment of BJ-5ta cells with TWS119, which increases $\beta$-catenin and WIP1 levels and reduces $p 53$ Ser15 phosphorylation in cells transfected with Cdk5rap2 siRNA \#2 (Figure 10A), results in loss of SA- $\beta$-gal staining in these cells (Figure 10B), suggesting that inhibition of GSK3 $\beta$ prevents senescence in Cdk5rap2depleted cells through upregulation of $\beta$-catenin and WIP1 and subsequent downregulation of p53 Ser15 phosphorylation. We then examined the effect of inhibition of WIP1 activity with GSK2830371 in Cdk5rap2-depleted cells treated with TWS119. Figure 10A shows that GSK2830371 has no effect on $\beta$-catenin and WIP1 levels in these cells but causes an increase in p53 Ser15 phosphorylation and thus, as shown in Figure 10B, an increase in SA- $\beta$-gal staining. These findings support our view that GSK3 $\beta$ acts upstream of $\beta$-catenin as well as WIP1 and, therefore, while GSK3 $\beta$ inhibition prevents senescence in Cdk5rap2-depleted cells by increasing $\beta$-catenin and WIP1 levels, reducing p53 Ser15 phosphorylation, direct inactivation of WIP1 in cells lacking Cdk5rap2 and GSK3 $\beta$ activity results in p53 Ser15 phosphorylation and increased senescence.

Promoter bashing analysis by transfecting a luciferase reporter vector carrying wt WIP1 promoter (pGL3-WIP1, supplementary Figure 3A) into cells transfected with Cdk5rap2 siRNA \#2 (Supplementary Figure 3B) or $\beta$-catenin siRNA (Supplementary Figure 3C) show reduced luciferase activity in these cells compared to cells transfected with control siRNA (Supplementary Figure 3, B \&C). Conversely, transfection with WIP1 lacking its NF-KB binding site (pGL3-WIP1$\Delta \kappa B$; Supplementary Figure $3 A$ ) has no effect on luciferase activity in Cdk5rap2- or $\beta$-catenindepleted cells. Treatment with TWS119 restored luciferase activity in Cdk5rap2-depleted cells transfected with pGL3-WIP1 (Supplementary Figure 3B, right panel), further suggesting that senescence due to Cdk5rap2 loss is controlled by GSK3 $\beta$ through regulation of the WIP1 promoter via $\beta$-catenin. 


\section{Discussion}

In this study, we provide evidence that Cdk5rap2 loss induces premature cell senescence through upregulation of GSK3 $\beta$ activity, which causes downregulation of $\beta$-catenin-modulated WIP1 level and subsequent maintenance of p53 activation through p53 Ser15 phosphorylation. These were demonstrated using BJ-5ta cells as well as Cdk5rap2 ${ }^{a n / a n}$ mice embryos and their corresponding ex vivo MEF cells. In BJ-5ta cells, we eliminated the possibility of off-target effects of siRNA used to deplete Cdk5rap2 by using two different Cdk5rap2 siRNAs (\#1 and \#2) that both successfully depleted Cdk5rap2 and induced similar senescent phenotypes that were not observed in cells transfected with control siRNA. For subsequent experiments, Cdk5rap2 siRNA \#2, which causes greater depletion of Cdk5rap2 was used. Premature BJ-5ta cell senescence due to Cdk5rap2 loss was verified by an increase in number of SAHF positive cells, upregulation of the senescenceassociated genes, $\mathrm{p} 21^{C I P 1}$ and $\mathrm{p} 16^{I N K 4 a} 41$, and increased staining for SA- $\beta$-gal. These senescent phenotypes observed in Cdk5rap2-depleted BJ-5ta cells are recapitulated in ex vivo MEFs isolated from Cdk5rap2 ${ }^{\text {an/an }}$ embryos, and consistent with a previous observation that MEFs isolated from mice carrying a frameshift loss-of-function mutation (R1334SfsX5) 6, 42 in Cdk5rap2 do not grow to confluence after passages 8 to $10^{43}$. However, the latter finding was not further investigated. In BJ-5ta cells, proliferation defect in Cdk5rap2-depleted cells was demonstrated by increased population of cells at $\mathrm{G}_{0} / \mathrm{G}_{1}$ and reduced population of cells at $\mathrm{S}$ phase, indicating reduced cell proliferation. In Cdk5rap2 ${ }^{a n / a n}$, cell proliferation defect is manifested by reduced body weights in E12.5, E17.5 as well as combined E12.5, E14.5, E15.5 and E17.5 embryos compared to Cdk5rap2 $^{+/+}$and Cdk5rap2 ${ }^{+/ a n}$.

Characterization of senescence upon loss of Cdk5rap2 in BJ-5ta cells revealed an increase in p53 Ser15 phosphorylation, an early event leading to cell senescence ${ }^{25,39}$. Unexpectedly but interestingly, increased p53 Ser15 phosphorylation in senescent Cdk5rap2-depleted cells is not due to activation of the $\mathrm{p} 53$ kinases, ATM, Chk1, or Chk2 ${ }^{24}$, but rather due to downregulation of WIP1 phosphatase expression. This concurs with previous reports that link cell senescence to WIP1-mediated p53 dephosphorylation at Ser15 ${ }^{28,29}$. While p53 phosphorylation at Ser15 was found to inhibit its interaction with the E3 ubiquitin ligase, Mdm2, preventing degradation and stabilizing $\mathrm{p} 53^{24}$, we did not observe increased p53 level in Cdk5rap2-depleted cells, but only noted elevated p53 Ser15 phosphorylation. Since p53 Ser15 phosphorylation is required for p53 activation $^{25}, 26$, WIP1-regulated p53 Ser15 phosphorylation and subsequent activation in Cdk5rap2-depleted cells likely account for senescence in these cells. Indeed, elevated level of $\mathrm{p} 21^{\mathrm{CIP1}}$, a major transcriptional target of $\mathrm{p} 53^{27}$ that serves as a senescence biomarker ${ }^{36}$, was observed upon loss of Cdk5rap2. We note, however, that absence of $\mathrm{yH} 2 \mathrm{AX}$ foci in Cdk5rap2depleted cells indicates that p53-associated senescence that is linked to WIP1 downregulation in these cells is independent of DDR activation. This is consistent with the lack of DDR-associated activation of ATM, Chk1 or Chk2 in p53-associated cell senescence induced by loss of Cdk5rap2.

Our finding that knocking down WIP1 in Cdk5rap2-depleted cells causes increased p53 Ser15 phosphorylation and number of SA- $\beta$-gal positive cells, while ectopic expression of WIP1 in these cells reverses such phenotypes establishes a link between cellular senescence due to Cdk5rap2 loss and downregulation of WIP1. This is in accord with previous findings that WIP1 ${ }^{-1}$ mice exhibit aging phenotypes in their hematopoietic stem cells, including impaired repopulating activity ${ }^{29}$, 
and $\mathrm{WIP}^{-1-} \mathrm{MEFs}^{29}$ and mesenchymal stem cells ${ }^{30}$ exhibit premature senescence. In addition, reduced level of WIP1 in primary chondrocytes triggers the onset of senescence and loss of the chondrocyte phenotype, while overexpression of WIP1 retains their proliferative capacity and delays the onset of senescence ${ }^{31}$.

Our observation that Cdk5rap2 loss causes downregulation of WIP1 mRNA and protein levels together with the fact that the WIP1 promoter contains an NF-KB binding site through which NF$K B$ positively regulates WIP1 expression ${ }^{32}$, and $\beta$-catenin associates with NF-KB to induce the expression of NF-KB target genes ${ }^{34}$ led to our view that Cdk5rap2 loss reduces WIP1 level through downregulation of $\beta$-catenin. In addition, our notion that the level of $\beta$-catenin is regulated by GSK3 $\beta$ activity is based on the fact that GSK3 $\beta$ phosphorylates $\beta$-catenin, targeting $\beta$-catenin for ubiquitination-mediated degradation by the proteasome pathway ${ }^{34}$ and thus inhibiting translocation of $\beta$-catenin into the nucleus ${ }^{44}$. Our finding that Cdk5rap2 interacts with GSK3 $\beta$ and such interaction inhibits GSK3 $\beta$ activity explains how loss of Cdk5rap2 downregulates $\beta$-catenin level. The Harmonizome database ${ }^{45}$, and previous immunoprecipitation and mass spectrometry analyses ${ }^{9}$ support our finding that $\mathrm{Cdk5}$ rap2 binds to GSK3 3 . Additional evidence that reflects Cdk5rap2-GSK3 $\beta$ interaction is their colocalization in the centrosome, which duplicates in synchrony with the cell cycle. Indeed, although GSK3 3 , which promotes mitotic progression, is mainly distributed throughout the cytoplasm, a subpopulation of GSK3 $\beta$ localizes at the centrosome ${ }^{46}$. Recently, the phosphorylated form of GSK3 $\beta$ has been mapped to the centrosome $^{47}$, where Cdk5rap2 exists ${ }^{48,49}$ and regulates centriole engagement and cohesion during the cell cycle ${ }^{43}$. It remains to be determined whether disturbance of this Cdk5rap2 function contributes to senescence upon loss of Cdk5rap2. Nonetheless, since AKT (protein kinase B), which regulates centrosome composition and integrity during mitosis ${ }^{50}$, phosphorylates GSK3 $\beta$ at Ser9 ${ }^{51,52}$, it is possible that Cdk5rap2 binding to centrosome-recruited GSK3 $\beta$ facilitates the inhibitory phosphorylation of GSK3 $\beta$ Ser9 by AKT. Potentially, loss of Cdk5rap2 allows the release of unphosphorylated and active GSK3 $\beta$ from the centrosome, causing GSK3 $\beta$ phosphorylation of $\beta$-catenin, which is then ubiquitinated and degraded via the proteasome pathway. Reduced $\beta$-catenin level leads to reduced NF-KB-mediated WIP1 phosphatase expression, which results in sustained p53 Ser15 phosphorylation that promotes p53-mediated p21 CIP1 expression, and ultimately induces cell senescence. Our finding that GSK3 $\beta$ inhibition restores $\beta$-catenin and WIP1 levels in cells lacking Cdk5rap2 establishes a link between increased GSK3 $\beta$ activity and decreased $\beta$-catenin and WIP1 levels in these cells. The fact that luciferase activity is reduced in WIP1 promoter-transfected cells depleted of Cdk5rap2 or $\beta$ catenin, and GSK3 $\beta$ inhibition restores luciferase activity in WIP1 promoter-transfected cells depleted of Cdk5rap2, further suggest that senescence caused by Cdk5rap2 loss is controlled by GSK3 $\beta$ through $\beta$-catenin regulation of the WIP1 promoter.

In summary, our studies reveal that loss of Cdk5rap2 triggers premature cell senescence via $\beta$ catenin-mediated downregulation of WIP1. Such senescence is associated with proliferation errors in both BJ-5ta cells and Cdk5rap2 ${ }^{a n / a n}$ mice. As Cdk5rap2 loss-of-function has been linked to developmental defects, it is possible that premature cell senescence contributes to these defects. In this paper, we provide novel insight into the molecular mechanisms by which cdk5rap2 loss-of-function causes premature cell senescence. 


\section{Materials and Methods}

Materials. hTERT-immortalized BJ-5ta human foreskin fibroblast cells and adenovirus carrying $\mathrm{H}$ Ras $^{G 12 V}$ and GFP alone were obtained from Drs. Tara Beattie and Karl Riabowol, respectively, at the University of Calgary. HEK293 cells were from ATCC (Manassas, VA, USA). The Cdk5rap2 antibody (A300-554A) was from Bethyl Laboratories (Montgomery, TX, USA). p21 ${ }^{\text {CIP1 }}$ (sc-271610), p16 ${ }^{\text {INK4a }}$ (sc-468), p53 (sc-393031), Ras (sc-35), histone H3 (sc-517576) and actin (sc-8432) antibodies, and protein A/G PLUS-agarose (sc-2003) were from Santa Cruz Biotech (Manassas, VA, USA). phosphoSer15-p53 (\#9284), GSK3ß (\#12456), phosphoSer9-GSK3ß (\#5558), ATM (\#92356), phosphoSer1981-ATM (\#13050), Chk1 (\#2360), phosphoSer345-Chk1 (\#2348), Chk2 (\#6334), phosphoThr68-Chk2 (\#2197), ß-catenin (\#8480), GST (\#2624) and Ki-67 (\#9129) antibodies were from Cell Signaling (Danvers, MA, USA). WIP1 antibody (ab236515) was from Abcam (Cambridge, MA, USA). The HRP-conjugated anti-rabbit (\#7074) and anti-mouse (\#7076) secondary antibodies were from Cell Signaling (Danvers, MA, USA). Primers and siRNAs were synthesized at the University of Calgary Core DNA services or GenePharma, Shanghai, China. Goat anti-mouse or anti-rabbit secondary antibodies conjugated with Alexa-488 or -594 were from Invitrogen (Carlsbad, CA, USA). Myc-tagged Cdk5rap2 and Flag-tagged GSK3 $\beta$ expression vectors, and pReceiver-M02 carrying WIP1 were from GeneCopoeia (Rockville, USA). GSK3 $\beta$ protein (14306) was from Upstate Biotech. (Lake Placid, NY, USA).

Animals. The Cdk5rap2 ${ }^{+/ a n}$ breeding pairs were purchased from JAX laboratory (Bar Harbor, ME, USA) and fed with commercial mice chow, provided water ad libitum and kept on a 12:12 hr light-dark cycle. Cdk5rap2 ${ }^{+/+}, C_{\text {Cdk5rap2 }}^{+/ a n}$ and Cdk5rap2 ${ }^{\text {an/an }}$ embryos were isolated from pregnant Cdk5rap2 ${ }^{+/ a n}$ mice. All animal studies conformed to regulatory standards and were approved by the University of Calgary Health Sciences Animal Care Committee.

Genotyping. Genomic DNAs were extracted from mice using the Extracta DNA prep kit (Quantabio, Edmonton, AB. Canada). Tissue samples were added to 50-100 $\mu$ l of extraction buffer, incubated at $95^{\circ} \mathrm{C}$ for $30 \mathrm{~min}$, and stabilized with an equal volume of stabilization buffer. DNA sample $(1 \mu \mathrm{l})$ was added to $10 \mu \mathrm{l}$ of Quantabio's AccuStart II PCR SuperMix containing 100 $\mathrm{nM}$ of the appropriate DNA primers. The forward primers used were: GAAACCAGGGTGACA GGTACA (wt Cdk5rap2) and AGATGTCATGTCTAAAGCAATCACT (an Cdk5rap2). The reverse primer used was the same for the wt and an reactions: CCTTTGTCTTTCTGCCCTGA. Based on the expected size of each fragment, the wt Cdk5rap2 allele corresponds to a 581 bp band whereas the mutant an Cdk5rap2 allele corresponds to a 500 bp band. The reaction mixtures were input into a BioRad thermocycler using PCR settings recommended by the Jackson Laboratory.

Cell culture. BJ-5ta human diploid foreskin fibroblast cells were cultured in Eagle's minimal essential medium (EMEM, Lonza) containing 10\% fetal bovine serum (FBS, GIBCO), and $50 \mathrm{U} / \mathrm{ml}$ penicillin and $50 \mathrm{mg} / \mathrm{ml}$ streptomycin (Invitrogen, Carlsbad). HEK293 human embryonic kidney cells were cultured in Dulbecco's modified Eagle medium (DMEM, Invitrogen), containing 10\% FBS, $50 \mathrm{U} / \mathrm{ml}$ penicillin and $50 \mathrm{mg} / \mathrm{ml}$ streptomycin. Cells were maintained at $37^{\circ} \mathrm{C}$ in a $5 \% \mathrm{CO}_{2}$ humidified incubator. After recovering from cryopreservation, BJ-5ta cells were used for up to 10 additional population doublings to maintains many characteristics of normal primary cells. 
Isolation of primary MEFs. Primary MEFs were isolated from E12.5 Cdk5rap2 ${ }^{+/+}, \mathrm{Cdk} 5 \mathrm{rap} 2^{+/ a n}$ and Cdk5rap2 ${ }^{a n / a n}$ embryos as described previously ${ }^{53}$. Briefly, embryos were washed with $1 x$ PBS, decapitated and eviscerated then washed again with PBS. Embryos were minced using sterile forceps and placed in 3-5 $\mathrm{ml}$ of $0.05 \%$ trypsin-EDTA, pipetted up and down to get cells into suspension and incubated at $37^{\circ} \mathrm{C}$ for $5 \mathrm{~min}$. Cell suspensions were transferred to tubes containing MEF medium (DMEM-high glucose supplemented with 10\% FBS, $50 \mathrm{U} / \mathrm{ml}$ penicillin and $50 \mathrm{mg} / \mathrm{ml}$ streptomycin (Invitrogen, Carlsbad), and $2 \mathrm{mM}$ GlutaMAX) then centrifuged at $1,000 \mathrm{rpm}$ for $5 \mathrm{~min}$. Cell pellets were resuspended in fresh media and plated in $10 \mathrm{~cm}$ cell culture dishes. Primary MEFs were cultured in DMEM supplemented with $10 \% \mathrm{FBS}$ and $50 \mathrm{U} / \mathrm{ml}$ penicillin and $50 \mathrm{mg} / \mathrm{ml}$ streptomycin (Invitrogen, Carlsbad) under hypoxic condition $\left(5 \% \mathrm{O}_{2}\right.$ and $5 \% \mathrm{CO}_{2}$ incubator). All experiments were performed in passage P2-P7 MEFs.

Plasmid/siRNA transfection and adenovirus infection. Cells cultured 18 hours and at about $60 \%$ confluency were transfected using Lipofectamine 2000 (Invitrogen) in serum-free medium, which was replaced with complete medium 5 hours post-transfection. Cells were harvested at different time points as indicated. siRNA target sequences are: control, CGUACGCGGAAUACUUCGAUU; Cdk5rap2 \#1, GGACGUGUUGCUUCAGAAAUU; Cdk5rap2 \#2, GAGUCAGCCUUCUGCUAAAUU; WIP1, CCAAUGAAGAUGAGUUAUAUU; GSK3 $\beta$, AGGAGACCACGACCUGUUAAUU; $\beta$-catenin, CTCGGGATGTTCACAACCGAA. Adenovirus infection was carried out at a MOI of 50-100. Media was then replaced with EMEM containing 10\% FBS 24 hours post infection and cells were incubated until the indicated time.

RNA extraction and real-time qRT-PCR. Total RNA was extracted using TRIzol reagent (Invitrogen, Carlsbad, CA, USA) according to the manufacturer's protocol, and transcribed into cDNA using high-capacity cDNA reverse transcription kit (Thermo Fisher, Waltham, MA). Real-time qRT-PCR was performed using power SYBR ${ }^{\circledR}$ green PCR master mix (Thermo Fisher, Waltham, MA), and an Applied Biosystems 7500 real-time PCR machine using a standard protocol. The PCR conditions were 35 cycles at $94^{\circ} \mathrm{C}$ for 20 seconds, $60^{\circ} \mathrm{C}$ for 20 seconds and $72^{\circ} \mathrm{C}$ for 35 seconds. The primer sets used were: WIP1-F, GGGAGTGATGGACTTTGGAA; WIP1-R, CAAGATTGTCCATGCTCACC; GAPDH-F, GGAGCGAGATCCCTCCAAAAT; GAPDH-R, GGCTGTTGTCATACTTCTCATGG. GAPDH was used for normalization.

Isolation of nuclear fraction. Lysates of BJ-5ta cells transfected with Cdk5rap2 siRNA or control siRNA were centrifugated at $800 \mathrm{rpm}$ for $10 \mathrm{~min}$. The resulting pellets were resuspended in cell lysis buffer containing $10 \mathrm{mM}$ HEPES; $\mathrm{pH}$ 7.5, $10 \mathrm{mM} \mathrm{KCl}, 0.1 \mathrm{mM}$ EDTA, $1 \mathrm{mM}$ dithiothreitol (DTT), 0.5\% Nonidet-40 (NP-40), $0.5 \mathrm{mM}$ PMSF, and the protease inhibitor cocktail, then incubated on ice for $30 \mathrm{~min}$ with intermittent mixing, and centrifuged at $12,000 \mathrm{xg}$ at $4^{\circ} \mathrm{C}$ for 15 $\mathrm{min}$. The pellets were washed three times with cell lysis buffer, and resuspended and incubated in nuclear extraction buffer containing 20 mM HEPES (pH 7.5), 400 mM NaCl, 1 mM EDTA, 1 mM DTT, $1 \mathrm{mM}$ PMSF and protease inhibitor cocktail for $30 \mathrm{~min}$. Nuclear fractions were harvested by centrifugation at $12,000 \mathrm{xg}$ for $15 \mathrm{~min}$ at $4^{\circ} \mathrm{C}$. 
Western blot analysis. Cell lysates $(50 \mu \mathrm{g})$ were resolved by SDS-PAGE, transferred to nitrocellulose membrane, and immunoblotted for Cdk5rap2, p21 ${ }^{\mathrm{CIP1}}, \mathrm{p} 16^{\text {INK4a }}$, p53, phospho-p53, Ras, histone, GSK3 3 , phosphoSer9-GSK3 $\beta$, ATM, phosphoSer1981-ATM, Chk1, phosphoSer345Chk1, Chk2, phosphoThr68-Chk2, $\beta$-catenin, WIP1 and actin. Following incubation with HRPconjugated anti-rabbit or anti-mouse secondary antibody, immunoreactive bands were detected using the ECL reagent (GE Healthcare, Little Chalfont, Buckinghamshire, UK). Western blot images were obtained using the ChemiDoc ${ }^{\mathrm{TM}}$ Imager (Bio-Rad) set at optimal exposure. No enhancements were performed.

Immunofluorescence microscopy. Cells transfected with Cdk5rap2 or control siRNA on coverslips were fixed with $4 \%$ paraformaldehyde/PBS for $10 \mathrm{~min}$, permeabilized using $0.1 \%$ Triton X100/PBS for $10 \mathrm{~min}$, then blocked in 2\% BSA/PBS for 1 hour at room temperature. Cover slips incubated with the indicated primary antibody for 1 hour followed by 20 min incubation with secondary antibodies were washed with $1 \times$ PBS, counterstained with DAPI and mounted on glass slides using ProLong ${ }^{\mathrm{TM}}$ Diamond Antifade Mountant (P36961, Invitrogen, Carlsbad, CA, USA). Images were captured using a Zeiss Axiovert 200 microscope. BJ-5ta cells transfected with Cdk5rap2 siRNA \#2 were analyzed for Ki-67 positive cells 3 days post-transfection.

Senescence-associated $\boldsymbol{\beta}$-galactosidase staining. Cells were fixed using $3 \%$ paraformaldehyde in PBS (pH 6.0) and stained with $1 \mathrm{mg} / \mathrm{ml}$ 5-bromo-4-chloro-indolyl- $\beta$-D-galactopyranoside (X-gal) solution containing $5 \mathrm{mM}$ potassium ferrocyanide, $5 \mathrm{mM}$ potassium ferricyanide, $150 \mathrm{mM} \mathrm{NaCl}$, and $2 \mathrm{mM} \mathrm{MgCl}_{2}$ in PBS (pH 6.0) for $16-20 \mathrm{hrs}$ at $37^{\circ} \mathrm{C}$.

Cell viability and cell cycle analyses. BJ-5ta cells transfected with Cdk5rap2 siRNA \#2 or control siRNA were seeded into 96-well plates at 5,000 cells per well 24 hours post transfection, then analyzed for cell viability at days 0, 2 and 4 using Cell Counting Kit-8 (CCK-8, Dojindo). For analysis of cell cycle distribution, cells transfected with Cdk5rap2 siRNA \#2 or control siRNA were fixed using cold $2 \%$ formaldehyde and stained with 7-AAD $(5 \mu \mathrm{g} / \mu \mathrm{l})$ then subjected to flow cytometry.

Immunoprecipitation. HEK293 cells tranfected with Myc-tagged Cdk5rap2 or Flag-tagged GSK3 $\beta$ or both for $48 \mathrm{hrs}$ were lysed in ice-cold lysis buffer containing $50 \mathrm{mM}$ Tris/pH 8.0, $150 \mathrm{mM} \mathrm{NaCl}$, 1\% NP-40, 10 mM EDTA, 5\% glycerol, 1 mM phenylmethylsulfonylflouride (PMSF), $10 \mu \mathrm{g} / \mathrm{ml}$ aprotinin, and $10 \mu \mathrm{g} / \mathrm{ml}$ leupeptin. Lysates were then clarified by centrifuged at 13,000 rpm for $25 \mathrm{~min}$ at $4^{\circ} \mathrm{C}$. For immunoprecipitation under denaturing condition, 1\% SDS was added in the lysis buffer. Lysates were pre-cleared by adding normal mouse or rabbit IgG + sepharose A/G beads and incubating at $4^{\circ} \mathrm{C}$ for $2 \mathrm{hrs}$ followed by centrifugation at $14,000 \mathrm{rpm}$ for $10 \mathrm{~min}$. Onetenth of the lysates from each sample was retained and used to assess input or total cell lysate in western blots. Pre-cleared cell lysates were subjected to immunoprecipitation using Myc or Flag antibody conjugated to protein $A / G$ agarose beads. After incubating the mixture overnight at $4^{\circ} \mathrm{C}$, immunoprecipitates were washed with lysis buffer three times at $4^{\circ} \mathrm{C}$.

Measurement of GSK3 $\beta$ activity. GSK3 $\beta$ activity was measured using the GSK-3 $\beta$ activity assay kit (Sigma, ON, Canada) following the manufacturer's protocol. Briefly, cells transfected with Cdk5rap2 or control siRNA were lysed in ice-cold lysis buffer containing $50 \mathrm{mM}$ Tris/pH 8.0, 150 $\mathrm{mM} \mathrm{NaCl}, 1$ \% NP-40, 10 mM EDTA, 5\% glycerol, 1 mM phenylmethylsulfonylflouride (PMSF), 10 
$\mu \mathrm{g} / \mathrm{ml}$ aprotinin and $10 \mu \mathrm{g} / \mathrm{ml}$ leupeptin. Cell lysates $(300 \mu \mathrm{g})$ were incubated with $2 \mu \mathrm{l}$ of antiGSK-3 $\beta$ and $30 \mu \mathrm{l}$ EZview Red protein-G affinity gel beads at $4^{\circ} \mathrm{C}$ for $3 \mathrm{hrs}$. The beads were recovered by centrifugation at $8,000 \mathrm{xg}$ for $30 \mathrm{sec}$ and washing with $500 \mu \mathrm{l}$ of ice-cold lysis buffer. The immunoprecipitates were mixed with $20 \mu \mathrm{l}$ of reaction mixture containing $25 \mu \mathrm{Ci} \gamma^{32 \mathrm{P}-\mathrm{ATP}}$

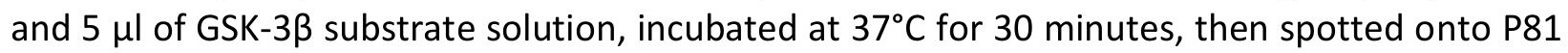
phosphate cellulose membranes. Membranes were washed 4 times with $0.5 \%$ phosphoric acid and once with acetone. Counting of incorporated radioactivity was performed using a Beckman scintillation counter.

Expression and purification of GST-Cdk5rap2. GST-Cdk5rap2 was cloned into pFastBac vectors from which baculovirus was generated according to the Bac-to-Bac ${ }^{\circledR}$ baculovirus protein expression system (Thermo Fisher, Waltham, MA). Sf9 insect cells were infected with P2 baculovirus carrying GST-Cdk5rap2 for 24 hrs. GST-Cdk5rap2 was purified by affinity chromatography using a glutathione (GSH)-conjugated agarose column (Sigma-Aldrich, St. Louis, MO). Sf9 cell lysates expressing GST-Cdk5rap2 were incubated with GSH-agarose for 1 hour at $4^{\circ}$ $\mathrm{C}$ and washed with $1 \times$ PBS containing 1\% Triton X-100. Bound proteins were eluted with $10 \mathrm{mM}$ reduced $\mathrm{GSH}$ in $50 \mathrm{mM}$ Tris elution buffer $(\mathrm{pH} 8)$.

GST pull down assay. GST-Cdk5rap2 ( $1 \mu$ mole) bound to glutathione-agarose beads was mixed with GSK3 $3(2 \mu \mathrm{g})$ at $4^{\circ} \mathrm{C}$ for $2 \mathrm{hrs}$. The pulled-down complex was washed 4 times with ice-cold GST lysis buffer (20 mM Tris- $\mathrm{HCl}$ (pH 8.0), $200 \mathrm{mM} \mathrm{NaCl}, 1 \mathrm{mM}$ EDTA (pH 8.0), 0.5\% NP-40, $2 \mu \mathrm{g} / \mu \mathrm{l}$ aprotinin, $1 \mu \mathrm{g} / \mu \mathrm{l}$ leupeptin, $0.7 \mu \mathrm{g} / \mathrm{ml}$ pepstatin and $25 \mu \mathrm{g} / \mathrm{ml}$ PMSF) by centrifugation at 2,500 rpm for $10 \mathrm{~min}$ and analyzed by SDS-PAGE and immunoblotting for GST and GSK3 $\beta$.

Generation of promoter constructs of wt WIP1 (pGL3-WIP1) and WIP1 with NF-kB binding site deletion (pGL3-WIP1- $\triangle$ KB). Using genomic DNAs isolated from HEK293 cells as a template, the WIP1 promoter region was amplified by PCR using the primer set: ACATTTTCTTGAGCTGATTTTGCTT (WIP1-F1) and TCGGAGAAGACGCTCACTCC (WIP1-R1). The promoter region for WIP1- $\triangle K B$ was generated by $P C R$ using two different sets of primers: ACATTTTCTTGAGCTGATTTTGCTT (WIP1-F1) and GTTTAAAAAGCACtta accgtcagct (WIP1-R2), and ACCGAGACTGTGCagctgacggttaaGTGCTT (WIP1-F2) and TCGGAGAAGACGC TCACTCC (WIP1-R1), with overlapping fragments (lowercase letters) in WIP1-R2 and WIP1-F2. Two PCR products were annealed and used as templates for subsequent 8 fusion PCR cycles ${ }^{54}$. PCR products were then purified using the GeneJET PCR Purification Kit (Thermo Fisher, Waltham, MA) and used as templates for PCR amplification using the WIP1-F1 and WIP1-R2 primer set. Generated WIP1 and WIP1- $\triangle K B$ promoter PCR products were cloned into pGL3-basic luciferase reporter vector (Promega, Madison, WI, USA) using Xhol and Bglll restriction enzyme sites and designated as pGL3-WIP1 and pGL3-WIP1- $\triangle K B$, respectively. Successful cloning was confirmed by DNA sequencing.

Luciferase assay. To measure luciferase activity, HEK293 cells were co-transfected with the indicated siRNA, pGL3-WIP1 or pGL3-WIP1- $\triangle K B$ and $p$ TK-Renilla luciferase vector using lipofectamine 2000 (Invitrogen, Carlsbad, CA, USA). Cell extracts were prepared 48 hours after transfection and luciferase activity was measured using the Dual-Luciferase Reporter assay 
bioRxiv preprint doi: https://doi.org/10.1101/2020.07.09.194761; this version posted July 11,2020 . The copyright holder for this preprint (which was not certified by peer review) is the author/funder, who has granted bioRxiv a license to display the preprint in perpetuity. It is made available under aCC-BY-NC 4.0 International license.

system (Promega, Madison, WI, USA). Renilla luciferase served as an internal control for normalization.

Statistical analysis. Student's t-test (unpaired, two-sided) or one or two-way analysis of variance (ANOVA) was used. Significance was set at $p<0.05$. 
Acknowledgements: We thank Drs. Tara Beattie and Karl Riabowol at the University of Calgary for providing us BJ-5ta cells, and adenovirus carrying Ras V12 (Adeno-Ras V12) and control virus carrying GFP alone, respectively. We also thank Dr. Angela Kaindl at the CharitéUniversitätsmedizin Berlin for providing a rabbit antibody against mouse Cdk5rap2. This work was supported in part by a grant from the NSERC (RGPIN/06270-2019) to KYL.

Authorship contributions: XW performed most of the experiments and drafted the manuscript. PS and ZS performed the experiments for data presented in Figures 4 and 11, respectively. XG, JLR and KYL contributed to the analysis and interpretation of data and/or provided constructive comments on experimental design and/or contributed to the preparation and writing of the manuscript. JLR and KYL critically revised the manuscript for important intellectual content and wrote the final version of the manuscript.

Disclosure of conflicts of interest: The authors declare no competing financial interests. 


\section{References}

1 Ching YP, Qi Z, Wang JH. Cloning of three novel neuronal Cdk5 activator binding proteins. Gene 2000; 242:285-294.

2 Jia Y, Fong KW, Choi YK, See SS, Qi RZ. Dynamic recruitment of CDK5RAP2 to centrosomes requires its association with dynein. PloS one 2013; 8:e68523.

3 Graser S, Stierhof YD, Nigg EA. Cep68 and Cep215 (Cdk5rap2) are required for centrosome cohesion. Journal of cell science 2007; 120:4321-4331.

4 Kim S, Rhee K. Importance of the CEP215-pericentrin interaction for centrosome maturation during mitosis. PloS one 2014; 9:e87016.

5 Hanafusa $\mathrm{H}$, Kedashiro S, Tezuka M et al. PLK1-dependent activation of LRRK1 regulates spindle orientation by phosphorylating CDK5RAP2. Nature cell biology 2015; 17:1024-1035.

6 Bond J, Roberts E, Springell $\mathrm{K}$ et al. A centrosomal mechanism involving CDK5RAP2 and CENPJ controls brain size. Nature genetics 2005; 37:353-355.

7 Rosales JL, Rattner JB, Lee KY. The primary microcephaly 3 (MCPH3) interacting protein, p35 and its catalytic subunit, Cdk5, are centrosomal proteins. Cell cycle 2010; 9:618-620.

8 Nasser $\mathrm{H}$, Vera $\mathrm{L}$, Elmaleh-Berges $\mathrm{M}$ et al. CDK5RAP2 primary microcephaly is associated with hypothalamic, retinal and cochlear developmental defects. J Med Genet 2020.

9 Chavali PL, Chandrasekaran G, Barr AR et al. A CEP215-HSET complex links centrosomes with spindle poles and drives centrosome clustering in cancer. Nature communications 2016; 7:11005.

10 Lancaster MA, Renner M, Martin CA et al. Cerebral organoids model human brain development and microcephaly. Nature 2013; 501:373-379.

11 Yigit G, Brown KE, Kayserili H et al. Mutations in CDK5RAP2 cause Seckel syndrome. Molecular genetics \& genomic medicine 2015; 3:467-480.

12 Ogrodnik M, Salmonowicz H, Jurk D, Passos JF. Expansion and Cell-Cycle Arrest: Common Denominators of Cellular Senescence. Trends in biochemical sciences 2019; 44:996-1008.

13 Cai B, Ma W, Bi C et al. Long noncoding RNA H19 mediates melatonin inhibition of premature senescence of c-kit(+) cardiac progenitor cells by promoting miR-675. Journal of pineal research 2016; 61:82-95.

14 Lee JS, Mo Y, Gan H et al. Pak2 kinase promotes cellular senescence and organismal aging. Proceedings of the National Academy of Sciences of the United States of America 2019; 116:13311-13319.

15 Rajarajacholan UK, Riabowol K. Aging with ING: a comparative study of different forms of stress induced premature senescence. Oncotarget 2015; 6:34118-34127.

16 De Meyer T, Nawrot T, Bekaert S, De Buyzere ML, Rietzschel ER, Andres V. Telomere Length as Cardiovascular Aging Biomarker: JACC Review Topic of the Week. Journal of the American College of Cardiology 2018; 72:805-813.

17 Zhu H, Blake S, Kusuma FK, Pearson RB, Kang J, Chan KT. Oncogene-Induced Senescence: from Biology to Therapy. Mechanisms of ageing and development 2020:111229.

$18 \mathrm{Gu} \mathrm{Y,} \mathrm{Han} \mathrm{J,} \mathrm{Jiang} \mathrm{C,} \mathrm{Zhang} \mathrm{Y.} \mathrm{Biomarkers,} \mathrm{oxidative} \mathrm{stress} \mathrm{and} \mathrm{autophagy} \mathrm{in} \mathrm{skin} \mathrm{aging.} \mathrm{Ageing}$ research reviews 2020; 59:101036.

$19 \mathrm{Ou} \mathrm{HL}$, Schumacher B. DNA damage responses and p53 in the aging process. Blood 2018; 131:488-495. 
20 Kuilman T, Michaloglou C, Mooi WJ, Peeper DS. The essence of senescence. Genes \& development 2010; 24:2463-2479.

21 Mallette FA, Gaumont-Leclerc MF, Ferbeyre G. The DNA damage signaling pathway is a critical mediator of oncogene-induced senescence. Genes \& development 2007; 21:43-48.

22 Bartkova J, Rezaei N, Liontos $M$ et al. Oncogene-induced senescence is part of the tumorigenesis barrier imposed by DNA damage checkpoints. Nature 2006; 444:633-637.

23 Di Micco R, Fumagalli M, Cicalese A et al. Oncogene-induced senescence is a DNA damage response triggered by DNA hyper-replication. Nature 2006; 444:638-642.

24 Kruse JP, Gu W. Modes of p53 regulation. Cell 2009; 137:609-622.

25 Catalano A, Rodilossi S, Caprari P, Coppola V, Procopio A. 5-Lipoxygenase regulates senescence-like growth arrest by promoting ROS-dependent p53 activation. The EMBO journal 2005; 24:170-179.

26 Lin W, Zhao Z, Ni Z, Zhao Y, Du W, Chen S. IFI16 restoration in hepatocellular carcinoma induces tumour inhibition via activation of p53 signals and inflammasome. Cell Prolif 2017; 50.

27 Georgakilas AG, Martin OA, Bonner WM. p21: A Two-Faced Genome Guardian. Trends in molecular medicine 2017; 23:310-319.

28 Sakai H, Fujigaki H, Mazur SJ, Appella E. Wild-type p53-induced phosphatase 1 (Wip1) forestalls cellular premature senescence at physiological oxygen levels by regulating DNA damage response signaling during DNA replication. Cell cycle 2014; 13:1015-1029.

29 Chen Z, Yi W, Morita Y et al. Wip1 deficiency impairs haematopoietic stem cell function via p53 and mTORC1 pathways. Nature communications 2015; 6:6808.

30 Tang $\mathrm{Y}$, Liu L, Sheng $\mathrm{M}$ et al. Wip1 knockout inhibits the proliferation and enhances the migration of bone marrow mesenchymal stem cells. Experimental cell research 2015; 334:310-322.

31 Cha BH, Lee JS, Kim SW, Cha HJ, Lee SH. The modulation of the oxidative stress response in chondrocytes by Wip1 and its effect on senescence and dedifferentiation during in vitro expansion. Biomaterials 2013; 34:2380-2388.

32 Lowe JM, Cha H, Yang Q, Fornace AJ, Jr. Nuclear factor-kappaB (NF-kappaB) is a novel positive transcriptional regulator of the oncogenic Wip1 phosphatase. The Journal of biological chemistry 2010; 285:5249-5257.

33 Ma B, Hottiger MO. Crosstalk between Wnt/beta-Catenin and NF-kappaB Signaling Pathway during Inflammation. Frontiers in immunology 2016; 7:378.

34 Blankesteijn WM, van de Schans VA, ter Horst P, Smits JF. The Wnt/frizzled/GSK-3 beta pathway: a novel therapeutic target for cardiac hypertrophy. Trends in pharmacological sciences 2008; 29:175-180.

35 Lizarraga SB, Margossian SP, Harris MH et al. Cdk5rap2 regulates centrosome function and chromosome segregation in neuronal progenitors. Development 2010; 137:1907-1917.

36 Kilic Eren M, Tabor V. The role of hypoxia inducible factor-1 alpha in bypassing oncogeneinduced senescence. PloS one 2014; 9:e101064.

37 Aird KM, Zhang R. Detection of senescence-associated heterochromatin foci (SAHF). Methods Mol Biol 2013; 965:185-196.

38 Severino J, Allen RG, Balin S, Balin A, Cristofalo VJ. Is beta-galactosidase staining a marker of senescence in vitro and in vivo? Experimental cell research 2000; 257:162-171. 
39 Zhang $\mathrm{Y}$, Zhang $\mathrm{Y}$, Zhong C, Xiao F. Cr(VI) induces premature senescence through ROSmediated p53 pathway in L-02 hepatocytes. Scientific reports 2016; 6:34578.

40 Feng Y, Xia Y, Yu G et al. Cleavage of GSK-3beta by calpain counteracts the inhibitory effect of Ser9 phosphorylation on GSK-3beta activity induced by $\mathrm{H}(2) \mathrm{O}(2)$. Journal of neurochemistry 2013; 126:234-242.

41 Shimizu I, Minamino T. Cellular senescence in cardiac diseases. Journal of cardiology 2019; 74:313-319.

42 Park JS, Lee MK, Rosales JL, Lee KY. Primary microcephaly 3 (MCPH3): revisiting two critical mutations. Cell cycle 2011; 10:1331-1333.

43 Barrera JA, Kao LR, Hammer RE, Seemann J, Fuchs JL, Megraw TL. CDK5RAP2 regulates centriole engagement and cohesion in mice. Developmental cell 2010; 18:913-926.

44 Tang X, Zheng D, Hu P et al. Glycogen synthase kinase 3 beta inhibits microRNA-183-96-182 cluster via the beta-Catenin/TCF/LEF-1 pathway in gastric cancer cells. Nucleic acids research 2014; 42:2988-2998.

45 Rouillard AD, Gundersen GW, Fernandez NF et al. The harmonizome: a collection of processed datasets gathered to serve and mine knowledge about genes and proteins. Database : the journal of biological databases and curation 2016; 2016.

46 Fumoto K, Hoogenraad CC, Kikuchi A. GSK-3beta-regulated interaction of BICD with dynein is involved in microtubule anchorage at centrosome. The EMBO journal 2006; 25:5670-5682.

47 Yoshino $Y$, Ishioka C. Inhibition of glycogen synthase kinase-3 beta induces apoptosis and mitotic catastrophe by disrupting centrosome regulation in cancer cells. Scientific reports 2015; 5:13249.

48 Fong KW, Choi YK, Rattner JB, Qi RZ. CDK5RAP2 is a pericentriolar protein that functions in centrosomal attachment of the gamma-tubulin ring complex. Molecular biology of the cell 2008; 19:115-125.

49 Wang Z, Wu T, Shi $\mathrm{L}$ et al. Conserved motif of CDK5RAP2 mediates its localization to centrosomes and the Golgi complex. The Journal of biological chemistry 2010; 285:2265822665.

50 Leonard MK, Hill NT, Bubulya PA, Kadakia MP. The PTEN-Akt pathway impacts the integrity and composition of mitotic centrosomes. Cell cycle 2013; 12:1406-1415.

51 Wilkinson MB, Dias C, Magida J et al. A novel role of the WNT-dishevelled-GSK3beta signaling cascade in the mouse nucleus accumbens in a social defeat model of depression. The Journal of neuroscience : the official journal of the Society for Neuroscience 2011; 31:90849092.

52 Aschenbach WG, Ho RC, Sakamoto $\mathrm{K}$ et al. Regulation of dishevelled and beta-catenin in rat skeletal muscle: an alternative exercise-induced GSK-3beta signaling pathway. American journal of physiology Endocrinology and metabolism 2006; 291:E152-158.

53 NavaneethaKrishnan S, Rosales JL, Lee KY. MPTP opening caused by Cdk5 loss is due to increased mitochondrial $\mathrm{Ca}(2+)$ uptake. Oncogene 2020; 39:2797-2806.

54 Xiong AS, Yao QH, Peng RH et al. PCR-based accurate synthesis of long DNA sequences. Nature protocols 2006; 1:791-797. 


\section{Figure Legend}

Figure 1. Cdk5rap2 loss triggers SAHF formation. A. Depletion of Cdk5rap2 in BJ-5ta human diploid foreskin fibroblasts. Lysates of cells transfected with Cdk5rap2 siRNA for 3 days were analyzed by SDS-PAGE and immunoblotting for Cdk5rap2 (left panel). Actin blot was used as loading control. Representative blots are from one of three independent experiments $(n=3)$ showing similar results. Ratios of levels of Cdk5rap2 vs actin (right panel) were calculated following densitometric analysis of blots using NIH Image J 1.61. Standard deviation for the 3 independent sets of experiments was calculated based on the ratios of the densitometric levels of Cdk5rap2 vs actin, with values from cells transfected with control siRNA normalized to 1.0. ${ }^{*} p<0.001$. B and C. Cdk5rap2 loss causes formation of SAHF. BJ-5ta cells transfected with Cdk5rap2 siRNA for 3 days were stained with DAPI (B) and HP1 $\gamma$ antibody (C), and subjected to microscopic examination. SAHF formation induced by infecting adenovirus carrying $\mathrm{H}-\mathrm{RAS}^{G 12 \mathrm{~V}}$ into BJ cells was used as positive control. Representative images of control and Cdk5rap2depleted cells, and cells infected with adenovirus carrying GFP alone or H-RAS ${ }^{G 12 V}$ are shown with DAPI and HP1 $\gamma$ stain-enriched and -devoid regions highlighted with open circles and squares, respectively.

Figure 2. Increased number of SAHF positive Cdk5rap2-depleted cells coincides with expression of p21 ${ }^{\text {CIP1 }}$ and p16 ${ }^{I N K 4 a}$. BJ-5ta cells transfected with Cdk5rap2 siRNA \#2 for 5 days were analyzed (i) for SAHF positive cells (A, upper panel) and by SDS-PAGE and immunoblotting for (ii) Cdk5rap2 and actin (A, middle panel), and (iii) $\mathrm{p} 21^{C I P 1}$ and $\mathrm{p} 16^{I N K 4 a}$ as well as Cdk5rap2 and actin (B, upper panel). The number of SAHF positive cells was assessed in 200 cells per treatment group in each of 3 independent experiments $(n=3)$. ${ }^{*} p<0.01$. Actin was used as loading control for immunoblotting. Representative blots are from one of three independent experiments $(n=3)$ showing similar results. Ratios of levels of Cdk5rap2, p21 ${ }^{C I P 1}$ and $\mathrm{p} 16^{\text {INK4a }}$ vs actin and standard deviation for the 3 independent sets of experiments ( $A$, lower panel and $B$, middle and lower panels) were calculated as described for Cdk5rap2 vs actin in Figure 1, with values from cells transfected with control siRNA at day 0 normalized to 1.0. ${ }^{*} p<0.02$. C. Cells transfected with Cdk5rap2 siRNA \#2 or control siRNA were subjected to SA- $\beta$-gal staining 3 days post-transfection. Representative images (left panel) are from one of three independent experiments $(n=3)$ showing similar staining patterns. The number of SA- $\beta$-gal positive cells was assessed in $\sim 200$ cells per treatment group in each of the 3 independent experiments $(n=3) .{ }^{*} p=0.0005$.

Figure 3. Cdk5rap2 loss causes decreased cell proliferation. BJ-5ta cells transfected with Cdk5rap2 siRNA \#2 were subjected to (A) cell viability assay, (B) cell cycle distribution analysis by flow cytometry, and (C) measurement of Ki-67 positive cells as described in Materials and Methods. Data represent means \pm SD from three separate experiments $(n=3)$. ${ }^{*} p<0.01$ (in $A$ and B). The percentage (\%) of Ki-67 positive cells (C, right panel) were assessed in $\sim 200$ cells per treatment group in each of the 3 independent experiments $(n=3) .{ }^{*} p=0.001$.

Figure 4. Cdk5rap2 ${ }^{a n / a n}$ embryos have reduced body weight and Cdk5rap2 ${ }^{\text {an/an }} \mathrm{MEFs}$ show senescent phenotype. A. Genomic DNAs from E12.5 Cdk5rap2 ${ }^{+/+}, \mathrm{Cdk} \mathrm{rap} 2^{+/ a n}$ and Cdk5rap2 ${ }^{\text {an/an }}$ littermates obtained from a Cdk5rap2 ${ }^{+/ a n}$ pregnant mouse were subjected to genotyping by PCR as described in Materials and Methods. Lane 1 is a negative control where no PCR template was 
added. Embryos were numbered (2-11) according to their weights (heaviest to lightest). B. Average weights of isolated E17.5 (left panel) and E12.5 to E17.5 (right panel) Cdk5rap2 ${ }^{+/}$, Cdk5rap2 $2^{+/ a n}$ and Cdk5rap2 ${ }^{\text {an/an }}$ embryos from different litters are shown. C. MEFs isolated from Cdk5rap2 $2^{+/+}, C_{k 5}$ rap2 ${ }^{+/ a n}$ and Cdk5rap2 ${ }^{a n / a n}$ embryos were subjected to SA- $\beta$-gal staining. Representative images (left panel) are from one of three independent experiments $(n=3)$ showing similar staining patterns. The number of SA- $\beta$-gal positive cells was assessed in $\sim 200$ cells per treatment group in each of the 3 independent experiments $(n=3) .{ }^{*} p=0.0002$. D. Growth of MEFs obtained from Cdk5rap2 ${ }^{+/+}, \mathrm{Cdk} \mathrm{rap} 2^{+/ a n}$ and Cdk5rap2 ${ }^{\text {an/an }}$ embryos was analyzed by cell viability assay. E. Lysates of MEFs isolated from Cdk5rap2 ${ }^{+/+}$, Cdk5rap2 ${ }^{+/ a n}$ and Cdk5rap2 an/an embryos were analyzed by SDS-PAGE and immunoblotting for Cdk5rap2, PCNA and p21 CIP1. TCE staining was used to assess protein loading.

Figure 5. Cdk5rap2 loss triggers cellular senescence through downregulation of WIP1-mediated p53 activation. A. BJ-5ta cells depleted of Cdk5rap2 show increased p53 phosphorylation at Ser15, which coincides with increased level of p21 ${ }^{C I P 1}$. Lysates of cells transfected with Cdk5rap2 siRNA \#2 for 3 days were analyzed by SDS-PAGE and immunoblotting for Cdk5rap2, phosphoSer15 p53 (pSer15-p53), p53, p21 ${ }^{C I P 1}$ and actin (A, left panel). Actin blot was used as loading control. Representative blots are from one of three independent experiments $(n=3)$ showing similar results. Ratios of levels of phosphoSer15 p53 (pSer15-p53) and p21 ${ }^{C I P 1}$ vs actin and standard deviation for the 3 independent sets of experiments ( $A$, right panel) were calculated as described for Cdk5rap2 vs actin in Figure 1, with values from cells transfected with control siRNA normalized to $1.0{ }^{*} p<0.005$. B. Lysates of cells infected with adenovirus carrying H-RASG12V or transfected with Cdk5rap2 siRNA \#2 for 3 days were analyzed by SDS-PAGE and immunoblotting for Cdk5rap2, phosphoSer1982-ATM (pSer1982-ATM), ATM, phosphoSer345Chk1 (pSer345-Chk1), Chk1, phosphoThr68-Chk2 (pThr68-Chk2), Chk2, H-RAS and Actin. Actin blot was used as loading control. C. Cdk5rap2 loss represses WIP1 mRNA and protein expression. Levels of WIP1 mRNA in cells transfected with Cdk5rap2 siRNA \#2 were determined by qRT-PCR using isolated total RNA as template. GAPDH was used for normalization. Relative levels of WIP1 mRNA (left panel) were calculated using the $2^{-\Delta \Delta C T}$ method. Relative levels from cells transfected with control siRNA were normalized to 1.0. Data represent means \pm SD of calculated ratios from three independent experiments $(n=3)$. ${ }^{*} p=0.002$. WIP1 protein expression was analyzed by immunoblotting (upper right panel). Actin blot was used as loading control. Representative blots from one of three independent experiments $(n=3)$ showing similar results are shown. Ratios of levels of WIP1 vs actin and standard deviation for the 3 independent sets of experiments (lower right panel) were calculated as described for Cdk5rap2 vs actin in Figure 1, with values from cells transfected with control siRNA normalized to 1.0. ${ }^{*} p<0.01$.

Figure 6. WIP1 loss triggers cellular senescence through p53 activation. BJ-5ta cells transfected with WIP1 siRNA were analyzed by (A) SDS-PAGE and immunoblotting for WIP1, phophoSer15p53, p53, and p21 ${ }^{C I P 1}$ (left panel), and (B) SA- $\beta$-gal staining (left panel). Actin was used as loading control for immunoblotting. Representative blots are from one of three independent experiments $(n=3)$ showing similar results. Ratios of levels of WIP1 vs actin ( $A$, middle panel) and phophoSer15-p53 vs p53 and p21 ${ }^{C I P 1}$ vs actin (A, right panel) and standard deviation for the 3 independent sets of experiments were calculated as described for Cdk5rap2 vs actin in Figure 1, 
with values from cells transfected with control siRNA normalized to $1.0 .{ }^{*} p<0.005$. Representative images of SA- $\beta$-gal staining in $B$ (left panel) are from one of three independent experiments $(n=3)$ showing similar staining patterns. The number of SA- $\beta$-gal positive cells $(B$, right panel) was assessed in $\sim 200$ cells per treatment group in each of the 3 independent experiments $(n=3)$. ${ }^{*} p=0.00016$.

Figure 7. Ectopic expression of WIP1 reverses the senescent phenotypes observed in cells depleted of Cdk5rap2. Lysates of BJ-5ta cells co-transfected with Cdk5rap2 siRNA \#2 and pReceiver-M02 carrying WIP1 were analyzed by SDS-PAGE and immunoblotting for Cdk5rap2 and WIP1 (A, upper panel), and SA- $\beta$-gal staining ( $B$, upper panel) $72 \mathrm{hrs}$ post-transfection. Actin was used as loading control for immunoblotting. Representative blots are from one of three independent experiments $(n=3)$ showing similar results. Ratios of levels of WIP1 vs actin and standard deviation for the 3 independent sets of experiments ( $A$, lower panel) were calculated as described for Cdk5rap2 vs actin in Figure 1, with values from cells co-transfected with control siRNA and empty vector normalized to $1.0 .{ }^{*} p<0.05$. Representative images of SA- $\beta$-gal staining in $B$ (upper panel) are from one of three independent experiments $(n=3)$ showing similar staining patterns. The number of SA- $\beta$-gal positive cells (B, lower panel) was assessed in $\sim 100$ cells per treatment group in each of the 3 independent experiments $(n=3) .{ }^{*} p<0.001$.

Figure 8. Cdk5rap2 loss reduces $\boldsymbol{\beta}$-catenin level. A. The WIP1 promoter contains an NF-kB binding site $^{32}$. BJ-5ta cells transfected with Cdk5rap2 siRNA \#2 (B), or $\beta$-catenin siRNA (C) for 3 days were analyzed by SDS-PAGE and immunoblotting. Nuclear fractions and whole cell lysates in (B) were probed for $\beta$-catenin and histone $\mathrm{H} 3$ (nuclear fraction) or Cdk5rap2 and actin (whole cell lysate), and whole cell lysates in (C) were probed for $\beta$-catenin, WIP1 and actin. Actin blot was used as loading control. Representative blots are from one of three independent experiments $(n=3)$ showing similar results. Ratios of levels of $\beta$-catenin vs histone H3 (in nuclear fraction) or actin (in whole cell lysate) in (B) and $\beta$-catenin or WIP1 vs actin in (C), right panels, and standard deviation for the 3 independent sets of experiments were calculated as described for Cdk5rap2 vs actin in Figure 1, with values from cells transfected with control siRNA normalized to 1.0. ${ }^{*} p<0.05$ (in B). ${ }^{*} p<0.005$ (in C).

Figure 9. GSK3 $\beta$ interaction with Cdk5rap2 inhibits its kinase activity. A. Lysates of BJ-5ta cells co-transfected with Myc-tagged Cdk5rap2 and FLAG-tagged GSK3 $\beta$ (upper panel) were subjected to immunoprecipitation (IP) using FLAG antibody (middle panel) or Myc antibody (lower panel) then analyzed for Cdk5rap2 and GSK3 $\beta$ co-immunoprecipitation by immunoblotting both IPs with Myc and FLAG antibodies. B. Cdk5rap2 directly interacts with GSK3ß. GST-Cdk5rap2 bound to GSH-agarose beads was mixed with GSK3 $\beta$ as described in Materials and Methods. The resulting complexes were washed extensively then analyzed by SDS-PAGE and immunoblotting for GST and GSK3 3 . C. Lysates of cells transfected with Cdk5rap2 siRNA \#2 for 3 days were analyzed by SDS-PAGE and immunoblotting for Cdk5rap2, phosphoSer9-GSK3 $\beta$ and GSK3 $\beta$ (left panel). Representative blots are from one of three independent experiments $(n=3)$ showing similar results. Ratios of levels of phosphoSer9-GSK3 $\beta$ vs GSK3 $\beta$ and standard deviation for the 3 independent sets of experiments (right panel) were calculated as described for Cdk5rap2 vs actin in Figure 1, with values from cells transfected with control siRNA normalized to 1.0. ${ }^{*} p=0.01$. D. Lysates of cells transfected with Cdk5rap2 siRNA \#2 for 3 days were subjected to IP using GSK3 $\beta$ 
antibody. The IPs were then examined for in vitro GSK3 $\beta$ kinase activity as described in Materials and Methods. Data represent means \pm SD from three independent experiments $(n=3)$. ${ }^{*} p=0.0027$. E. Inhibition of GSK3 $\beta$ activity with TWS119 in cells depleted of Cdk5rap2 restores $\beta$ catenin and WIP1 expression (left panel). Representative blots from one of three independent experiments $(n=3)$ showing similar results are shown. Ratios of levels of $\beta$-catenin and WIP1 vs actin and standard deviation for the 3 independent sets of experiments (right panel) were calculated as described for Cdk5rap2 vs actin in Figure 1, with values from cells transfected with control siRNA and treated with DMSO normalized to 1.0. ${ }^{*} \mathrm{p}<0.05$.

Figure 10. Inhibition of GSK3 $\beta$ in Cdk5rap2-depleted cells inhibits senescence that is induced upon inhibition of WIP1 activity. A. BJ-5ta cells transfected with Cdk5rap2 siRNA \#2 were treated with TWS119 and/or GSK2830371, a potent inhibitor of WIP1 activity. Cell lysates were then analyzed by SDS-PAGE and immunoblotting for Cdk5rap2, $\beta$-catenin, WIP1, phosphoSer15-p53, p53 and actin (left panel). Actin blot was used as loading control. Representative blots from one of three independent experiments $(n=3)$ showing similar results are shown. Ratios of levels of $\beta$ catenin and WIP1 vs actin and phosphoSer15-p53 vs p53, and standard deviation for the 3 independent sets of experiments (right panel) were calculated as described for Cdk5rap2 vs actin in Figure 1, with values from cells transfected with control siRNA and treated with DMSO normalized to 1.0. ${ }^{*} p<0.05$. B. Representative images of $S A-\beta$-gal staining (upper panel) are from one of three independent experiments $(n=3)$ showing similar staining patterns. The number of SA- $\beta$-gal positive cells (lower panel) was assessed in $\sim 100$ cells per treatment group in each of the 3 independent experiments $(n=3) .{ }^{*} p<0.05$. 


\section{Supplementary Figure Legend}

Supplementary Figure 1. Cdk5rap2-depleted cells have no detectable yH2AX foci. BJ-5ta cells transfected with Cdk5rap2 siRNA \#2 for 3 days were stained with DAPI and $\gamma \mathrm{H} 2 \mathrm{AX}$ antibody. Cells

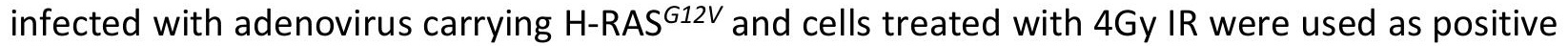
controls for $\mathrm{YH} 2 \mathrm{AX}$ detection. Merged images of $\mathrm{YH} 2 \mathrm{AX}$ and DAPI staining are shown. Representative images are from one of three independent experiments showing similar staining patterns. The indicated percentage (\%) of $\mathrm{yH} 2 \mathrm{AX}$ positive cells was assessed in $\sim 200$ cells per treatment group in each of the 3 independent experiments $(n=3)$.

Supplementary Figure 2. Purification of GST-Cdk5rap2. Lysate of Sf9 insect cells expressing GSTtagged Cdk5rap2 was subjected to affinity purification using a glutathione-agarose column. After collecting the flow-through, the column was washed until no more protein was detected in the wash. Bound proteins were eluted from the column with elution buffer containing $10 \mathrm{mM}$ reduced glutathione. Three elution fractions (E1-E3) were collected and subjected to SDS-PAGE and immunoblotting for Cdk5rap2 (upper panel). SYPRO Ruby staining (lower panel) was performed to assess protein loading and GST-Cdk5rap2 purification.

Supplementary Figure 3. Cdk5rap2 regulates WIP1 promoter activity via $\beta$-catenin. A. Sequence of pGL3 luciferase reporter vector carrying WIP1 or WIP1- $\triangle K B$ promoter. $B$ and $C$. Loss of Cdk5rap2 (B, left and right panels) or $\beta$-catenin (C) inhibits WIP1 promoter activity as measured by luciferase reporter activity but inhibition of GSK3 $\beta$ with TWS119 in Cdk5rap2-depleted cells restores WIP1 promoter activity (B, right panel). Data represent means \pm SD from three $(n=3)$ independent experiments. ${ }^{*} p<0.05$. 
A

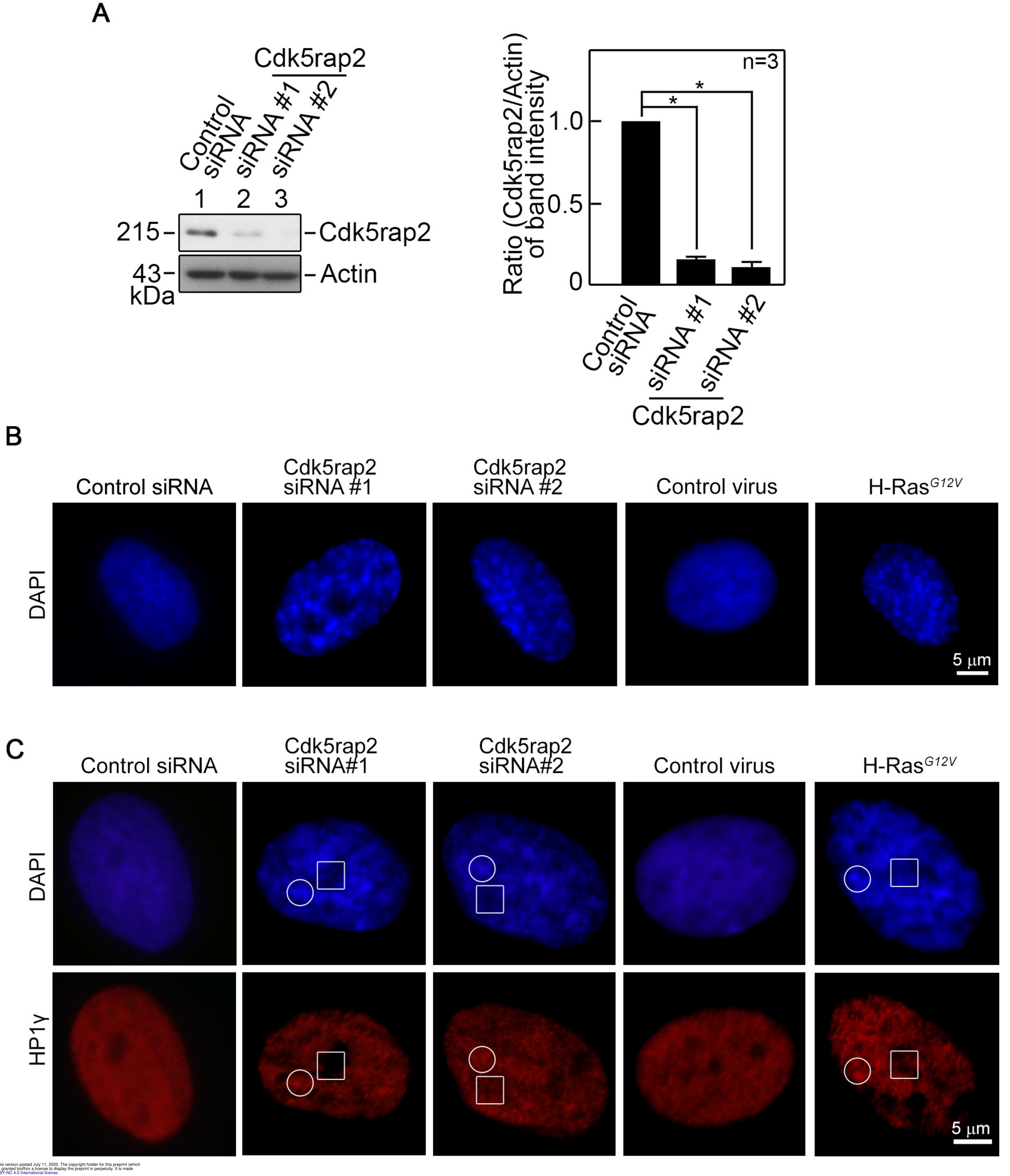

B

Fig. 1 
A
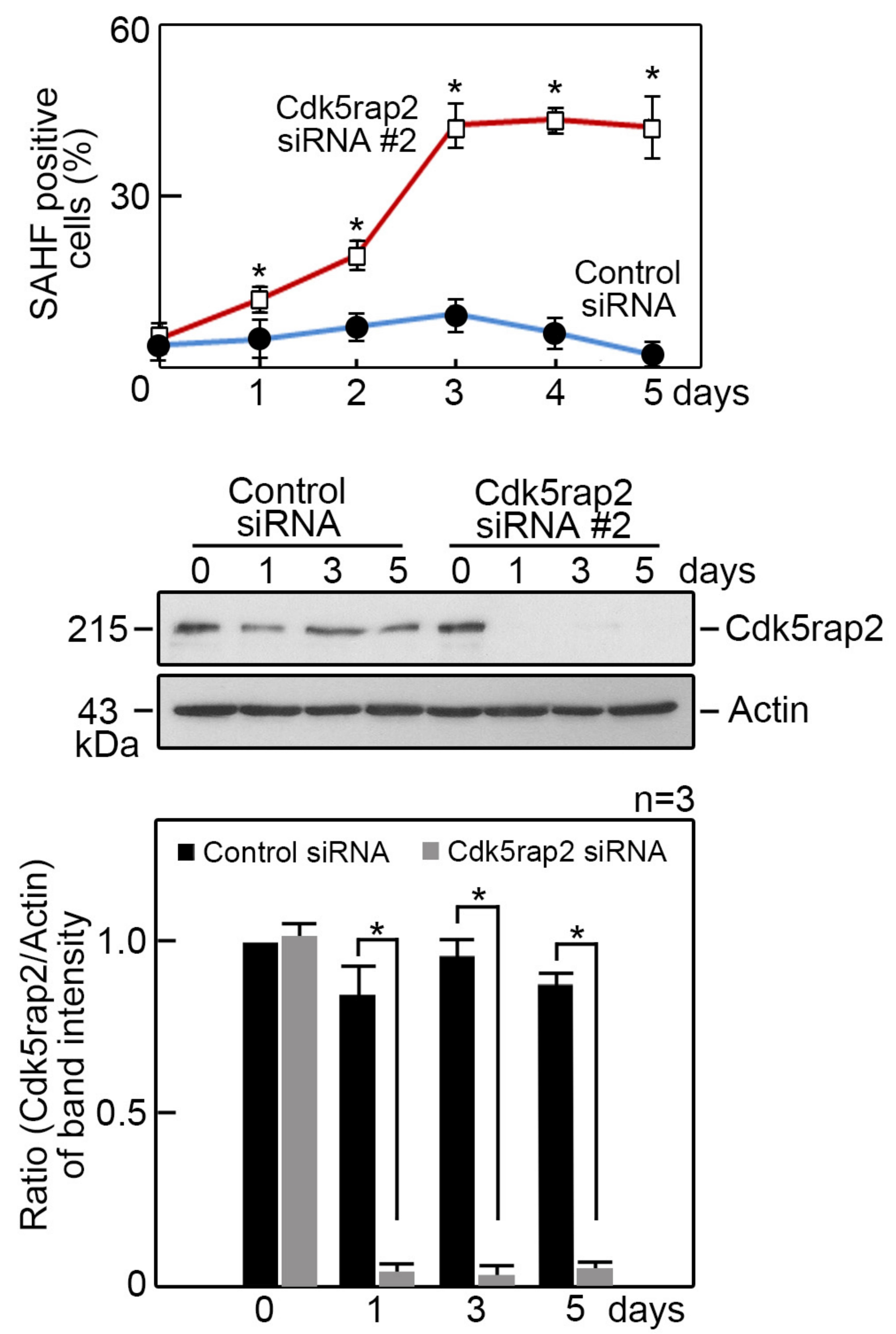

C

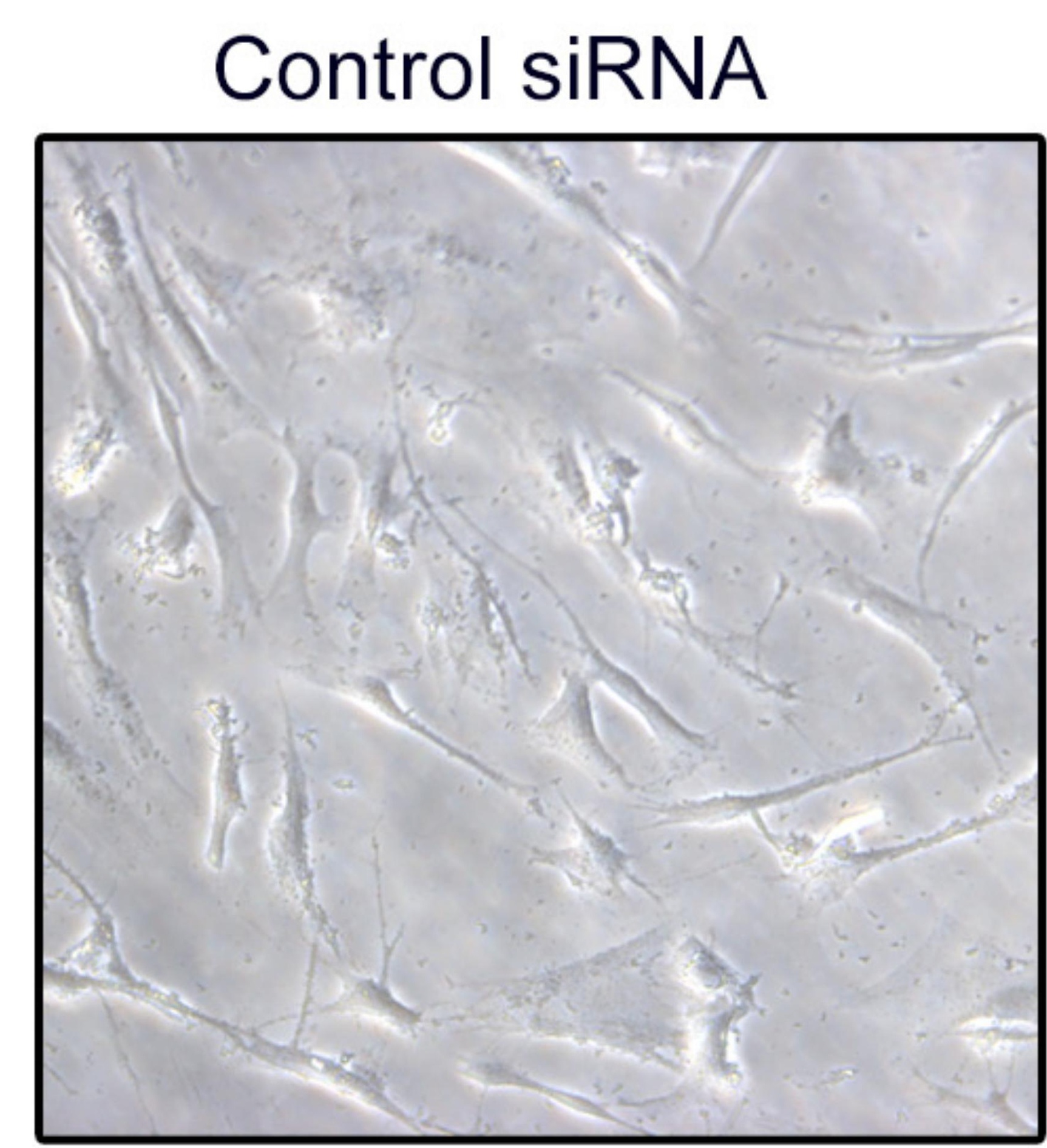

B
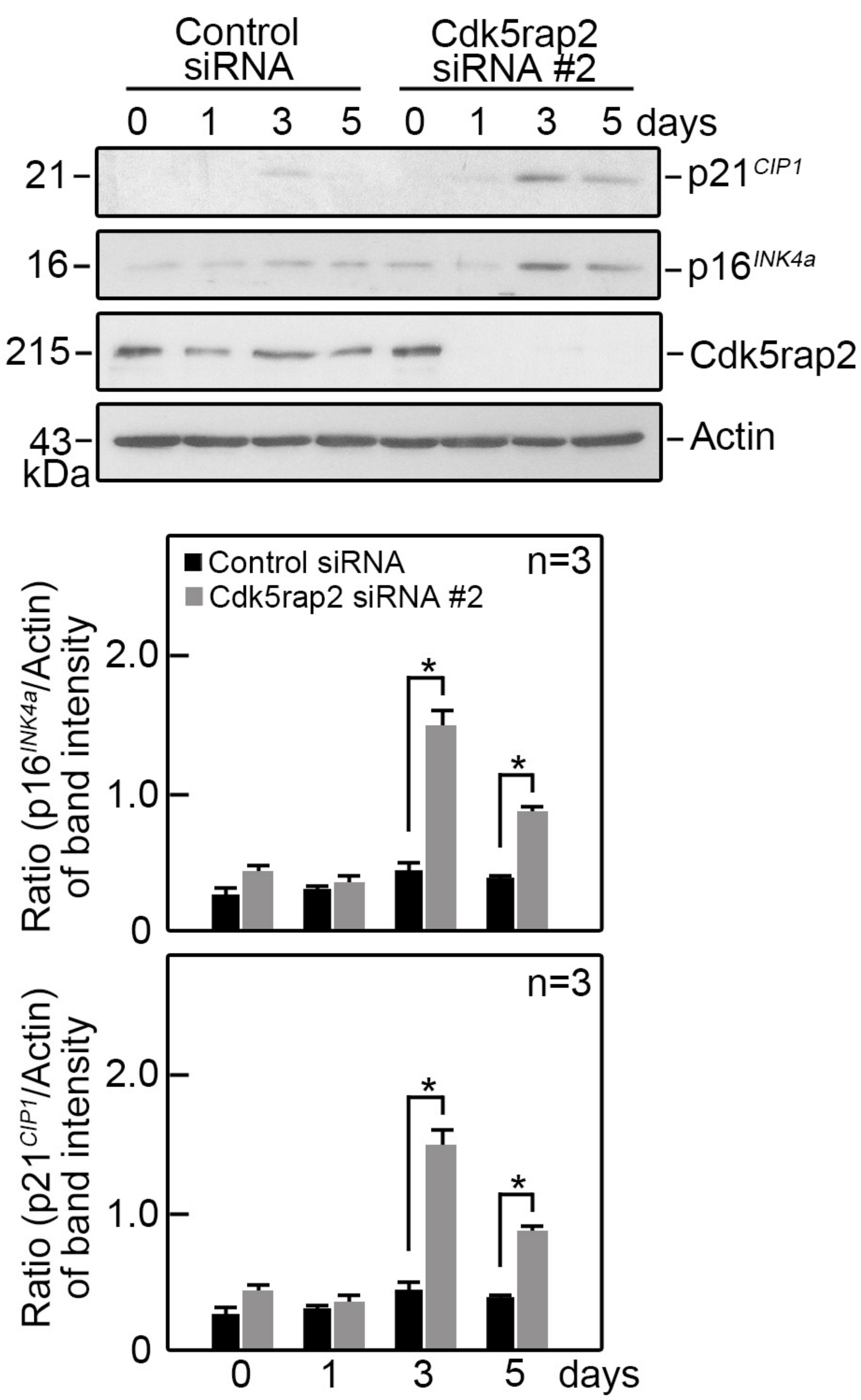

Cdk5rap2 siRNA \#2

$100 \mu \mathrm{m}$

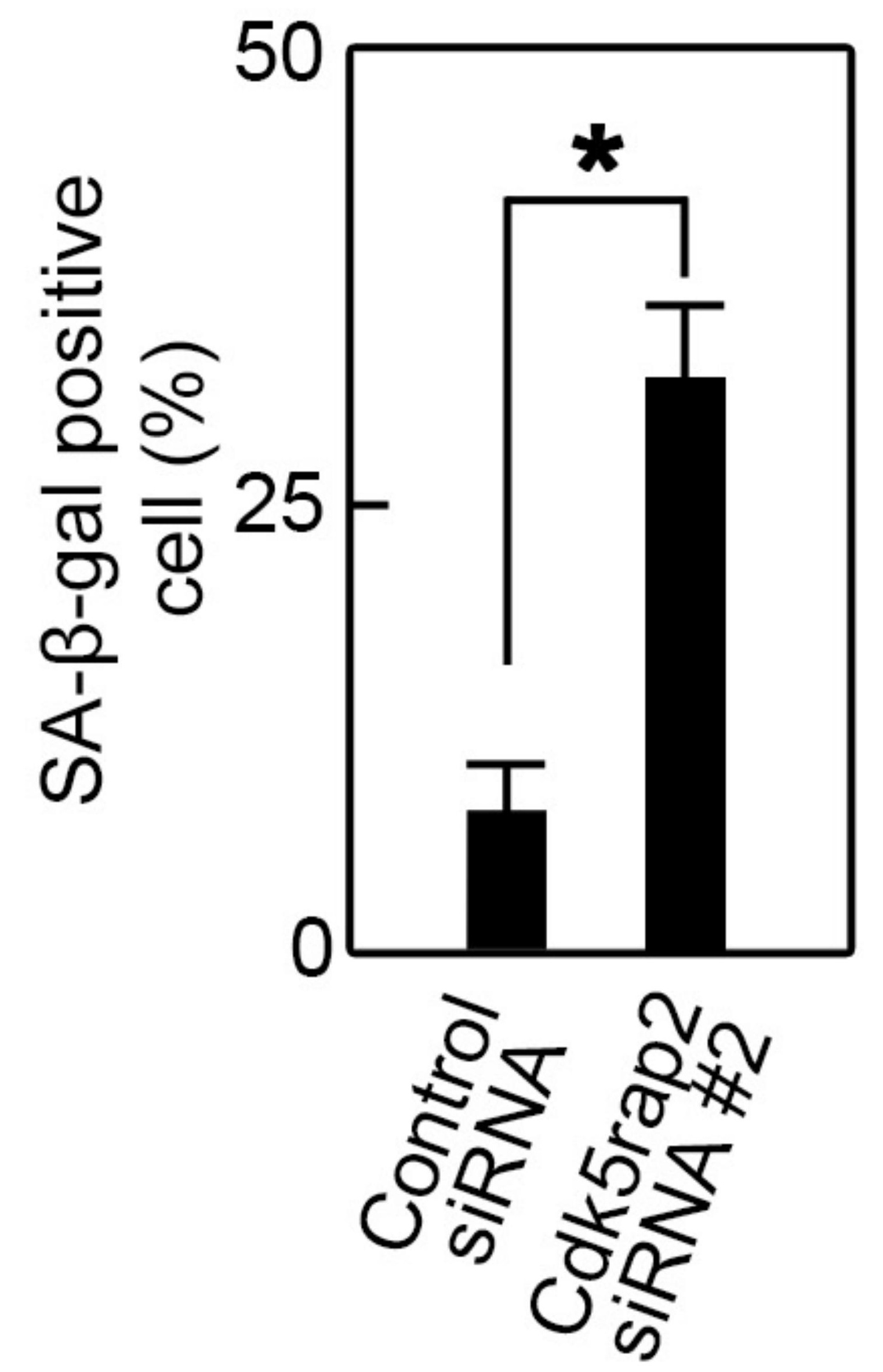

Fig. 2 
A

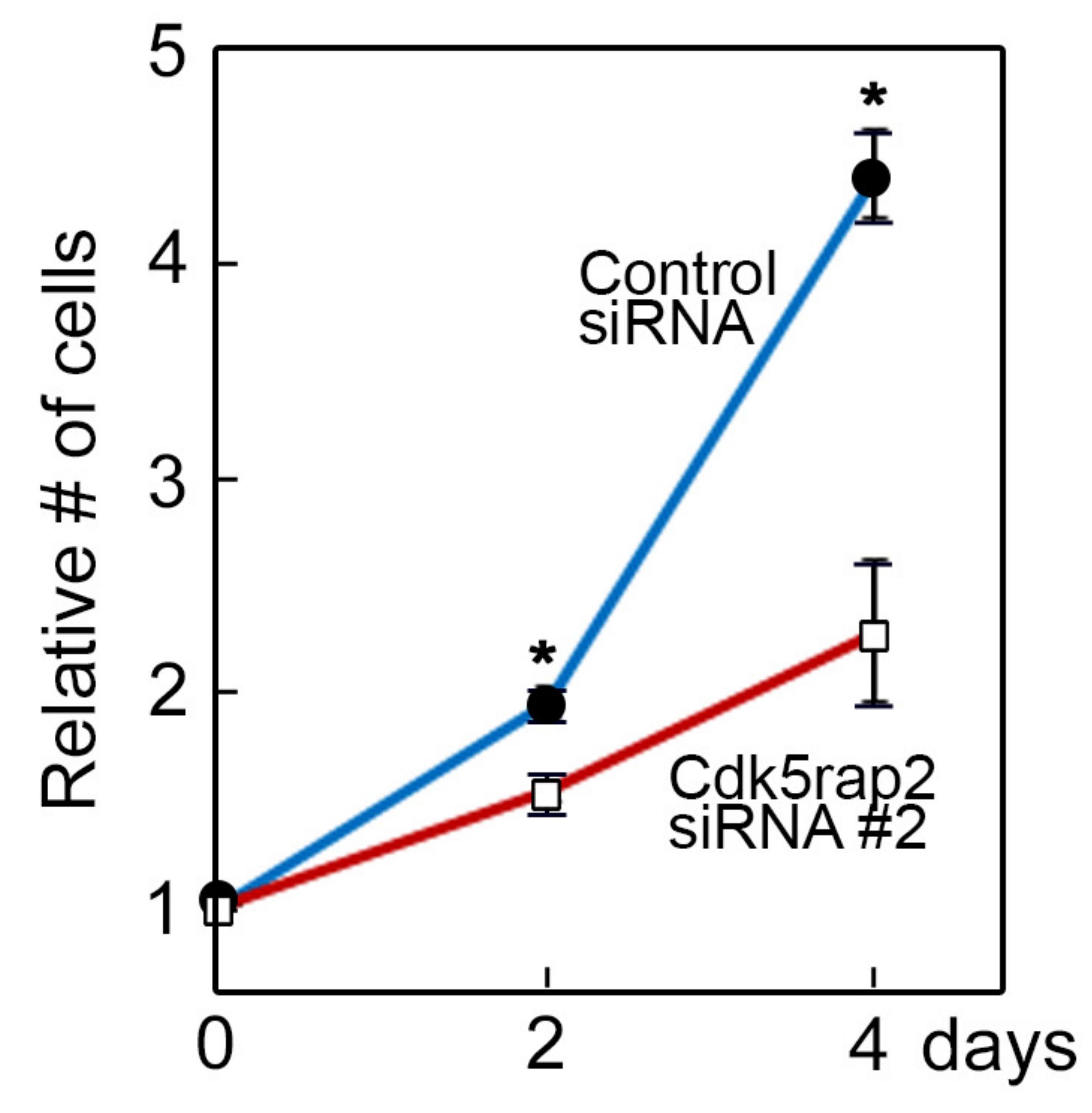

B

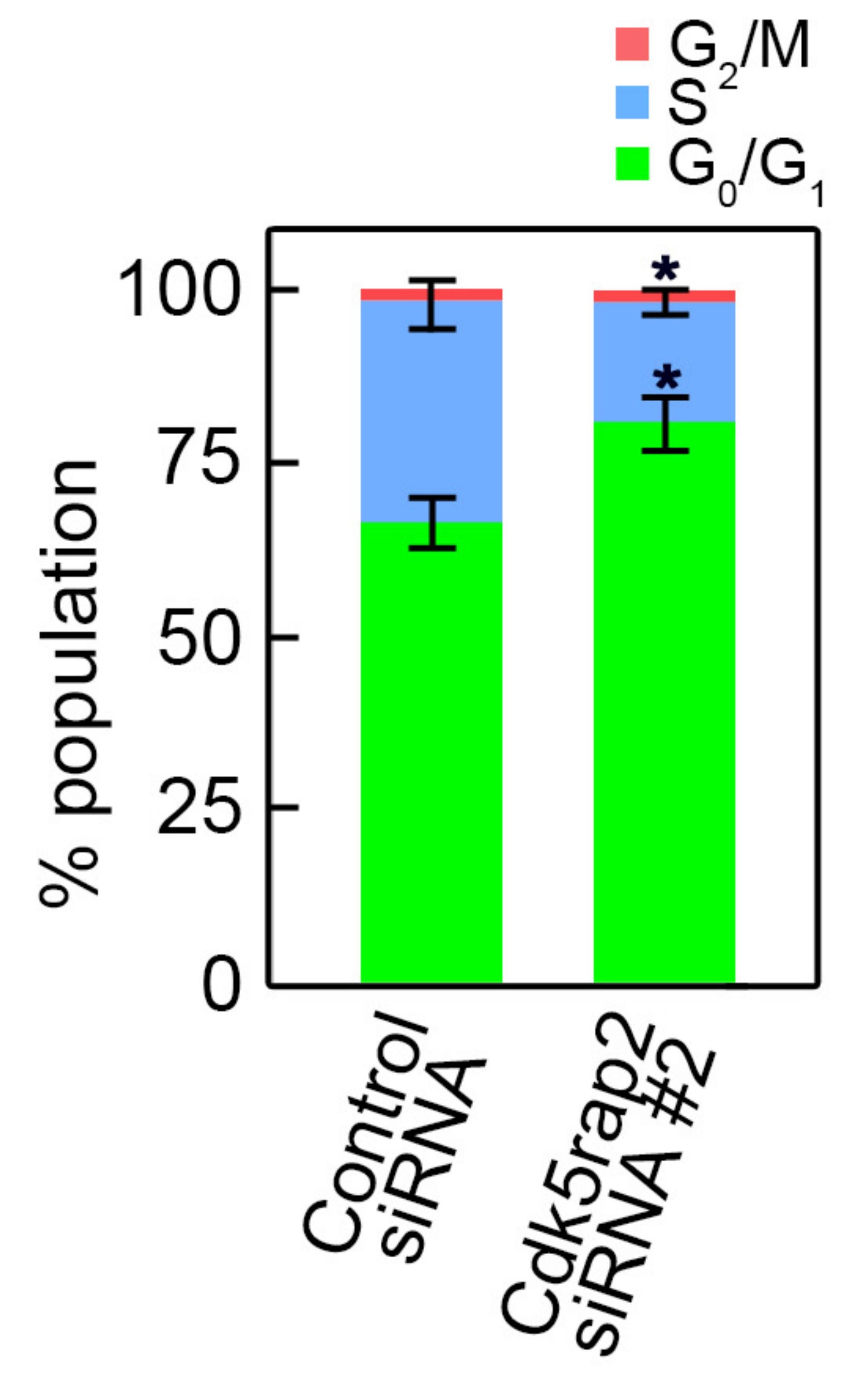

C
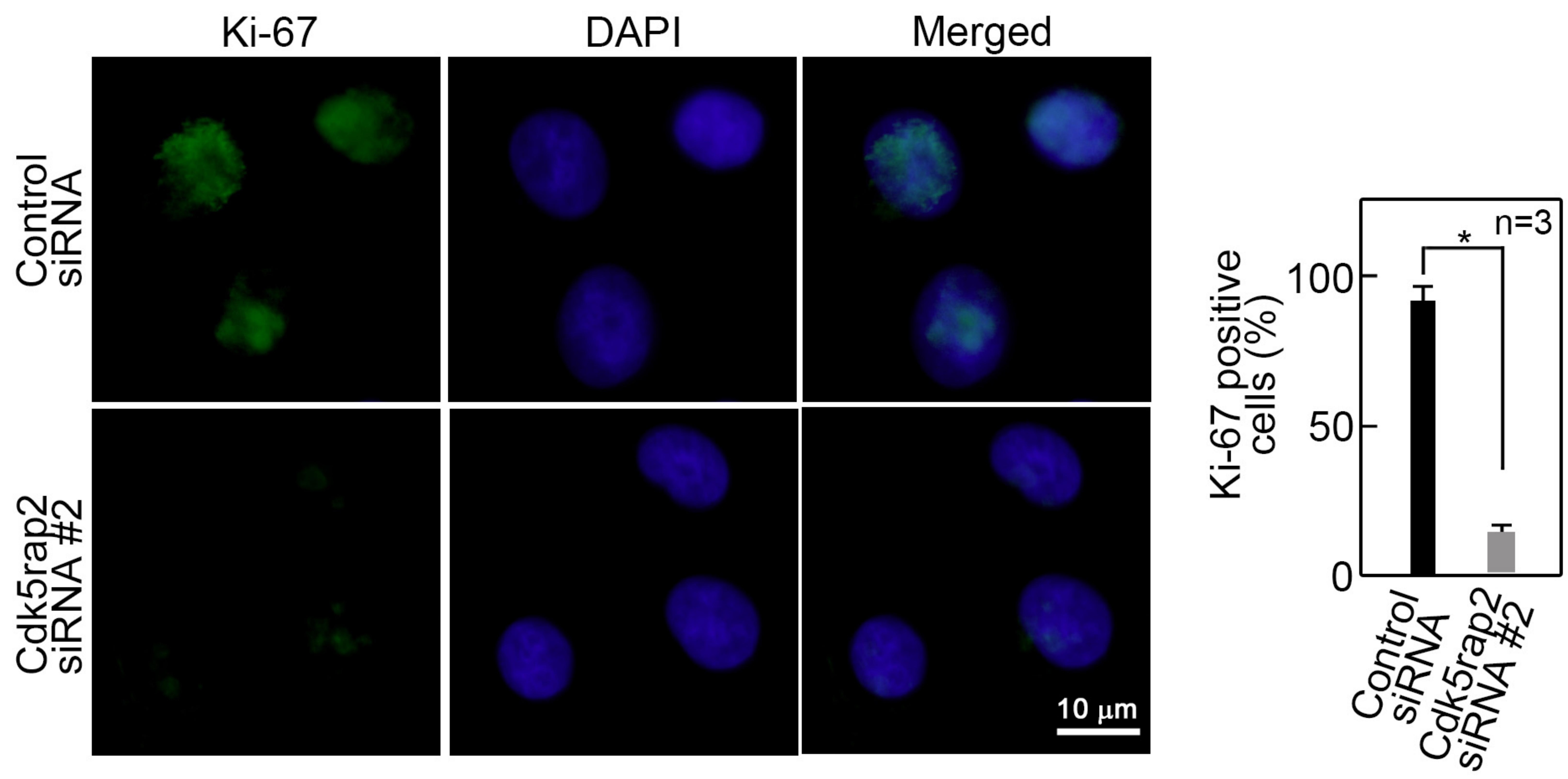

Fig. 3 
A

Body

weights:

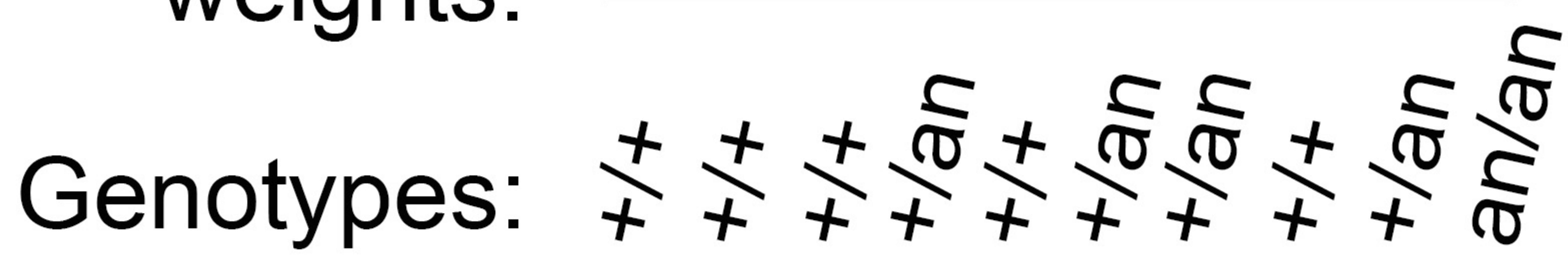

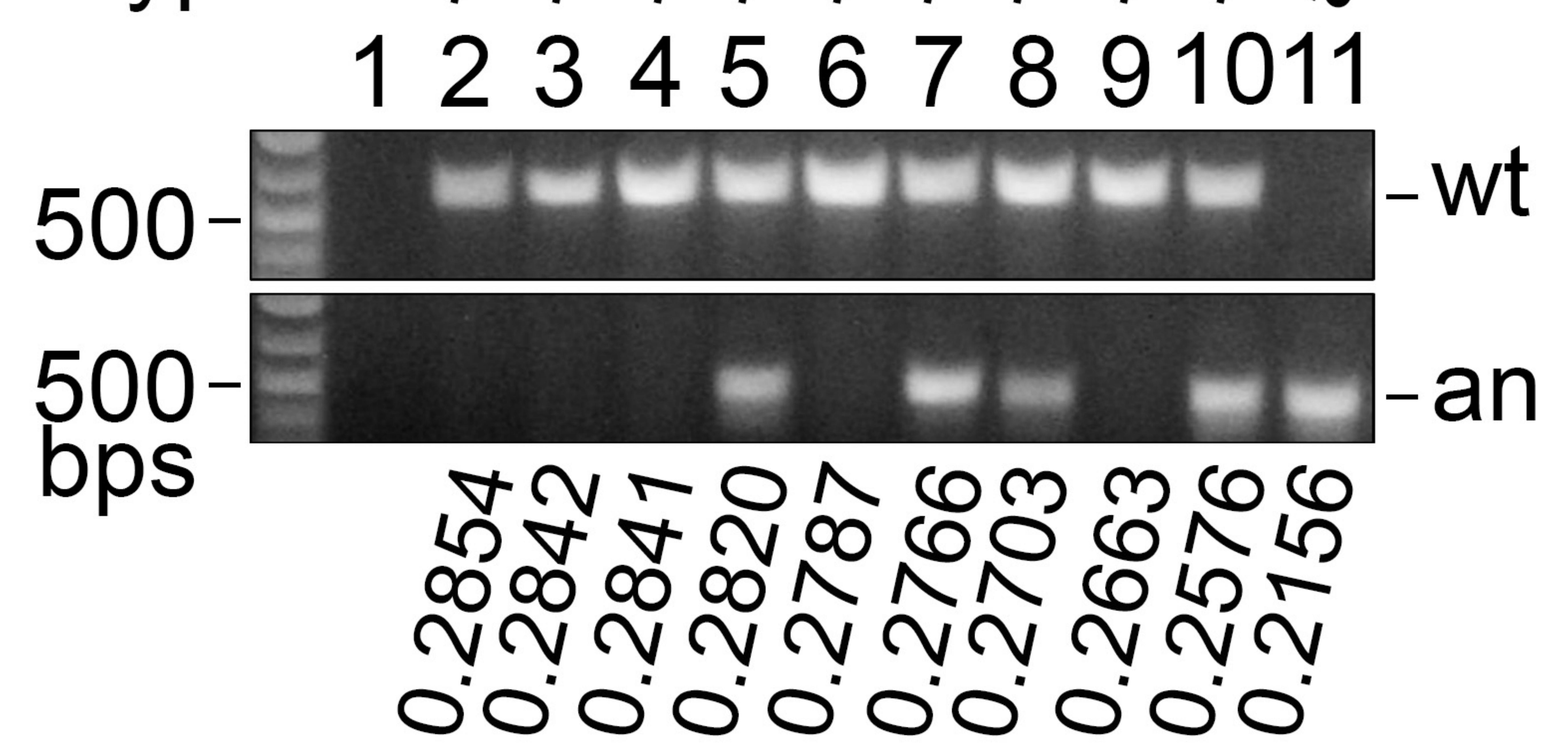

C

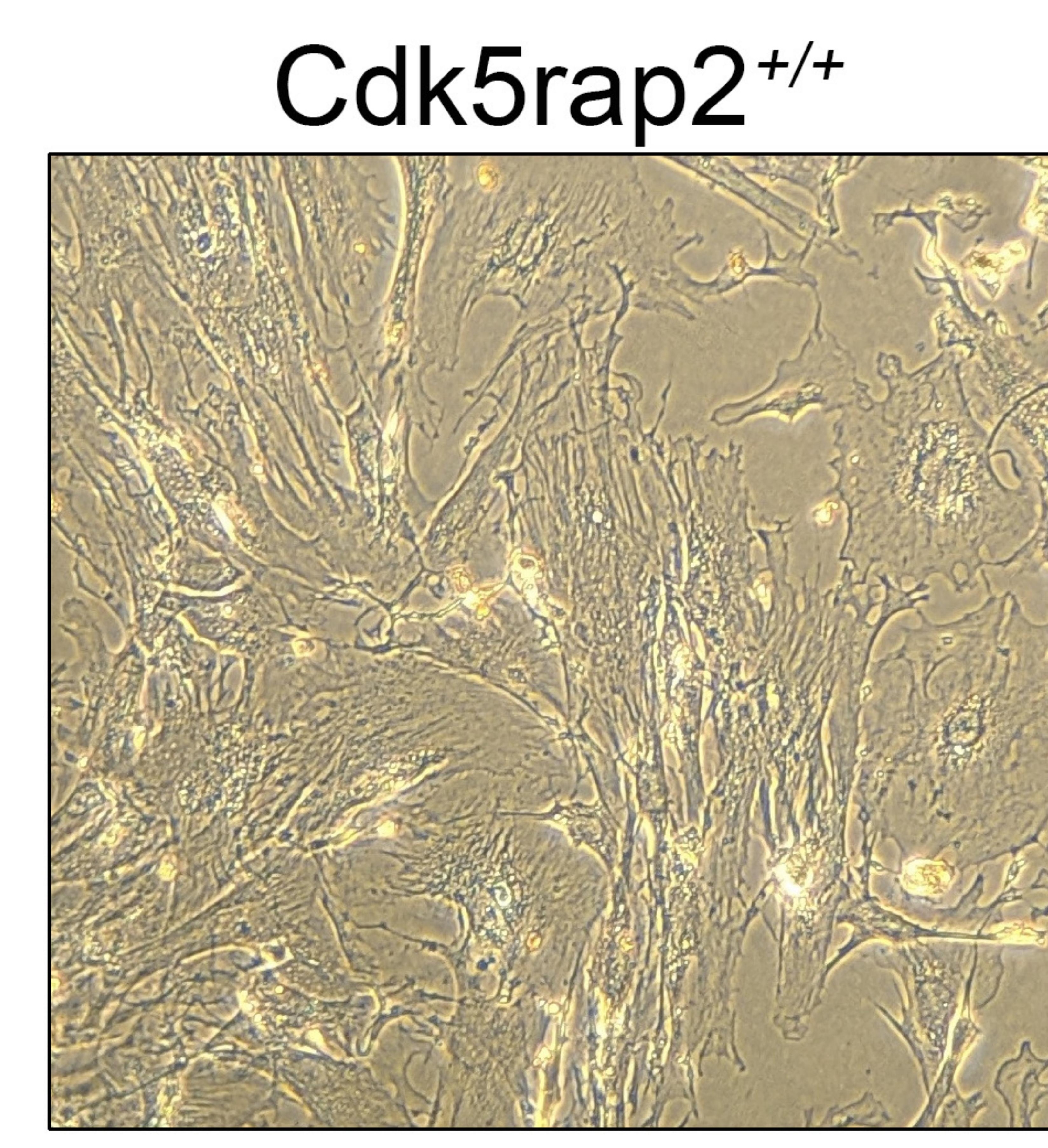

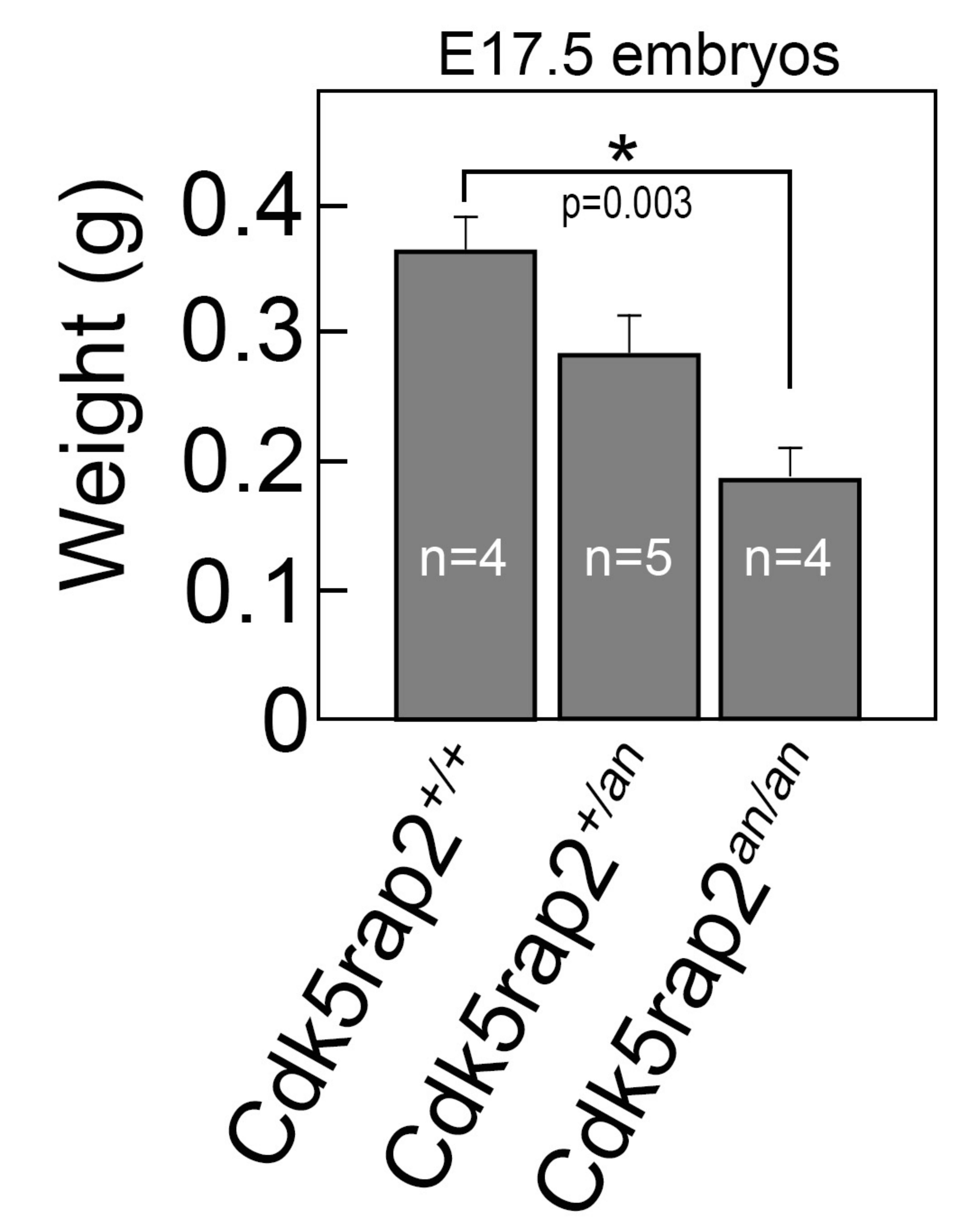

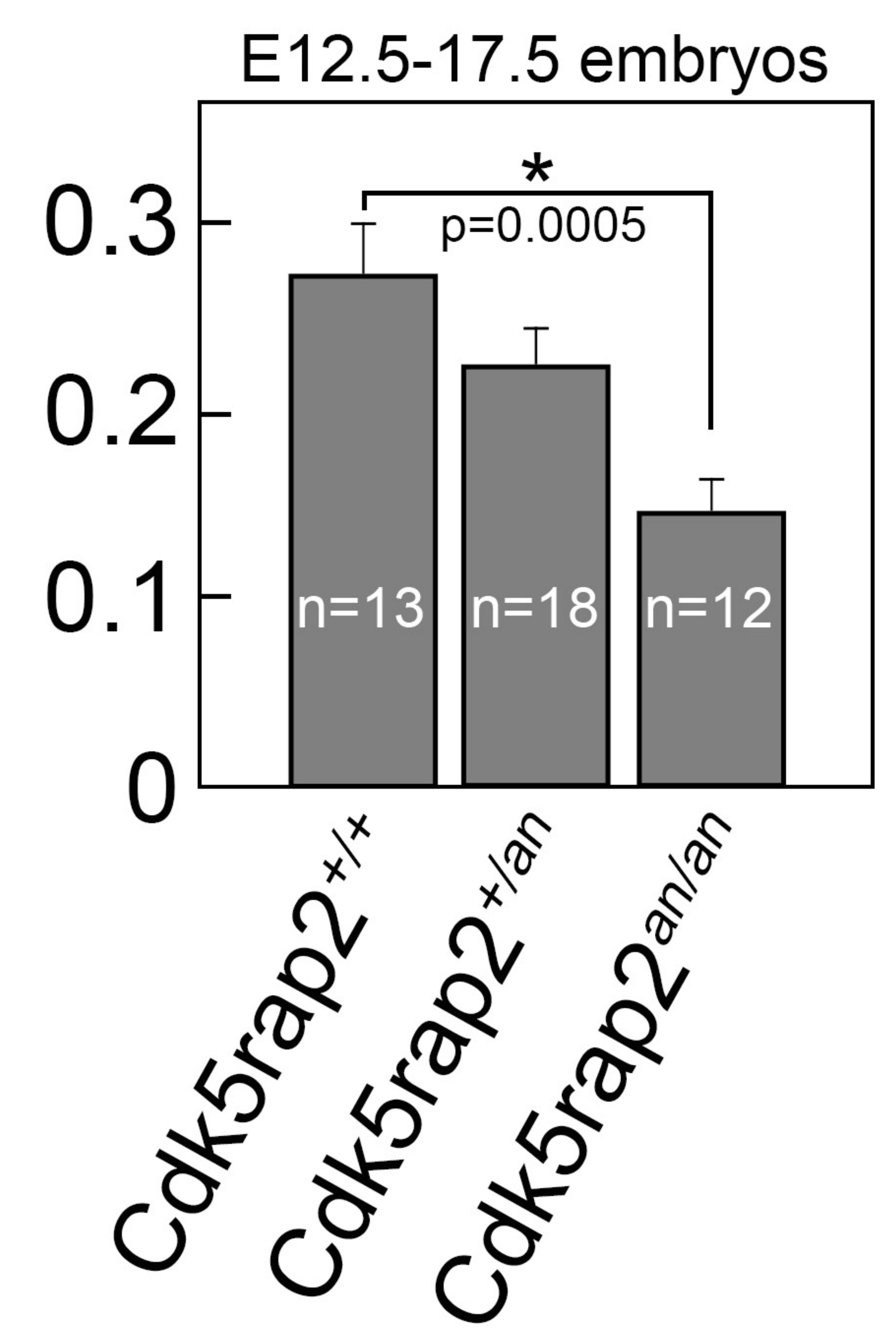

Cdk5rap2 $2^{+/ a n}$

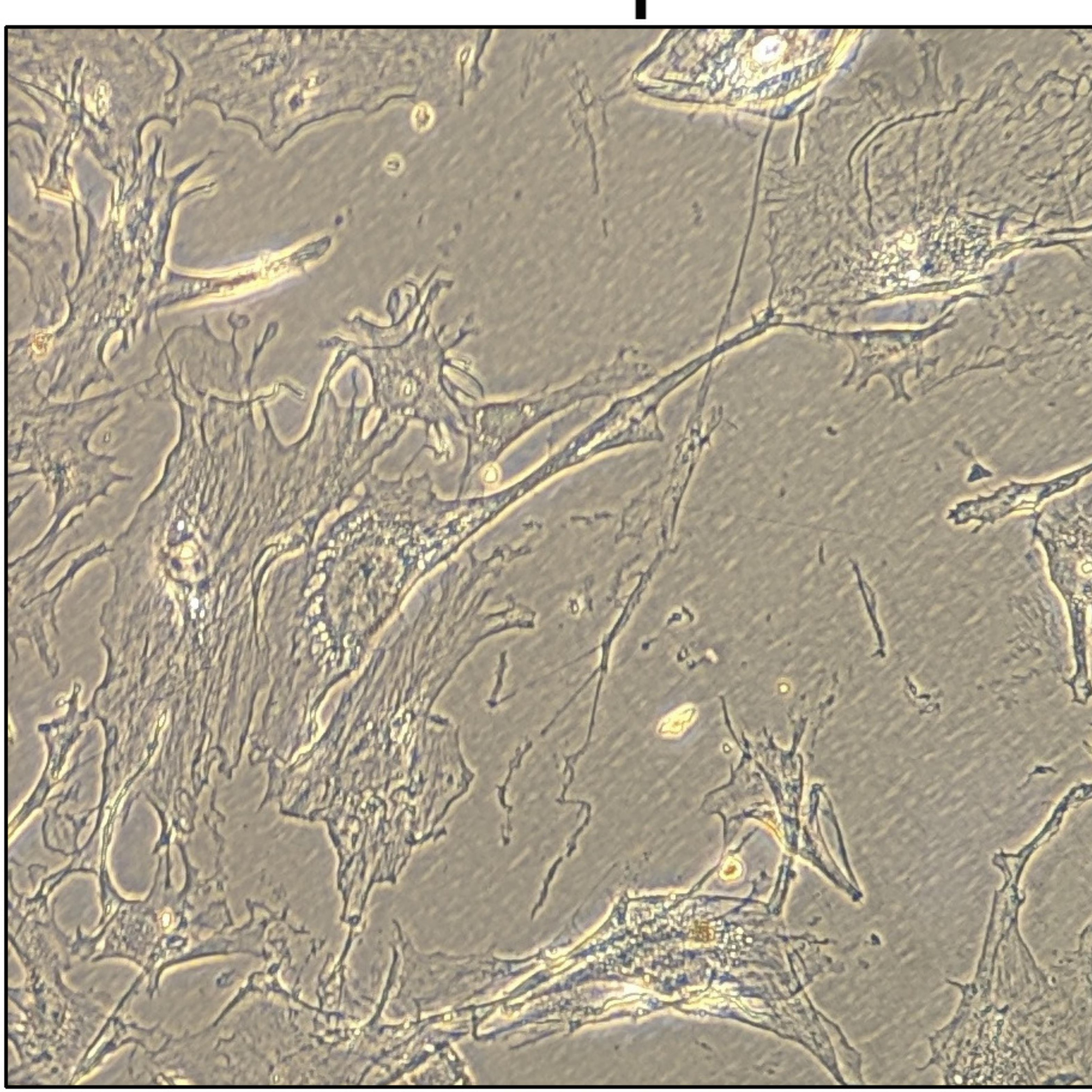

Cdk5rap2 $2^{a n / a n}$

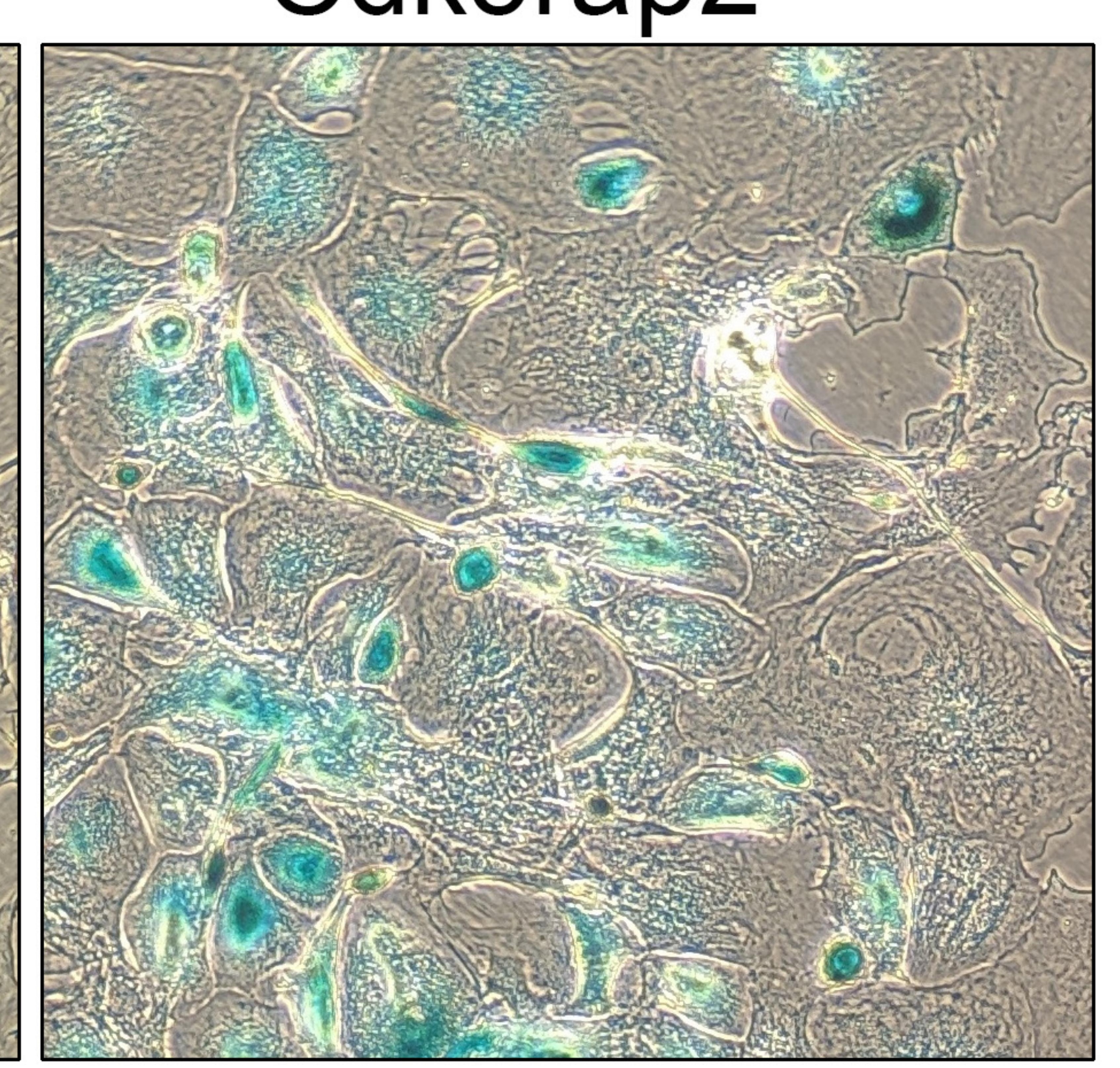

D

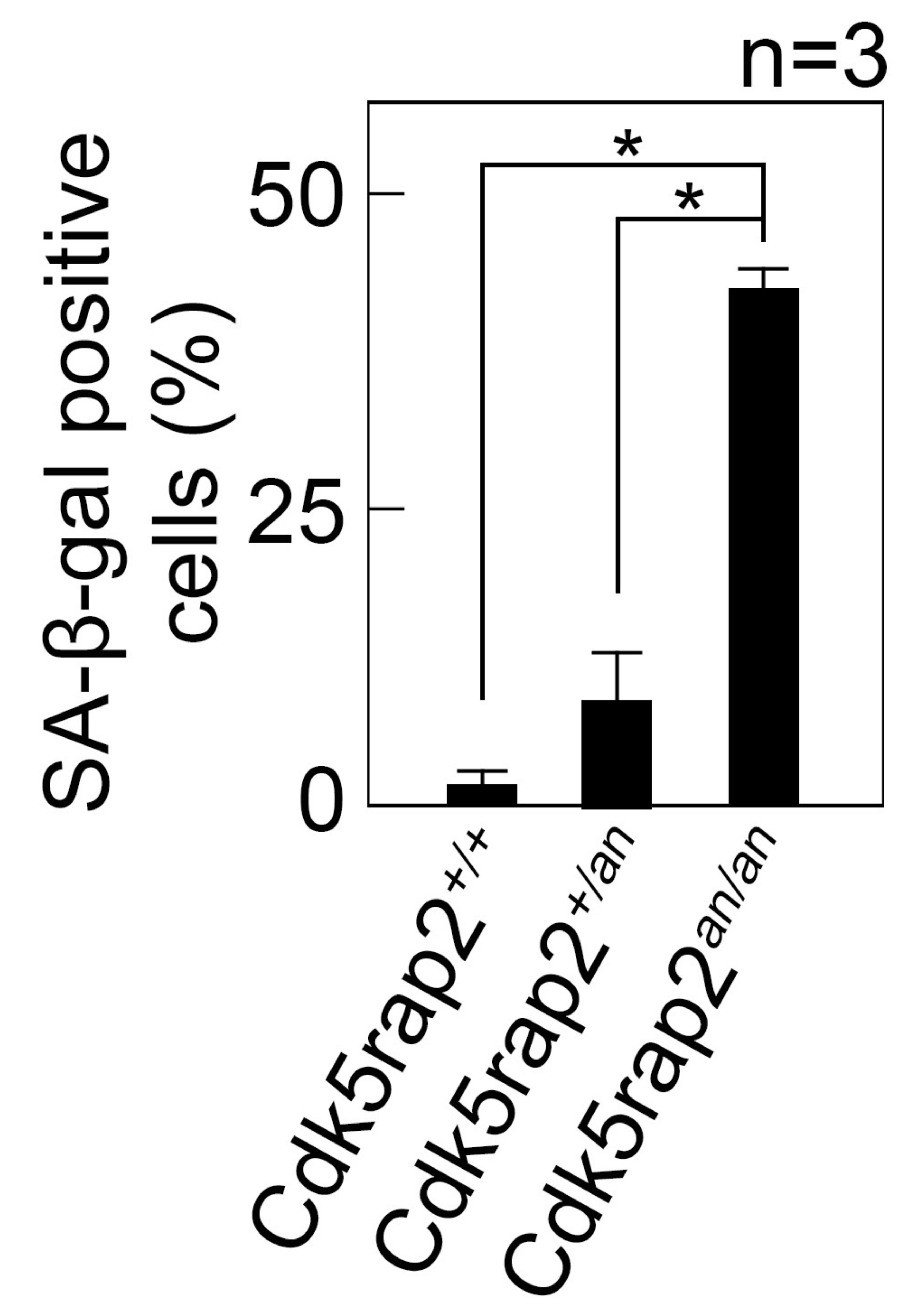

Fig. 4 
A
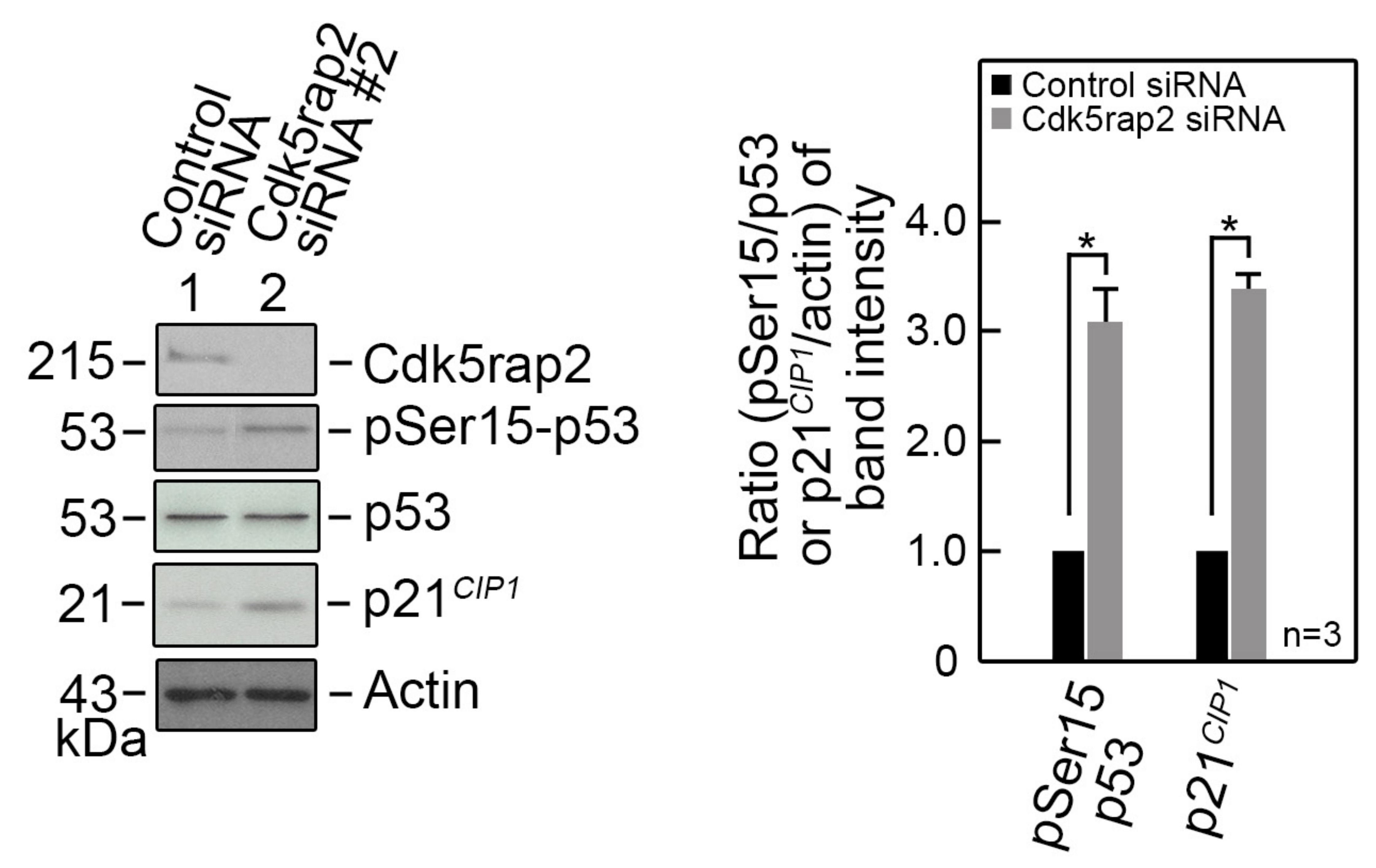

B

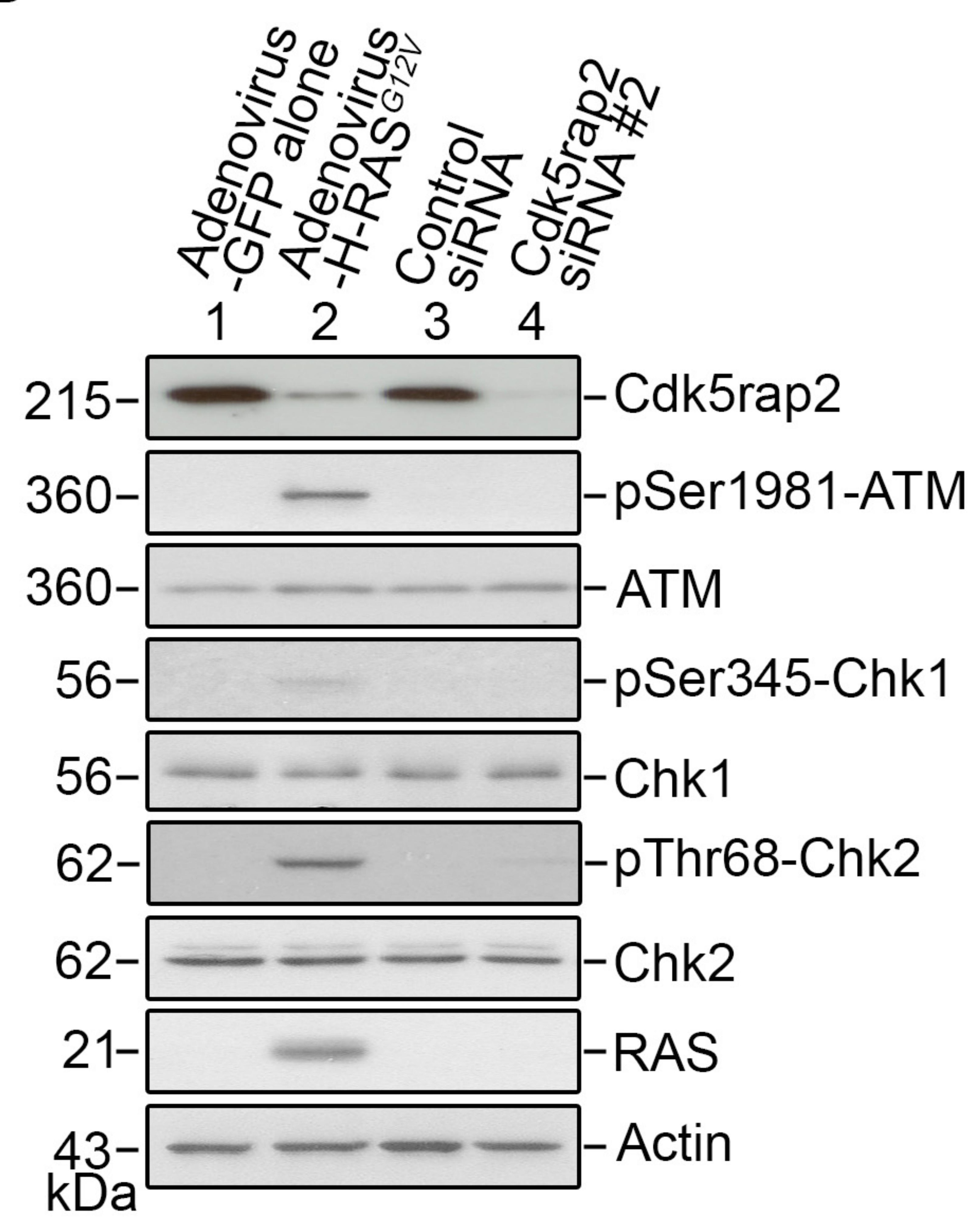

C

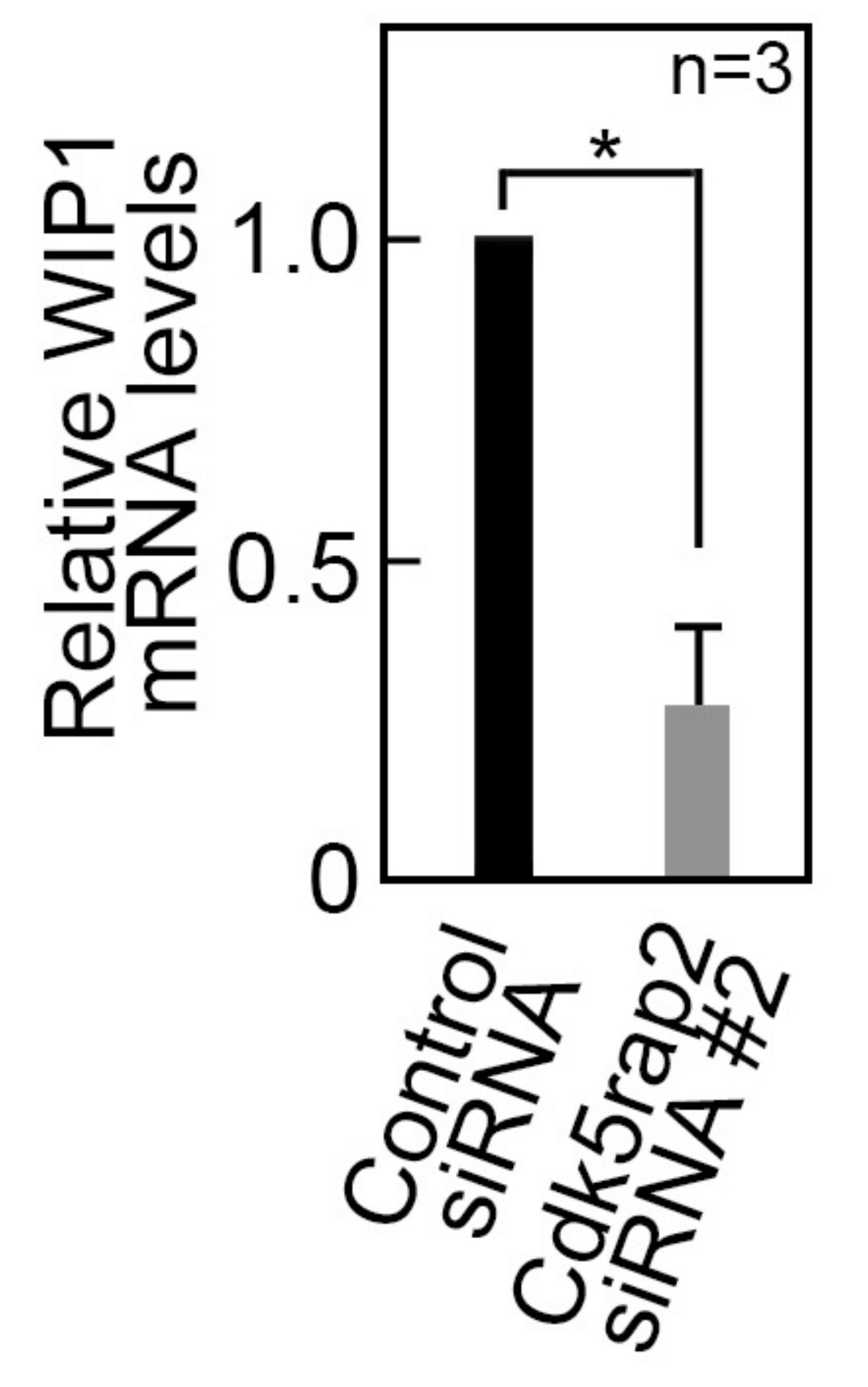

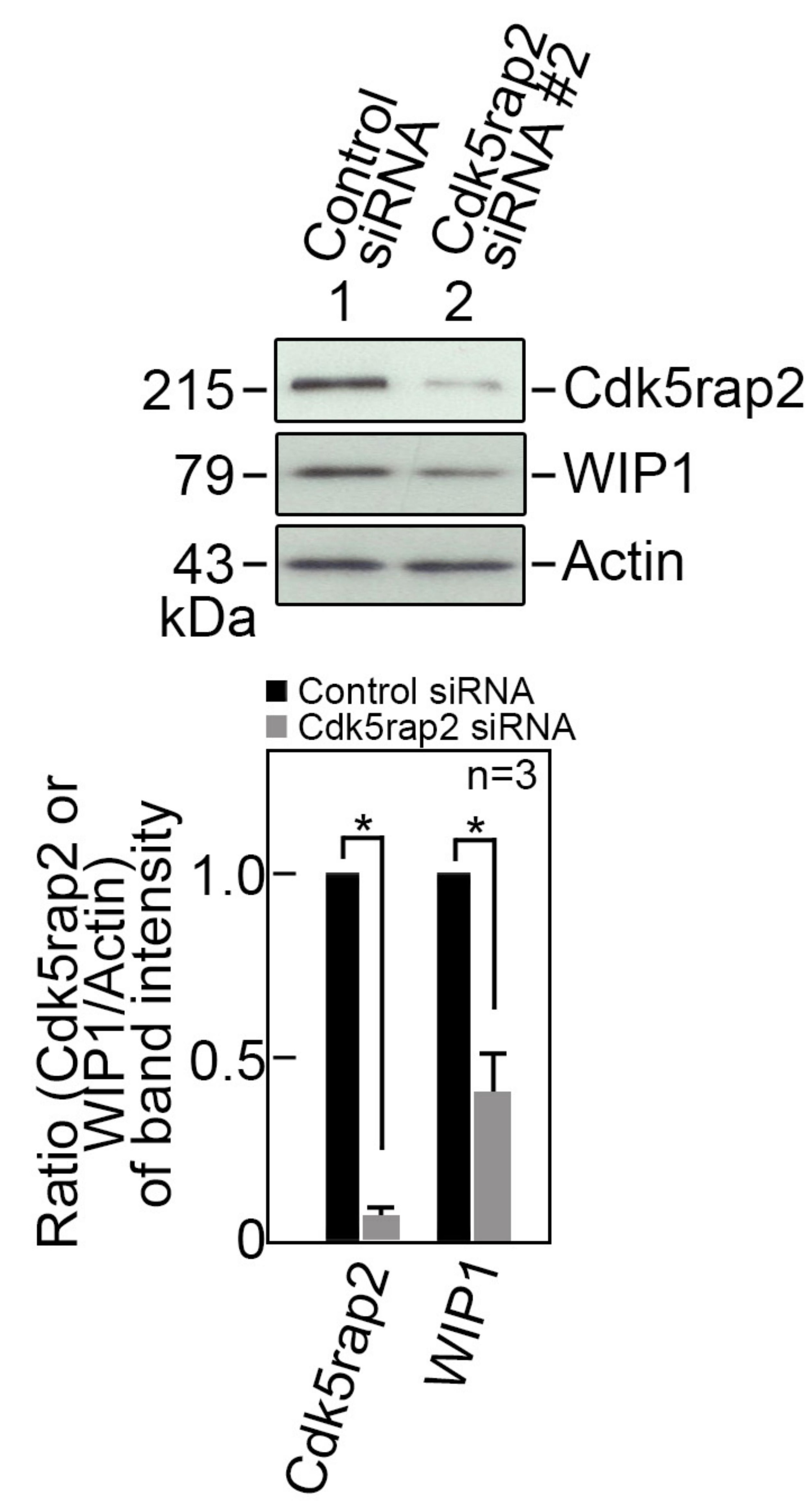

Fig. 5 
A
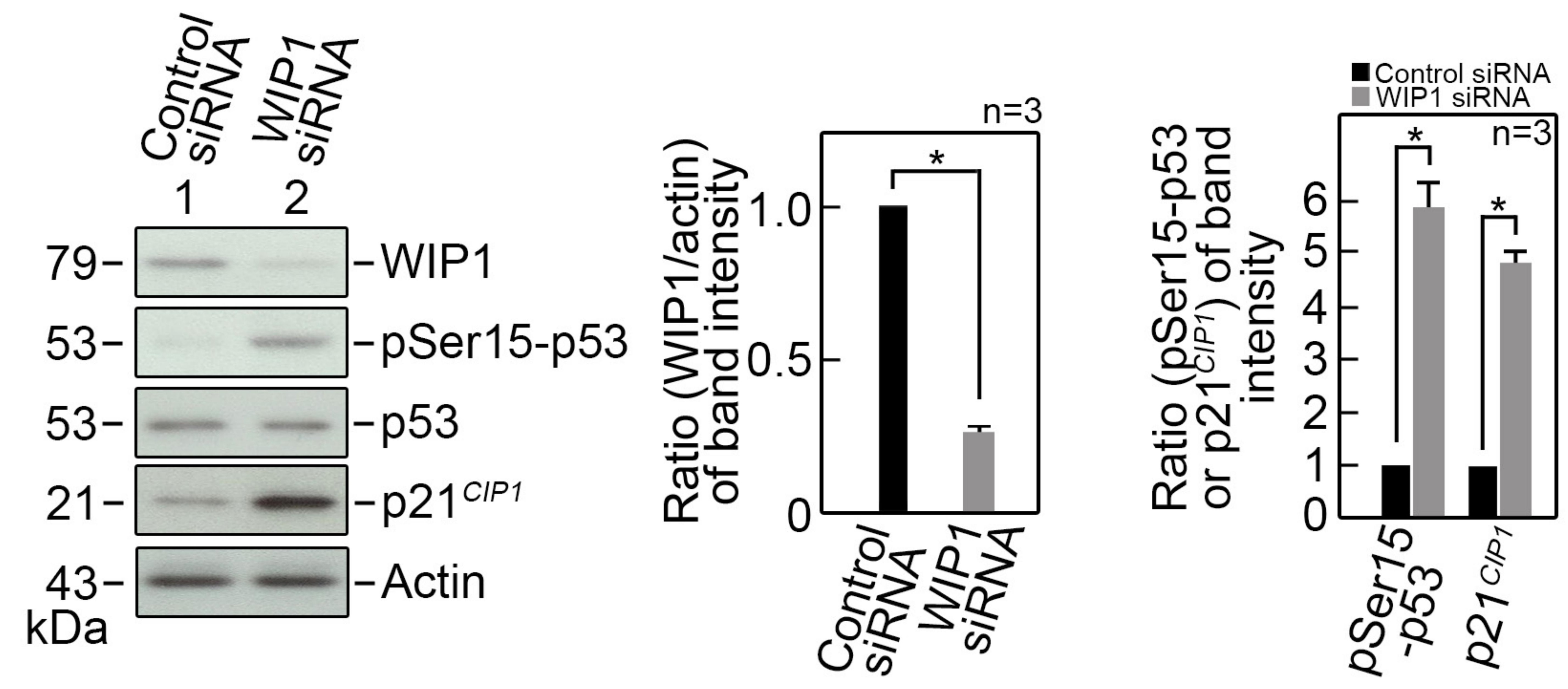

B
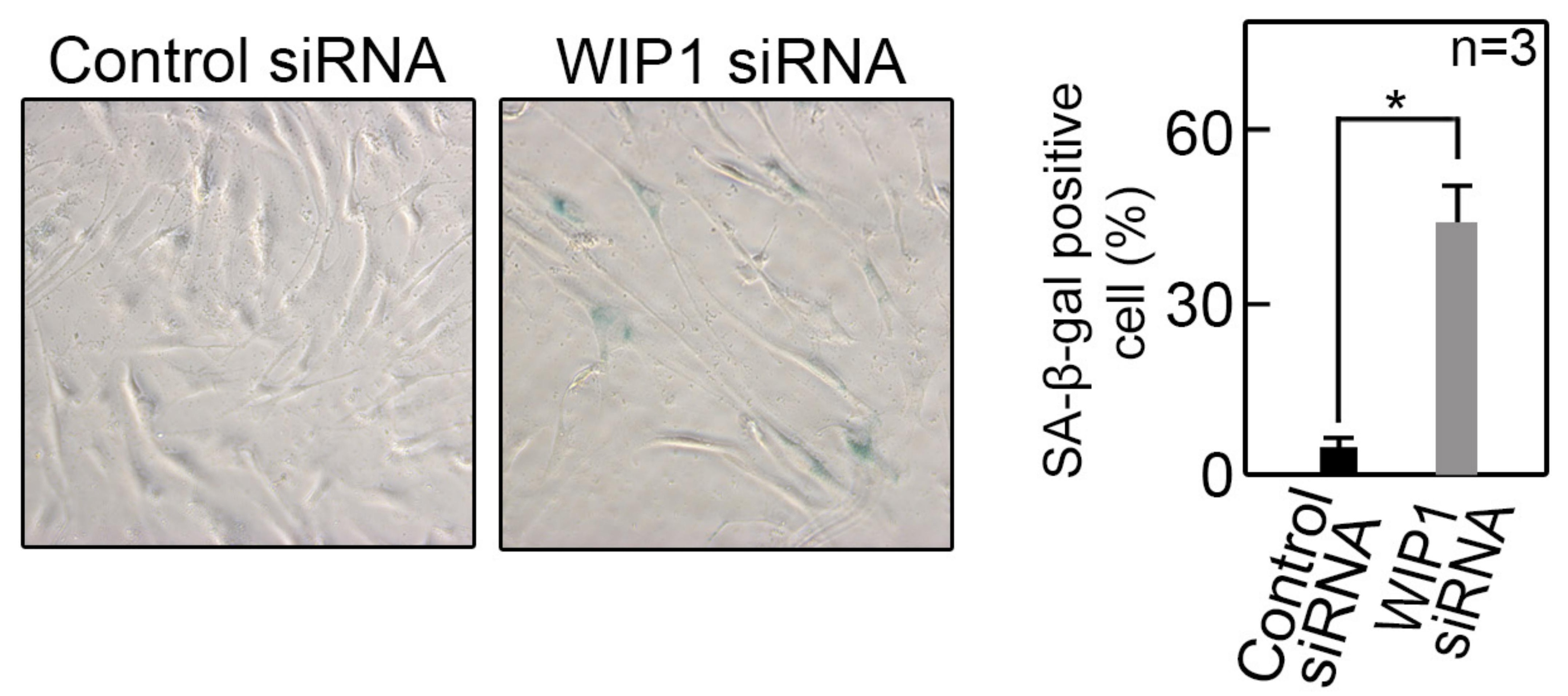

Fig. 6 
A

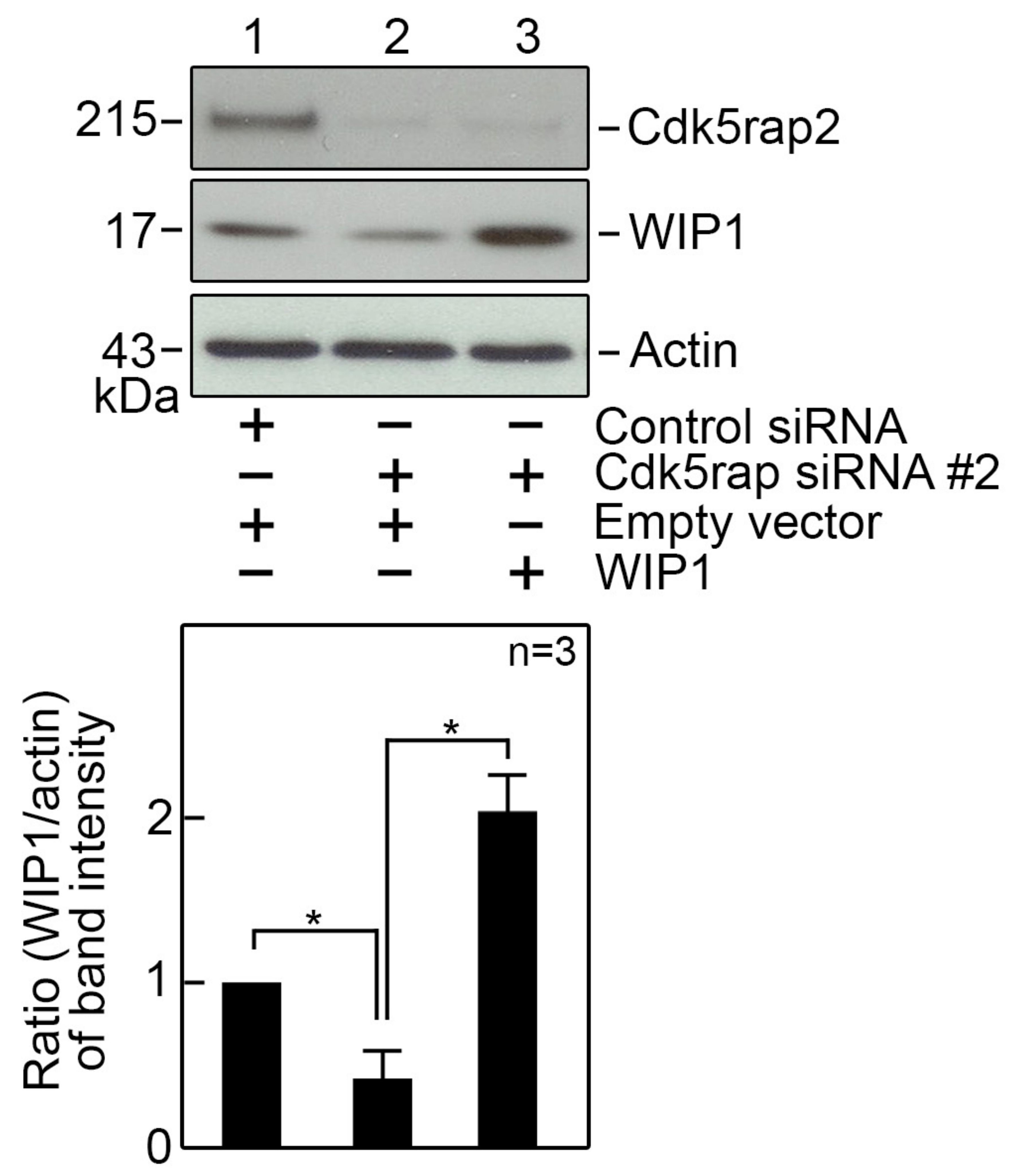

B
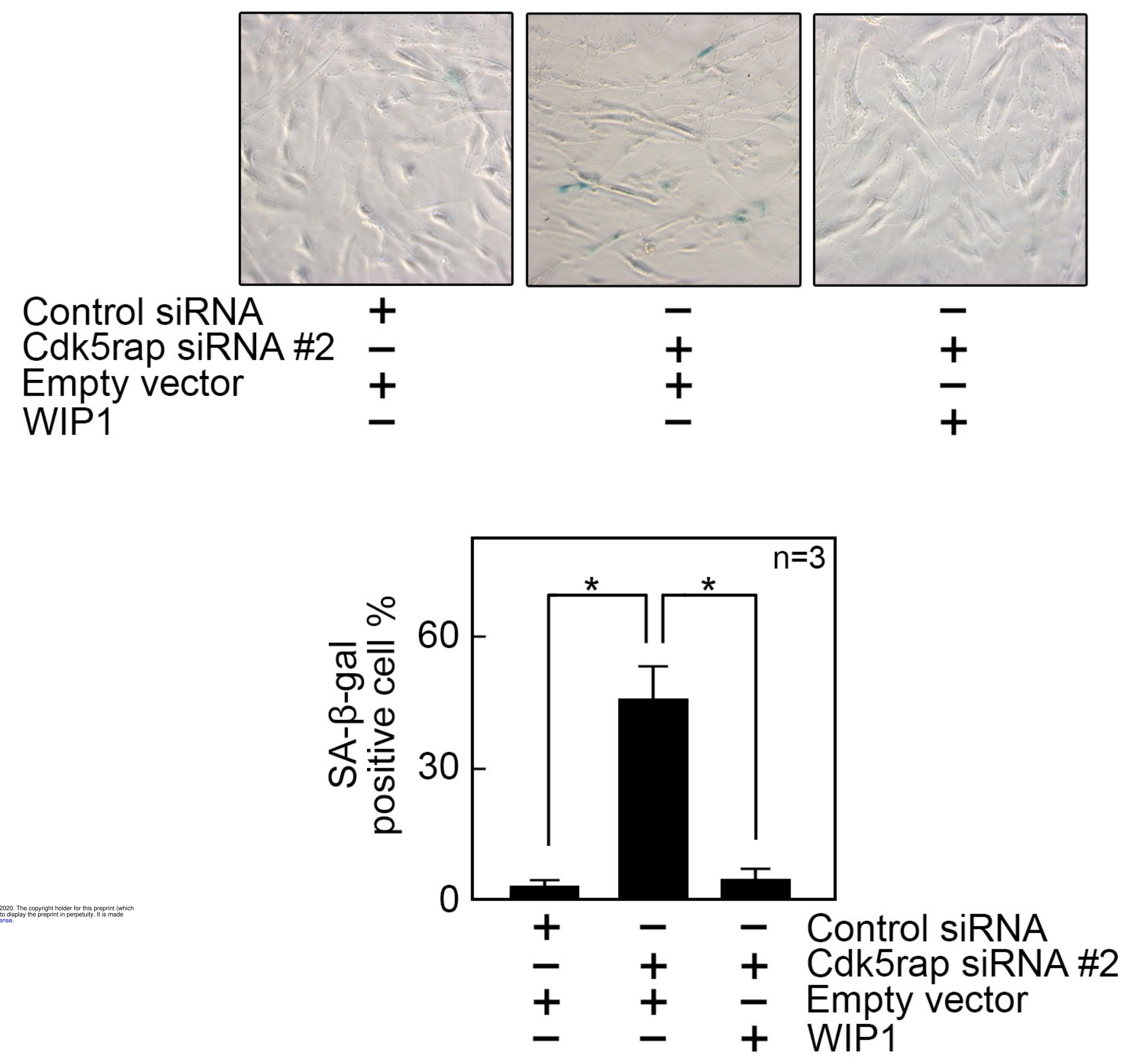

Fig. 7 
A

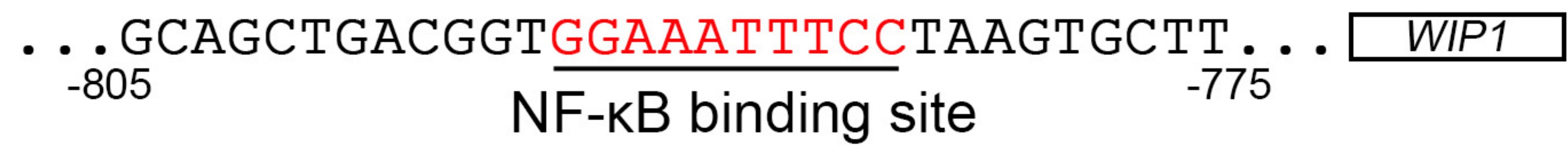

B
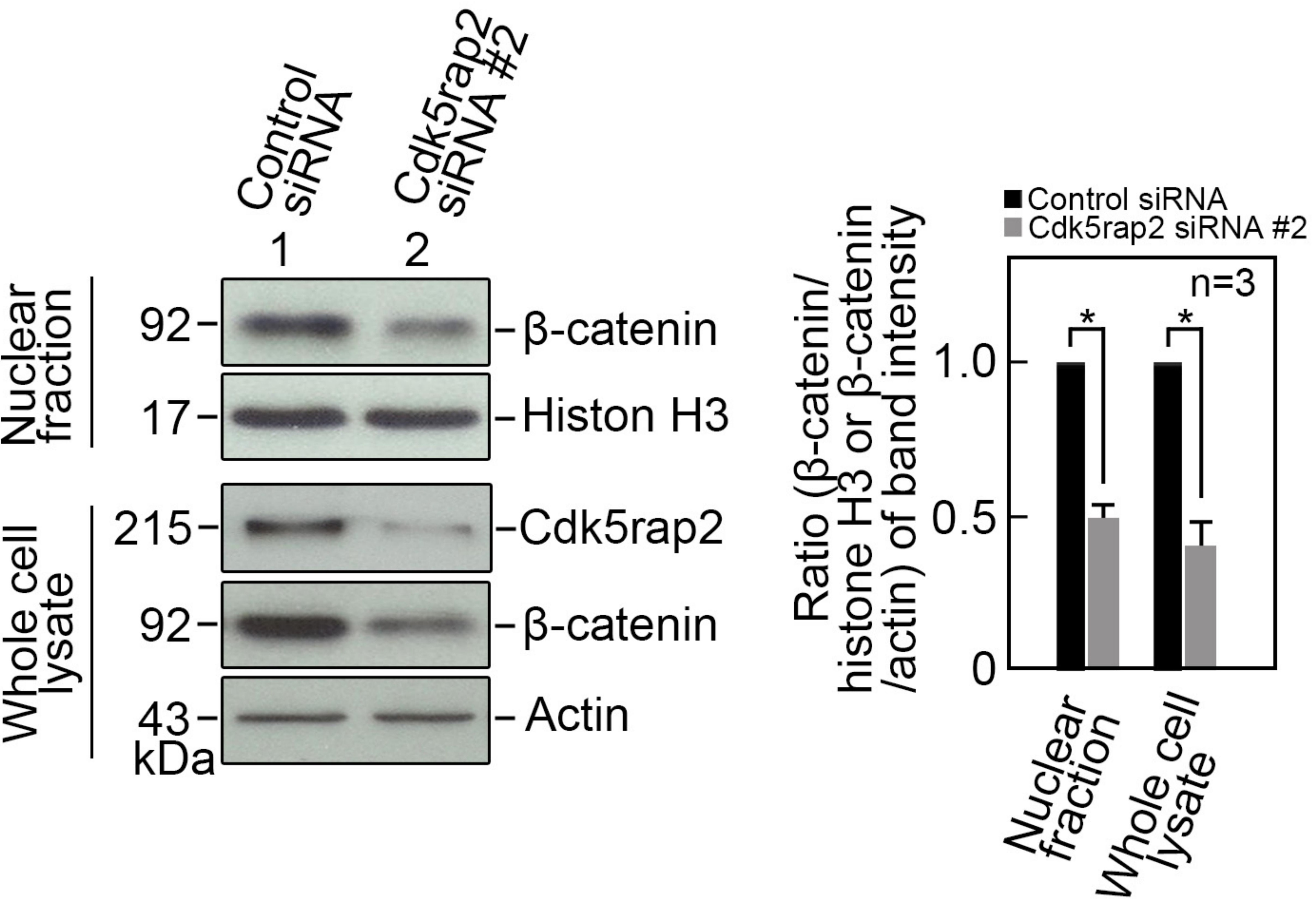

C
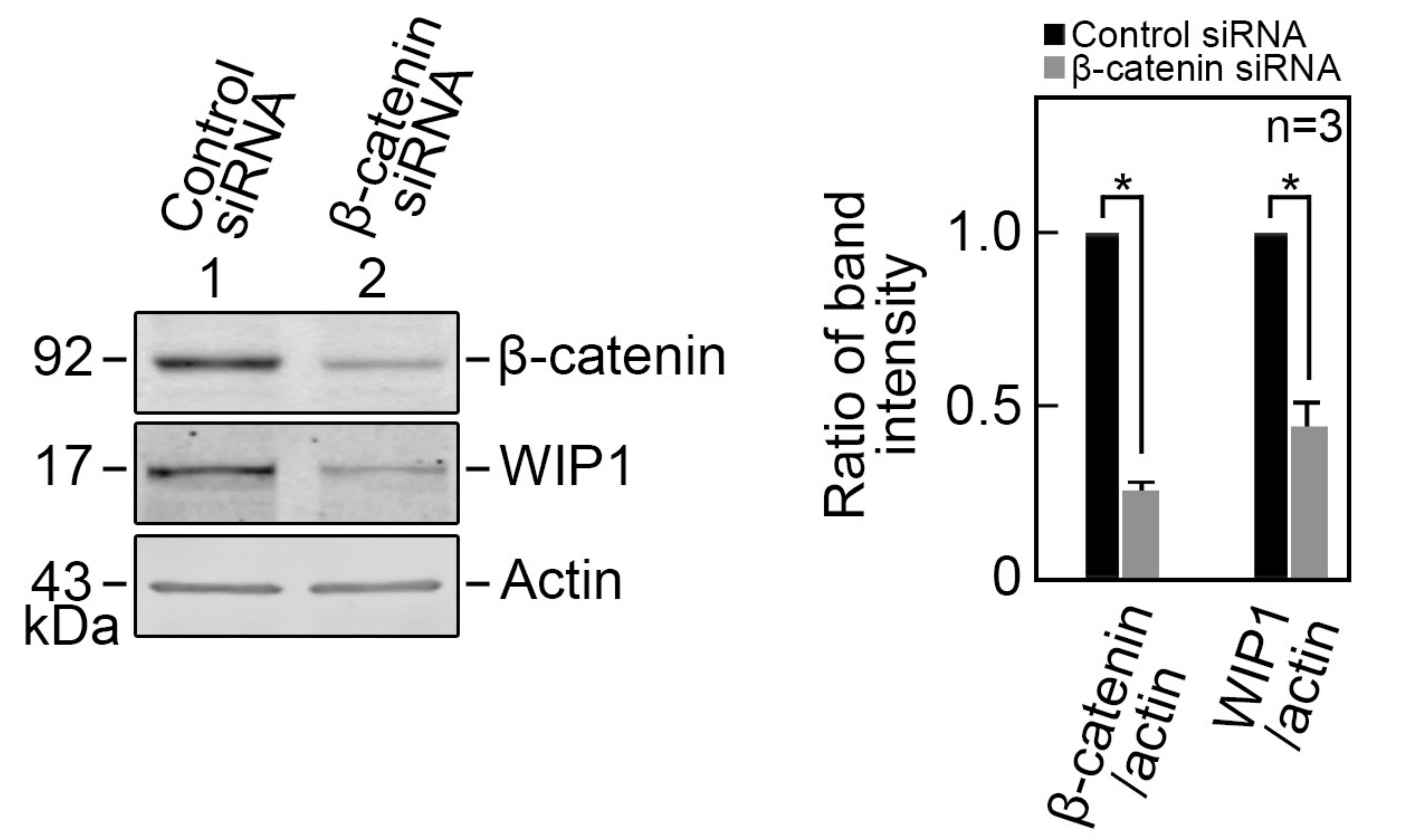

Fig. 8 
A

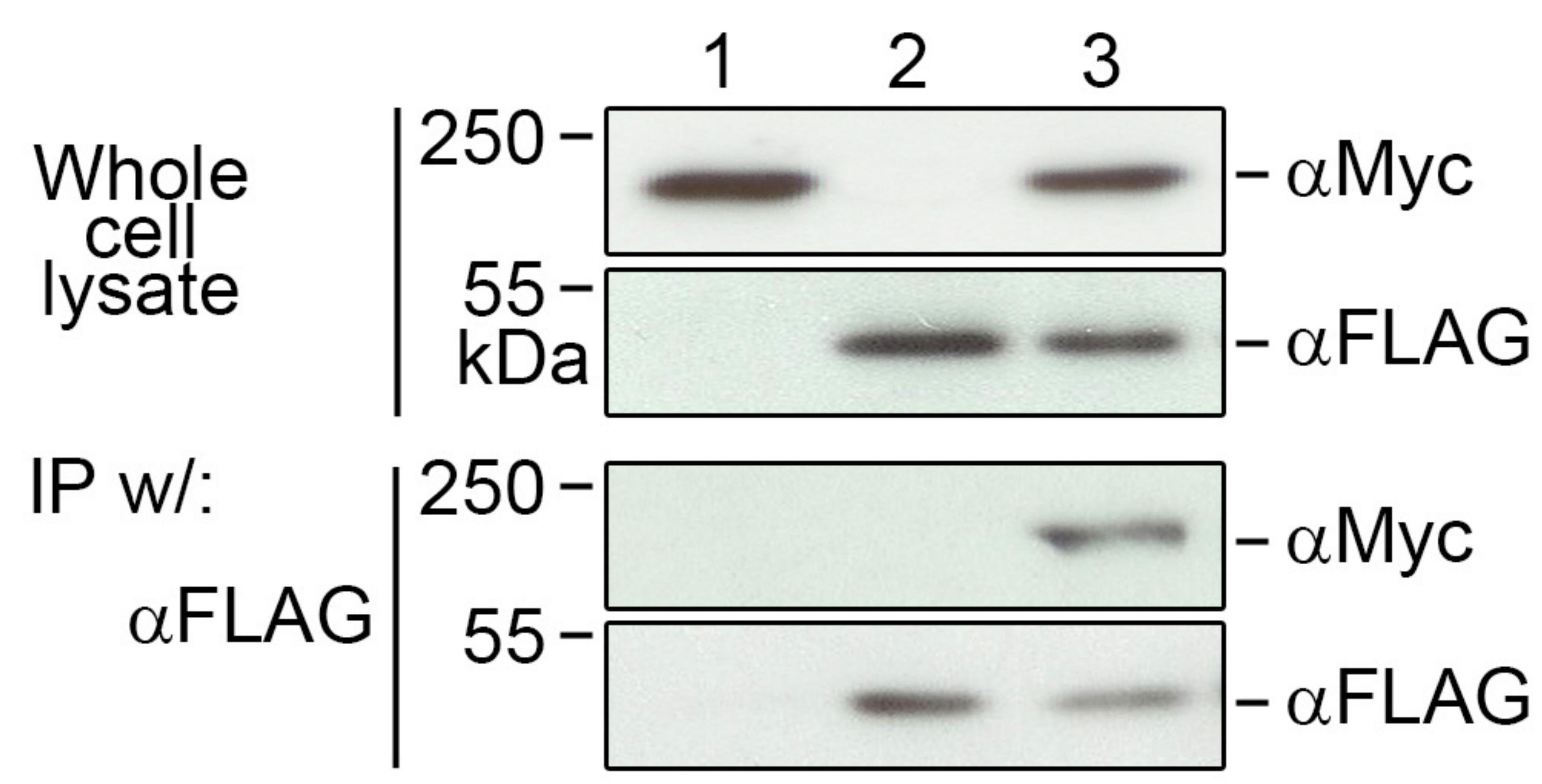

aMyc $\mid \begin{array}{ll}250- & - \\ 55- & -\alpha M y c\end{array}$

$\underset{\text { FLAG-GSK3 }}{\text { Myc-Cdk5rap2 }}+\overline{+}+$
B

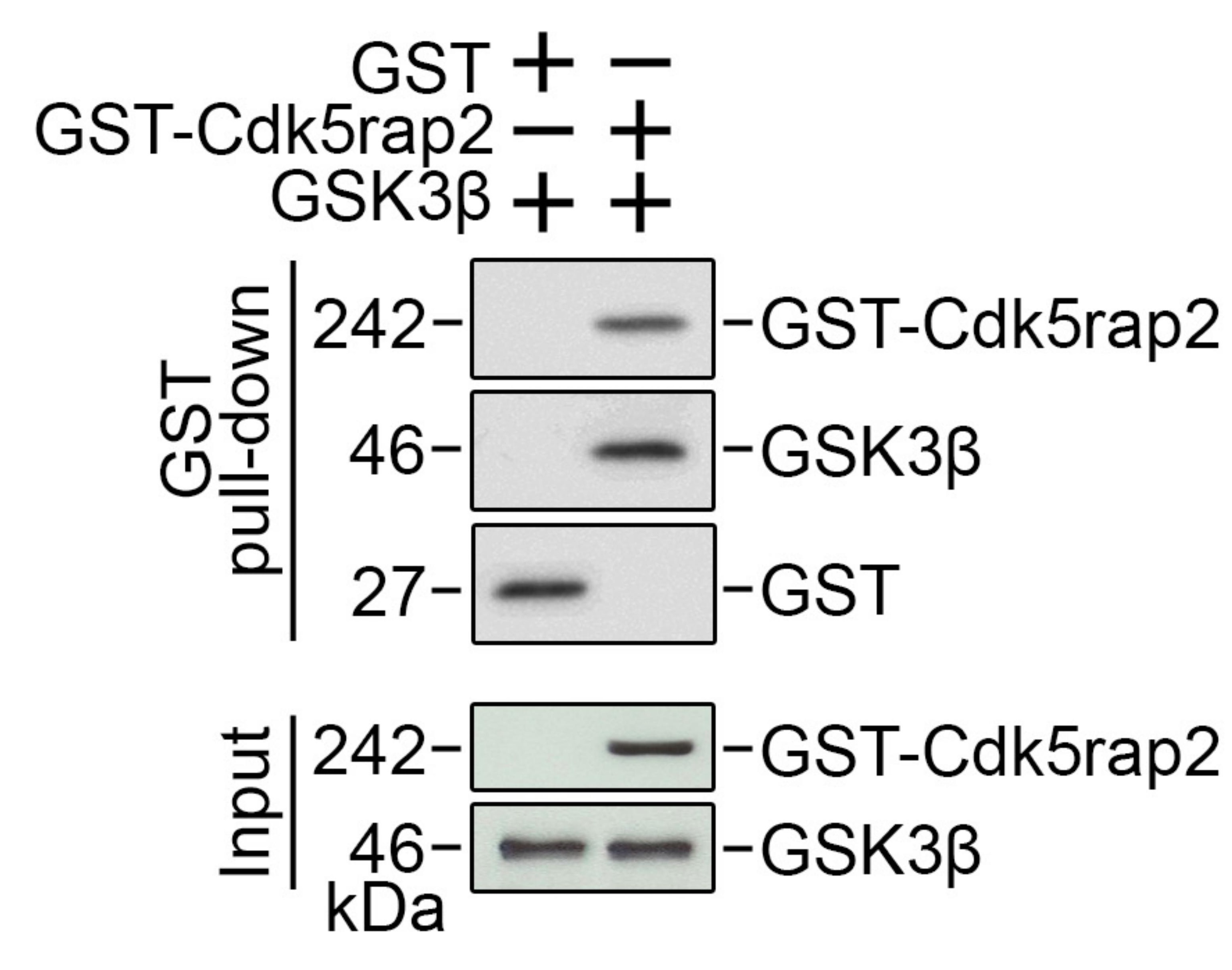

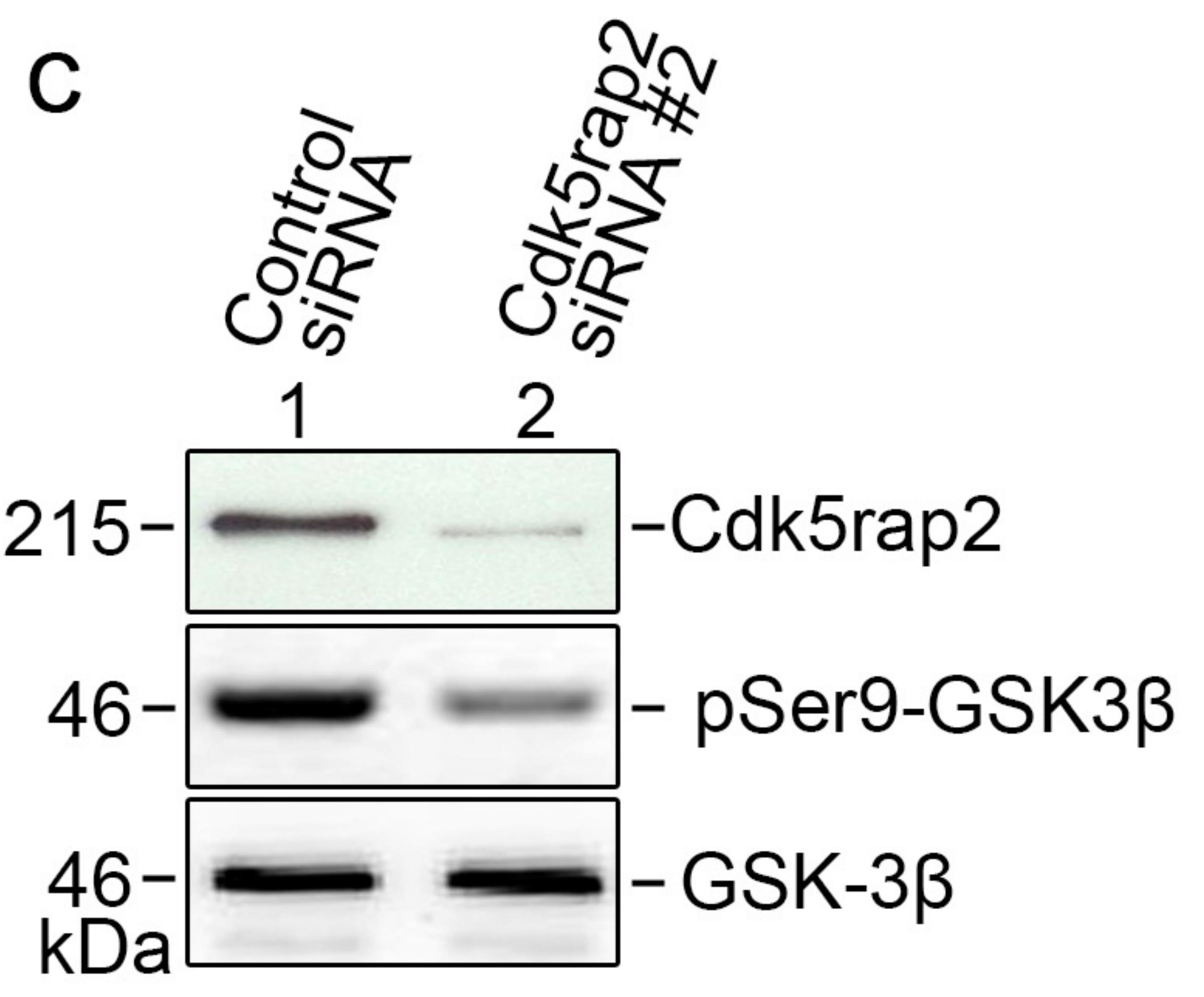

E

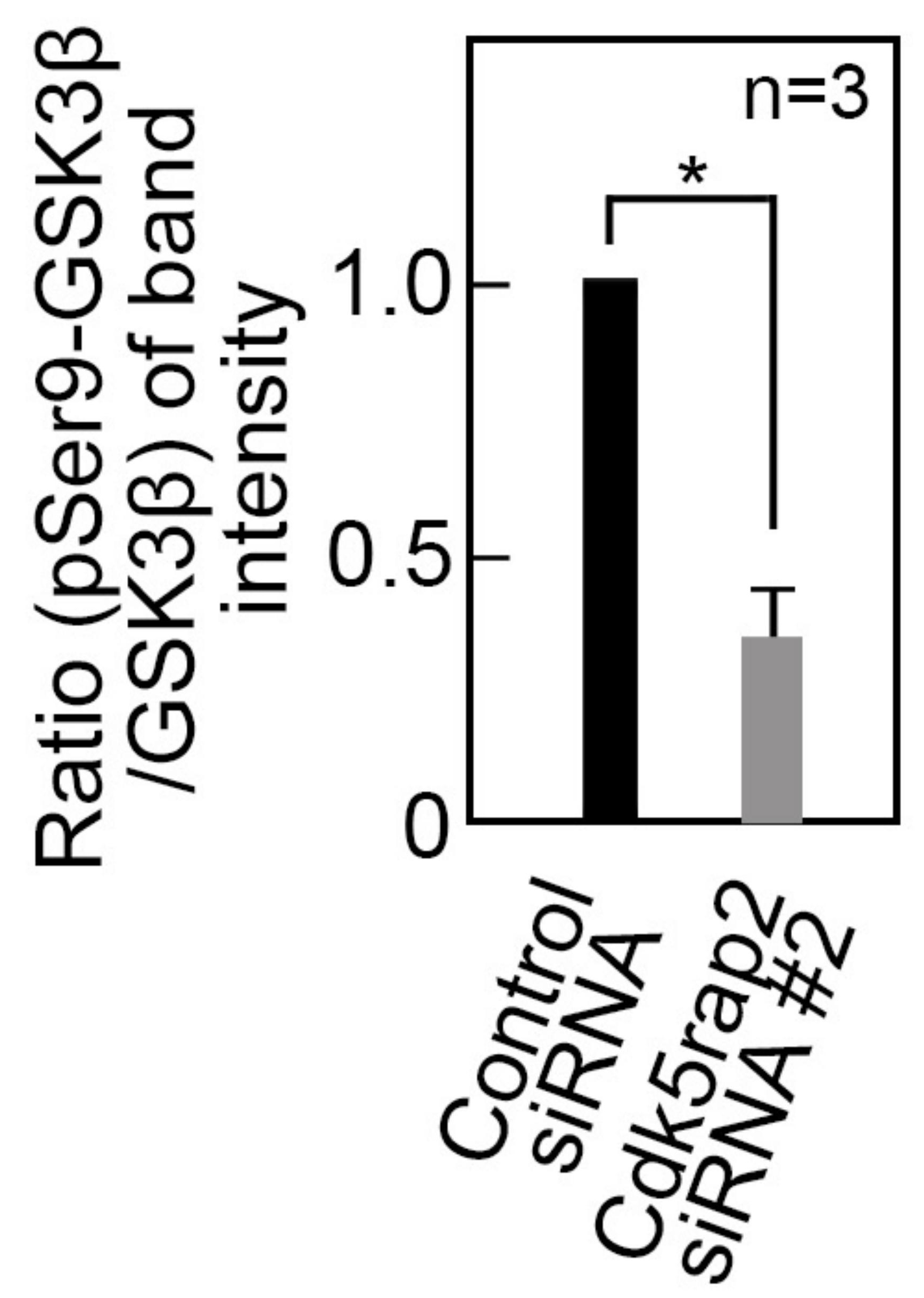

D

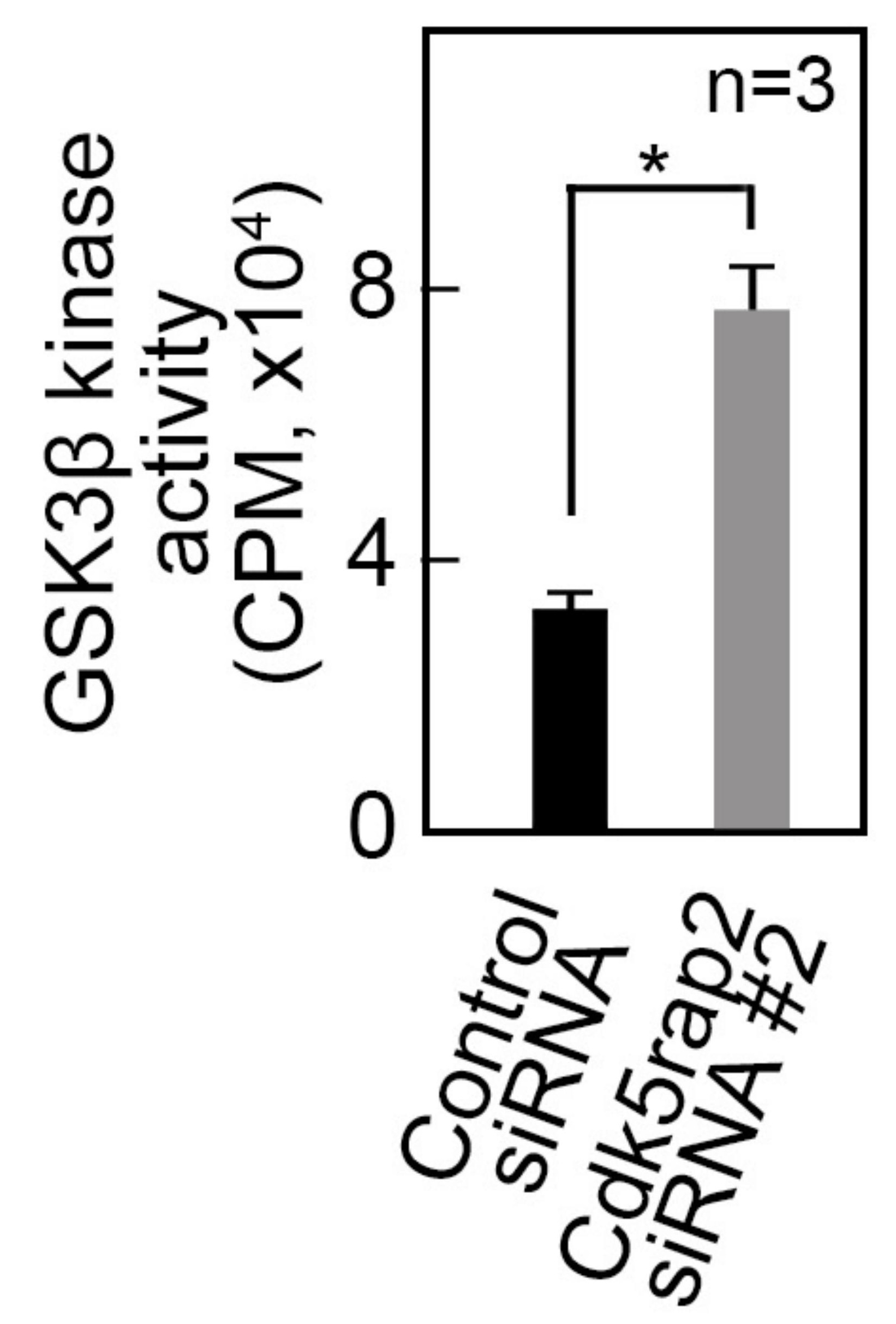

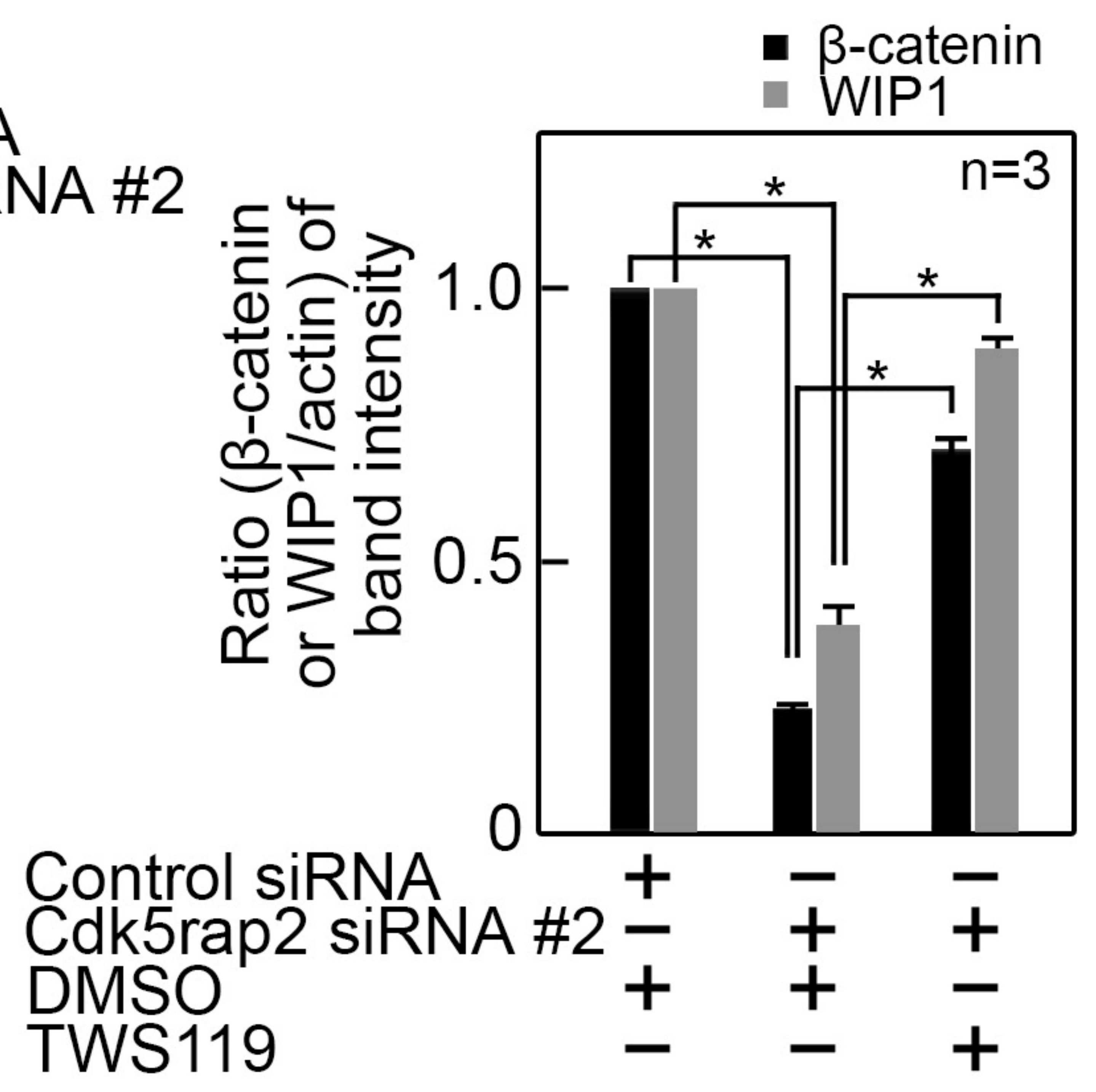

Fig. 9 
A

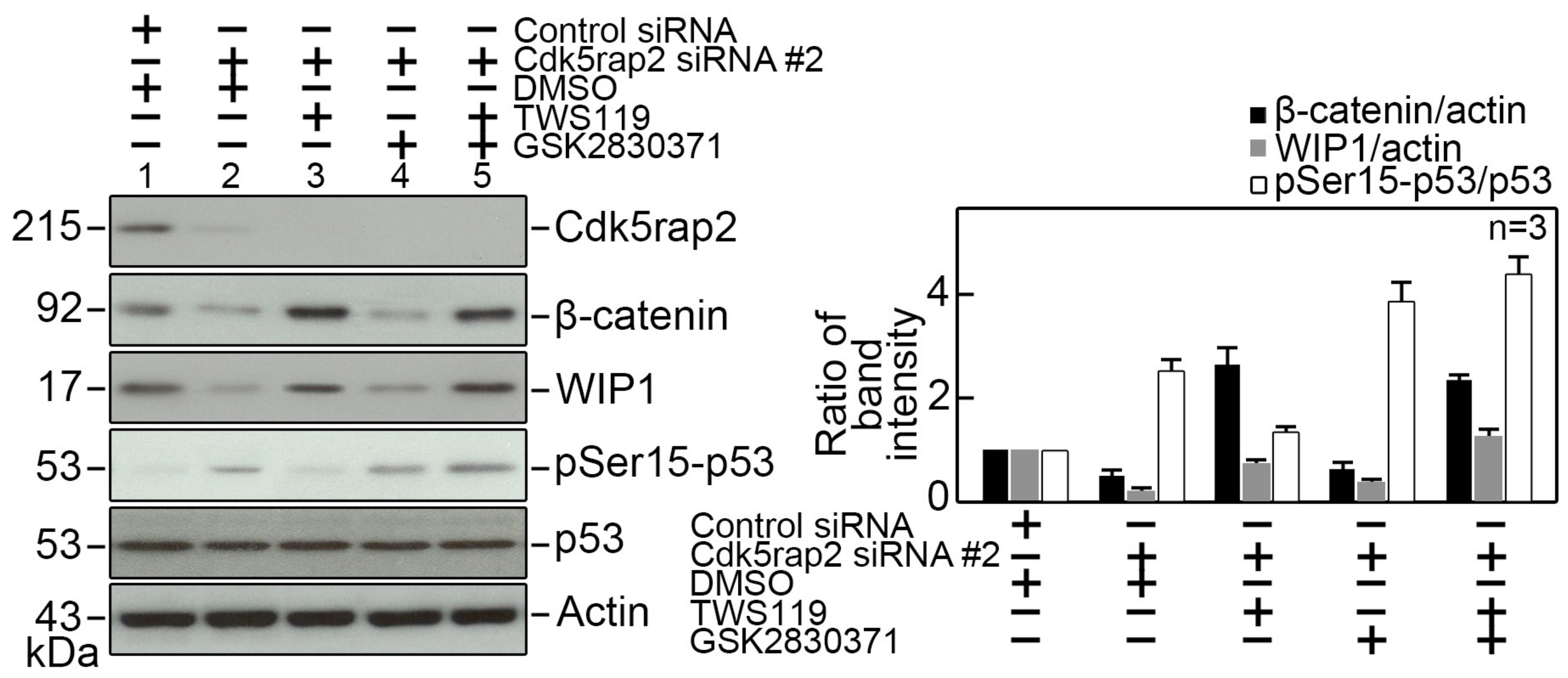

B

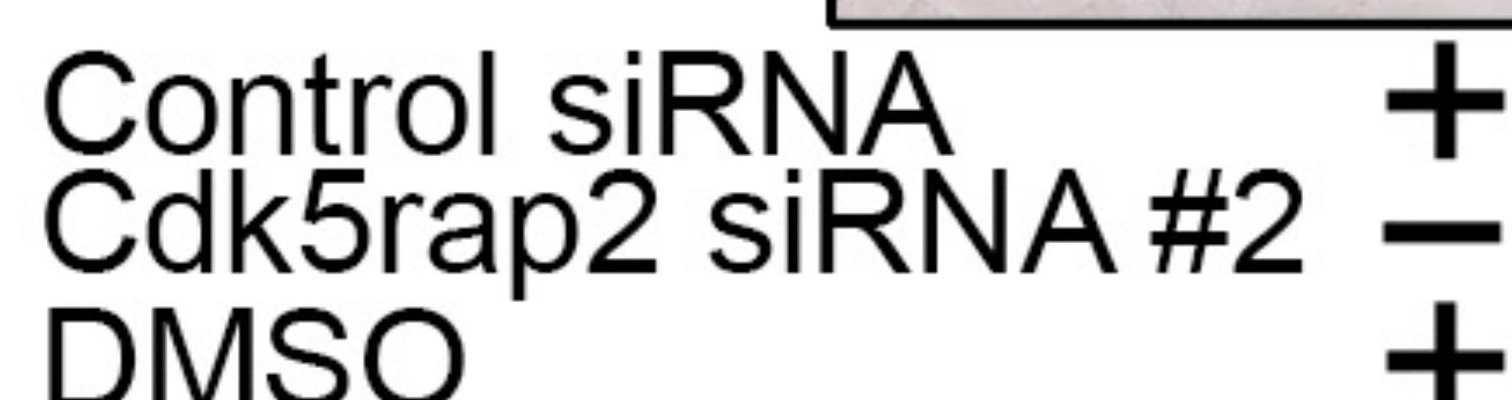

TWS119

GSK2830371

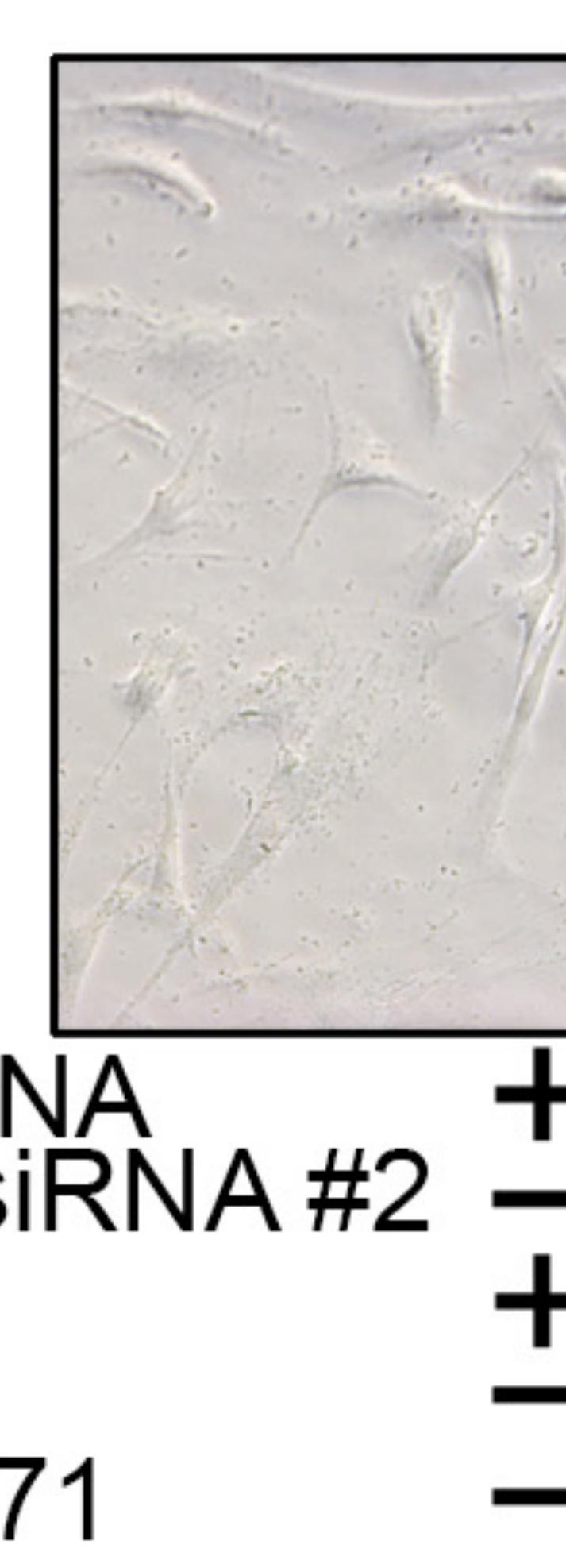

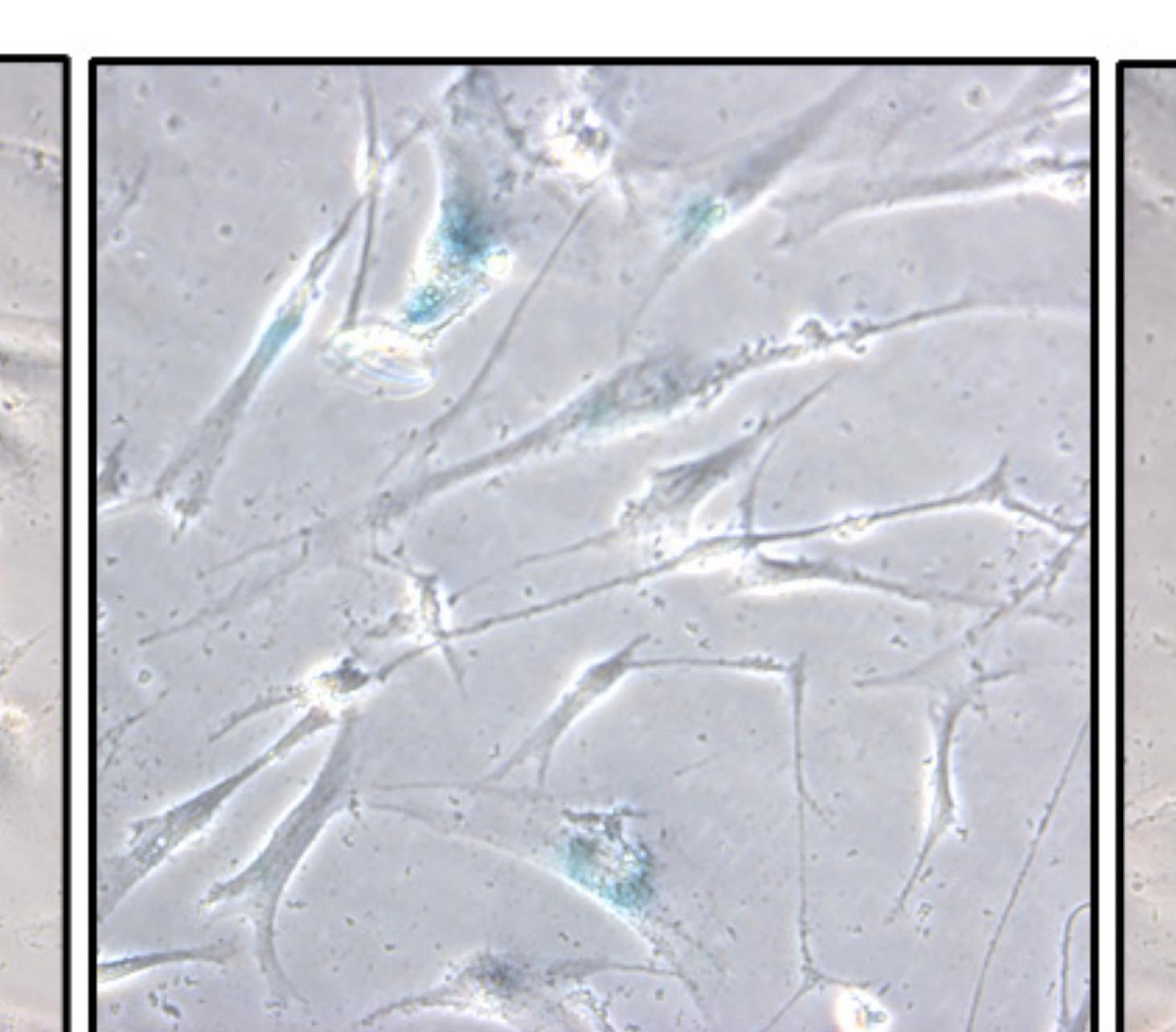
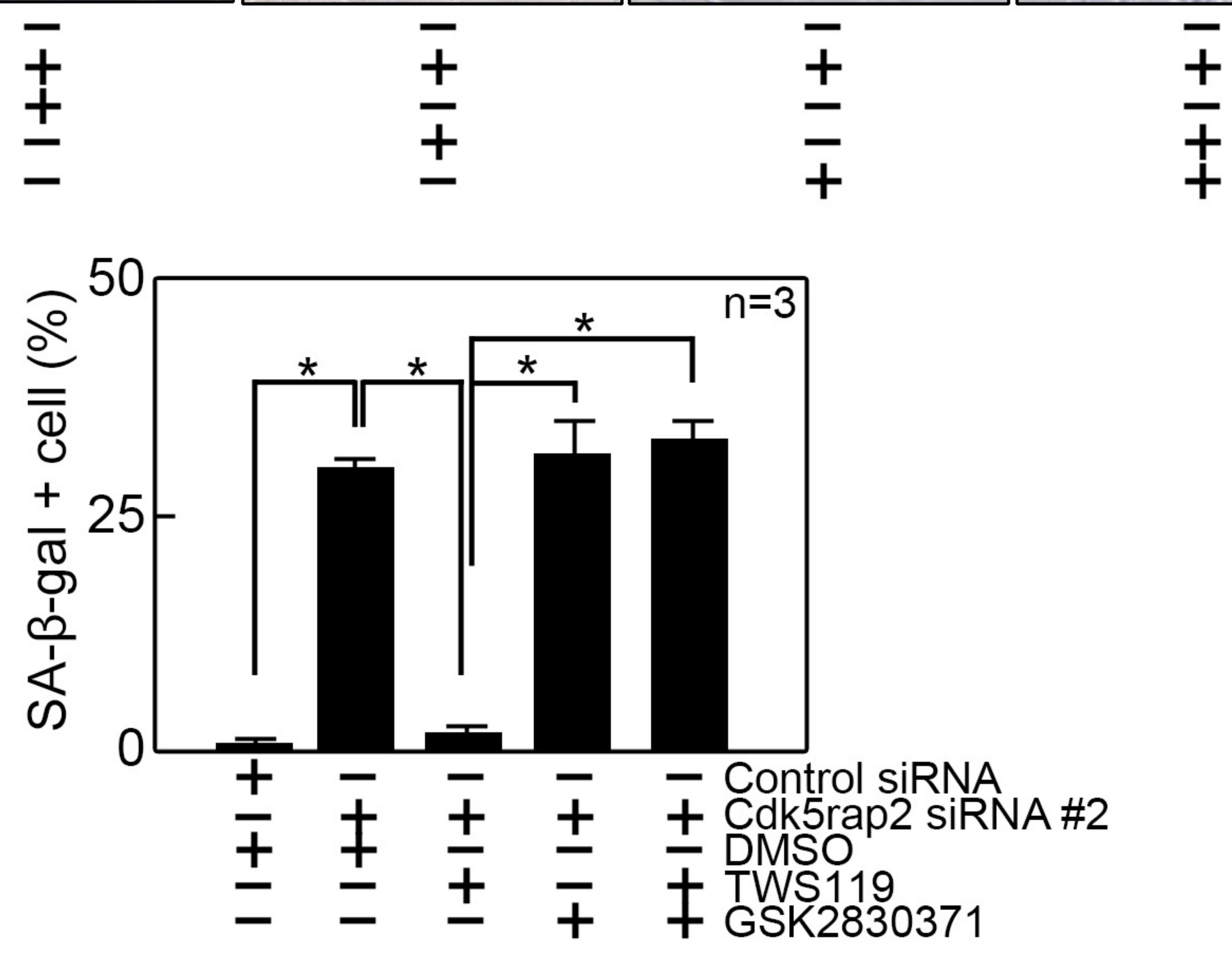

Fig. 10 


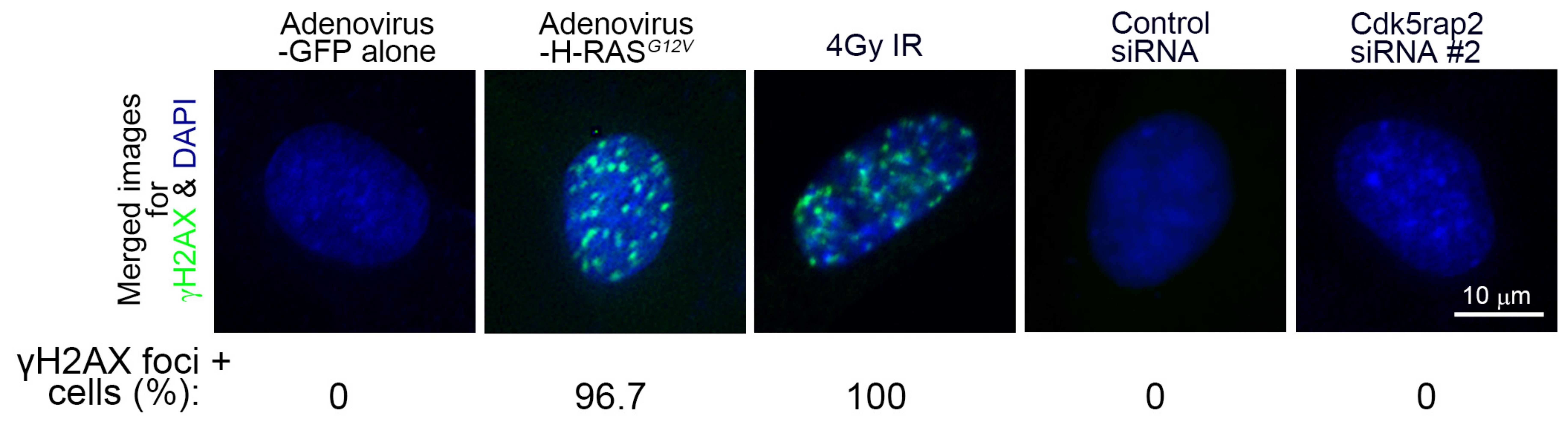

Sup Fig. 1 


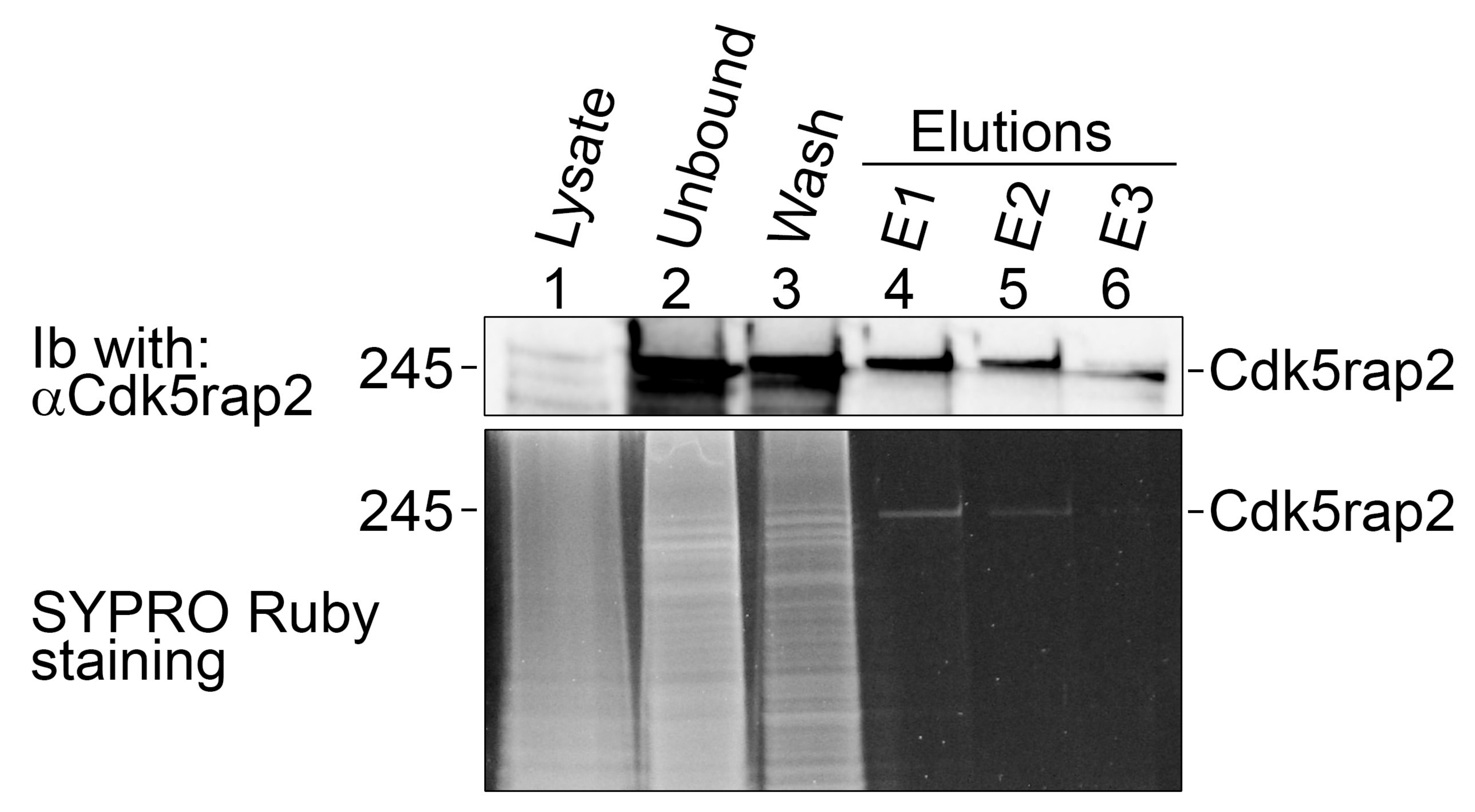

Supplementary Figure 2 
A

NF-KB binding site

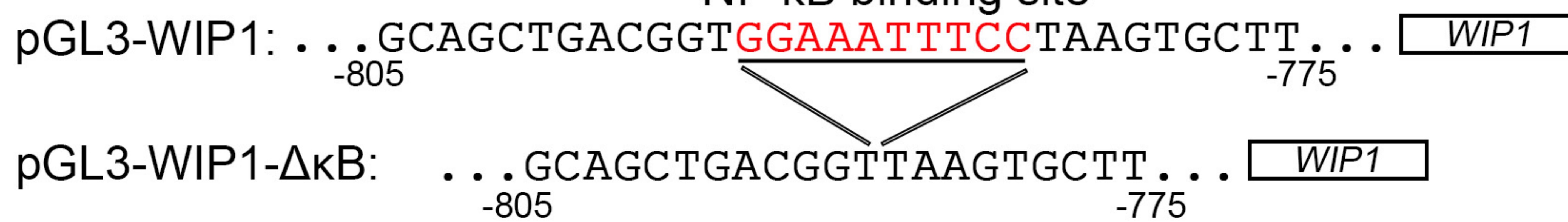

B

- pGL3-WIP1

C

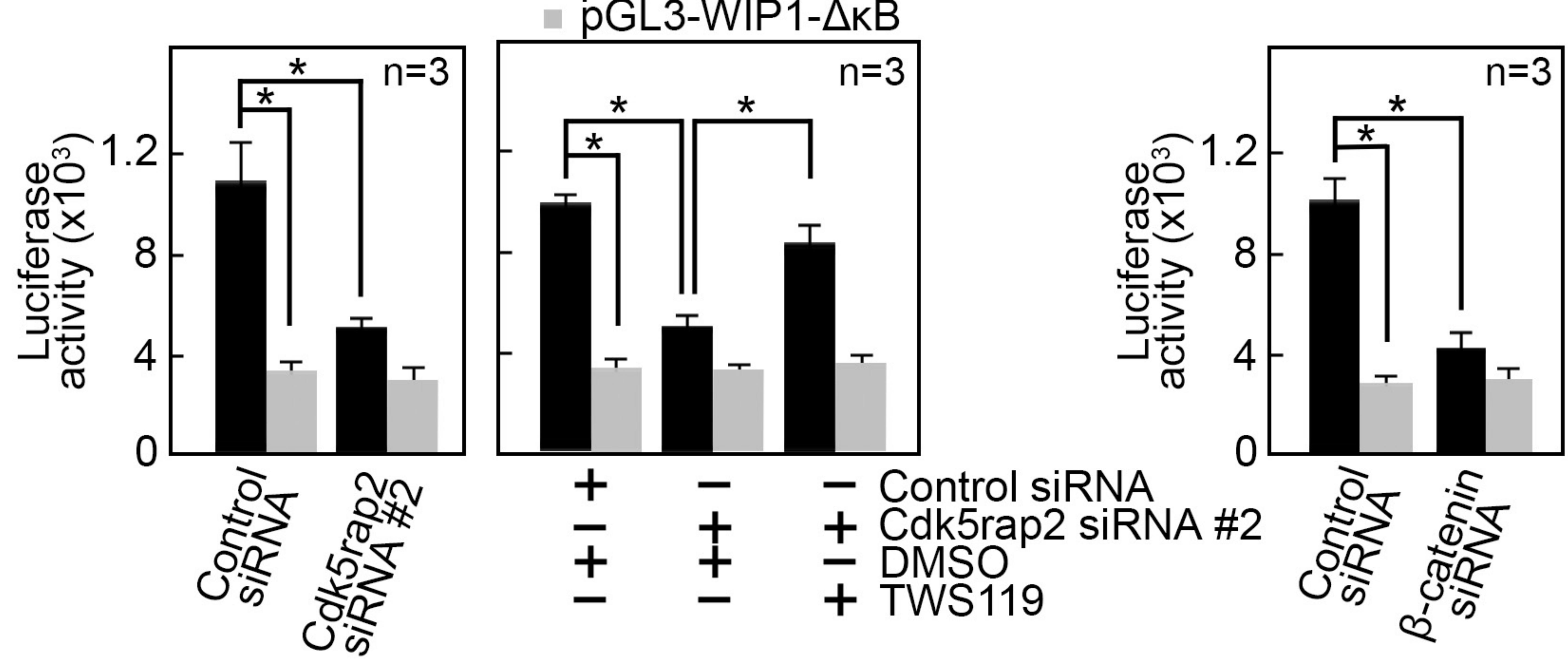

Supplementary Figure 3 